\title{
Mechanism of Water-conducting Fractured Zone in Jiaojia Gold Mine with Deep Mining Based on Constitutive Model
}

\section{ChuMing Pang}

Shandong University of Science and Technology

Ying Wang ( $\sim$ wy18764896712@163.com )

Shandong University of Science and Technology

Longqing Shi

Shandong University of Science and Technology

Yongkui Shi

Shandong University of Science and Technology

\section{Research Article}

Keywords: constitutive model, three-dimensional geological model, water-conducting fractured zone, Jiaojia gold mine

Posted Date: May 17th, 2021

DOI: https://doi.org/10.21203/rs.3.rs-451470/v2

License: (9) This work is licensed under a Creative Commons Attribution 4.0 International License. Read Full License 


\title{
Mechanism of Water-conducting Fractured Zone in Jiaojia Gold
}

\section{Mine with Deep Mining Based on Constitutive model}

\author{
ChuMing Pang ${ }^{1}$, Ying Wang ${ }^{2, *}$, Longqing Shi ${ }^{3}$, Yongkui Shi ${ }^{1}$ \\ ${ }^{1}$ College of Energy and Mining Engineering, Shandong University of Science and Technology, \\ Qingdao 266590, China \\ ${ }^{2}$ Resource College, National Engineering Laboratory for Coalmine Backfilling Mining, Shandong \\ University of Science and Technology, Tai'an 271019, China. \\ ${ }^{3}$ State Key Laboratory of Mining Disaster Prevention and Control Co-founded by Shandong \\ Province and the Ministry of Science and Technology, Shandong University of Science and \\ Technology, Qingdao 266590, China
}

\begin{abstract}
The deep resources of the gold mines have great potential to be the leading area of the national gold industry. However, with the increase of mining depth in Jiaojia gold mine of Shandong province, China, the overburden stress is increasing, the spatial and temporal distribution of mining stress field is more complex to cause spatial structure of overlying strata seriously damaged, which often leads to mine water disaster. Therefore, the research on the law of surrounding rock stress and water-conducting fractured zone development has become an important topic for safe mining of gold mines. In this paper, based on the analysis of borehole data and profile map, three-dimensional geological model was established to predict the height of the water-conducting fracture zone by using Sufer17, Rhino 6, Griddle plug-in and FLAC3D software, and the mining process with the method of downward horizontal slice stoping-filling was simulated by using constitutive model. Results show that the maximum height of the water-conducting fractured zone is about $21.2 \mathrm{~m}$ during the whole mining at -700 level, the shape is from near horizontal to micro arch, the failure range of the plastic area near the fault is larger than that far away from the fault. The stress distribution on both sides of the fault is not continuous, which is larger in the hanging wall than that in the footwall. The stress concentration zone is formed in the front and back of the stope during mining process and increases with mining depth. This method can restore the original state of underground stress field to the greatest extent, and make up for the lack of empirical formula theory and the limitation of similar material method for deep mining, which is relatively more accurate and reliable.
\end{abstract}

Keywords: constitutive model; three-dimensional geological model; water-conducting fractured zone; Jiaojia gold mine

\section{Introduction}

The Jiaodong area is located in eastern and northern Shandong Peninsula which is $500 \mathrm{~km}$ SE of Beijing and on the northeast of major city Qingdao with extremely special location, unique and excellent metallogenic conditions, huge potential gold resources. It accounts for about $20 \%$ of China's gold reserves and output. It is the most important gold concentration area in China. Jiaojia gold mine is located in the northwest of Jiaodong. The Jiaojia gold deposit is formed in the granite of the footwall of Jiaojia fault, which is the ore-controlling fault. Although most of the surface and shallow gold deposits are easy to find and mine, the deep resources of the gold mines also have great potential for continue to be the leading area of the national gold industry in Jiaodong. On the other side, with the increase of 
mining depth, the overburden stress is increasing, the spatial and temporal distribution of mining stress field is more complex, spatial structure of overlying strata is broken. In addition, the fractures will develop well during gold mining because the mining stope is very close to the Jiaojia fault zone, and they will become the storage space and migration channel for free water leading to the increase of mine water inflow and the occurrence of water inrush (Gao WF, et al. 2020; Qiu M, et al. 2017, Shi LQ, et al. 2019; Shi LQ, et al. 2017). Therefore, the research on the law of surrounding rock stress and water-conducting fractured zone development has become an important topic for safe mining of gold mine (Shi LQ, et al. 2019).

Tan $\mathrm{Lu}$ fault zone is a main fault zone formed in a series of NE trending giant fault systems in the Middle Proterozoic on the east Asian continent (Fig.1), which has a complicated structural, petrogenesis and mineralization evolutionary history (Terhemba SB, et al. 2020). The Jiaojia fault, belonging to one of the branch faults of Tan $\mathrm{Lu}$ fault, with a continuous and stable main fault surface marked by gray-black fault gouge, has the most intensive gold deposits among the branch faults. The deposit is basically distributed along the middle of the fracture zone, from the inside to the outside, in turn, there are pyrite alteration cataclasite, pyrite alteration granite cataclasite, alteration granite. To take the main fault surface as the boundary, the tectonic rock is basically symmetrical and zoned. Both sides of the fault are affected by the structure, the rock is broken and the fracture is developed, which is a favorable place for the storage and movement of groundwater.

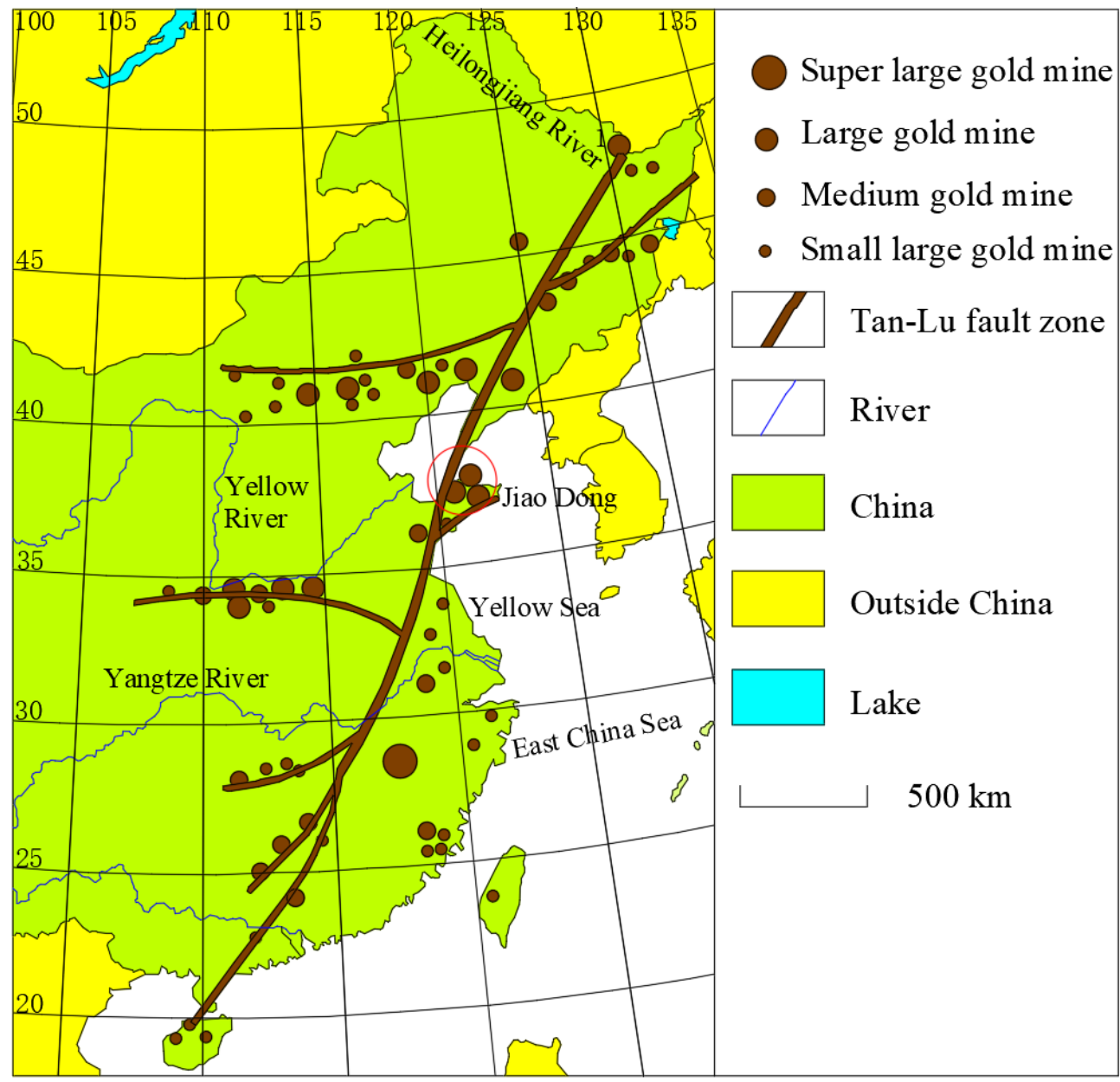

Fig. 1 Tanlu fault zone

Water-conducting fractured zone as an important embodiment of overlaying rock failure law, it 
can be generally determined by four methods, that is, empirical formula (Fan H, et al. 2020), numerical simulation (Dar I A, et al. 2010; Guo C, et al. 2020; Nikić, Z, et al. 2019; Ross S. 2018; Sener E, et al. 2005), similar material experiment (Maria K, et al. 2019), and field measurement (Almadani S, et al. 2019). There are "natural slope theory", "circular arch theory" and "zonal theory" in abroad research (Chu FJ. 2012; Syd SP. 1978; Helmut K. 1983), Russia published the method guide to determine the height of water-conducting fractured zone in 1973. With the rapid development of computer technology, numerical simulation has been widely used in the solution of the height of water-conducting fractured zone. In this paper, three-dimensional geological model was established based on borehole data to simulate the spatial and temporal distribution of mining stress field in deep mining of Jiaojia gold mine (Fig.2) and to study on the development shape and height characteristics of the overburden water-conducting fractured zone through the research of overburden failure law, stress variation and deformation law. This method can restore the original state of underground stress field to the greatest extent, and make up for the lack of empirical formula theory and the limitation of similar material method for deep mining, which is more accordant with practical.

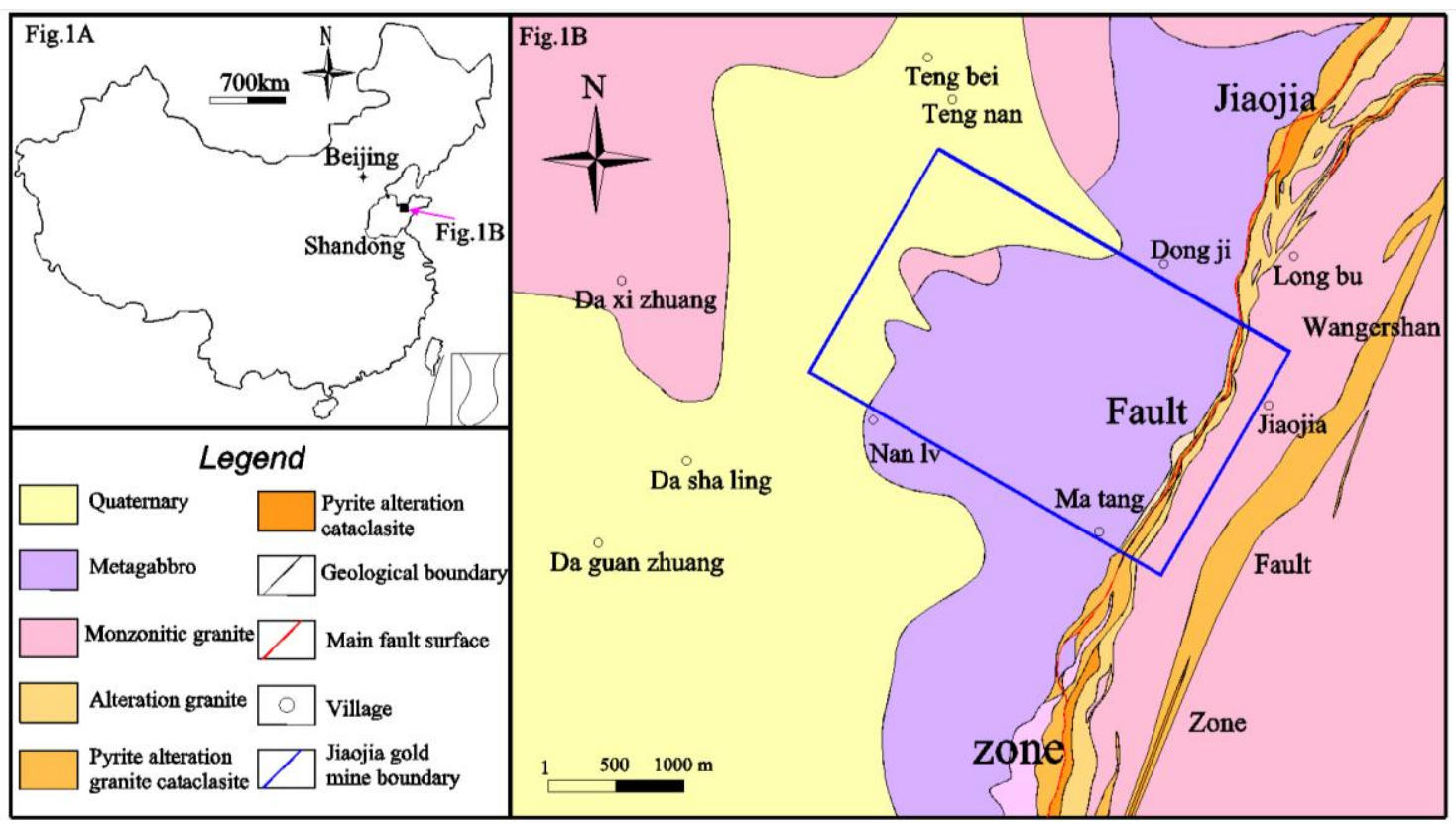

Fig. 2 Jiaojia gold mine area

\section{Study area}

Jiaojia gold mine area strata are relatively simple, the Cenozoic Quaternary is distributed in southwest area (Fig.2), because of the thickness of the Quaternary strata is very thin compared with the bedrock, and the impact on the deep mining is negligible, so the Quaternary is no longer considered in the scope of research. The Archaean and Proterozoic Jiaodong group (Ar-Ptljf) is distributed in the middle east part of the study area, that is, the upper wall of Jiaojia fault zone, and some of them are trapped in the granite $\left(\gamma_{5}^{1}\right)$. Jiaodong group (Ar-Ptljf) strata have intrusive contact or fault contact with the Mesozoic magmatic rocks, in addition, widespread magmatic rocks and developed fault structures are in this area. The NNE-SSW compressive torsional structures in mining area are developed and the Jiaojia fault zone controls the formation of gold, it has the strike of $30^{\circ} \sim 40^{\circ}$, the tendency of northwest and the dip angle of $29^{\circ} \sim 43^{\circ}$. The fault zone is more than 20 kilometers long and $80 \sim 200$ meters wide.

Jiaojia gold mine is located in the middle of Jiaojia gold mine area, west of Jiaojia fault zone. The 
horizontal slice stoping-filling method is main mining method, and the main filling material is tailings from the concentrator. In this paper, the study area is located in the south of exploratory line 80 , the north of exploratory line 160, the west of borehole 120ZK42 and the east of borehole 136ZK604, the whole study area is covered by metagabbro (Fig 3).

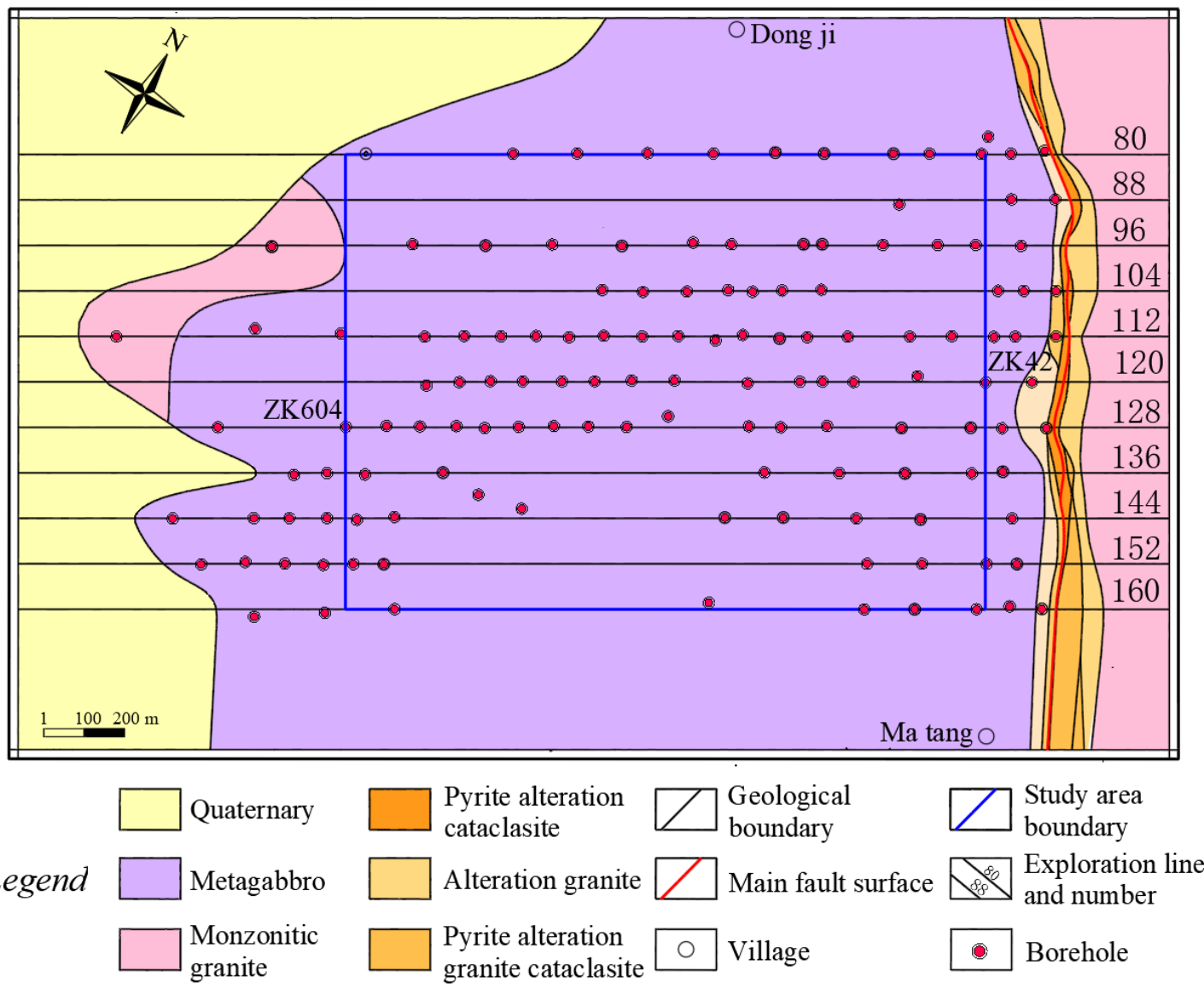

Fig. 3 Jiaojia gold mine

Considering lithology and rock mechanics characteristics, the study area is divided into 8 strata (Table 1), that is, metagabbro, sericite granite (hanging wall), pyrite sericite granite cataclasite (hanging wall), pyrite sericite cataclasite(hanging wall), pyrite sericite cataclasite(foot wall), pyrite sericite granite cataclasite (foot wall), sericite granite (foot wall), monzonitic granite. 
Table 1 Characteristics of strata in the study area

\begin{tabular}{|c|c|c|c|c|}
\hline $\begin{array}{l}\text { Geologic } \\
\text { column }\end{array}$ & $\begin{array}{c}\text { Name of } \\
\text { rock }\end{array}$ & $\begin{array}{l}\text { thickness } \\
\text { (m) }\end{array}$ & $\begin{array}{c}\text { Fracture } \\
\text { development }\end{array}$ & Remark \\
\hline $\begin{array}{l}\times \times \times \\
\times \times \times \\
\times \times \times\end{array}$ & $\begin{array}{c}\text { Metagabbro } \\
\text { (M) }\end{array}$ & $36-465$ & $\begin{array}{l}\text { Almost no } \\
\text { fissures, some } \\
\text { rock breaking }\end{array}$ & $\begin{array}{l}\text { No water leaking, no gushing water, very little water quantity, great variation } \\
\text { of thickness and increases then decreases gradually from the main fault surface to } \\
\text { the west. Good quality, complete, overall block structures with high strength. }\end{array}$ \\
\hline $\begin{array}{ll}\mathrm{C} & + \\
+ & \mathrm{C} \\
\mathrm{C} & +\end{array}$ & $\begin{array}{l}\text { Alteration } \\
\text { granite } \\
\text { (A-G1) }\end{array}$ & $5-991$ & $\begin{array}{l}\text { Some small } \\
\text { fissures filled } \\
\text { mud, rock } \\
\text { breaking, }\end{array}$ & $\begin{array}{l}\text { Very little water quantity, occasional water leaking. Great variation of } \\
\text { thickness and increases gradually from the main fault surface to the west. } \\
\text { Water-abundance varies greatly, most of the fractures were mainly transpressional } \\
\text { and shearing with poor connectivity. Mainly good quality rock, some of them were } \\
\text { medium. The rock mass is relatively complete or medium integrity, overall block } \\
\text { structure with low strength. }\end{array}$ \\
\hline
\end{tabular}

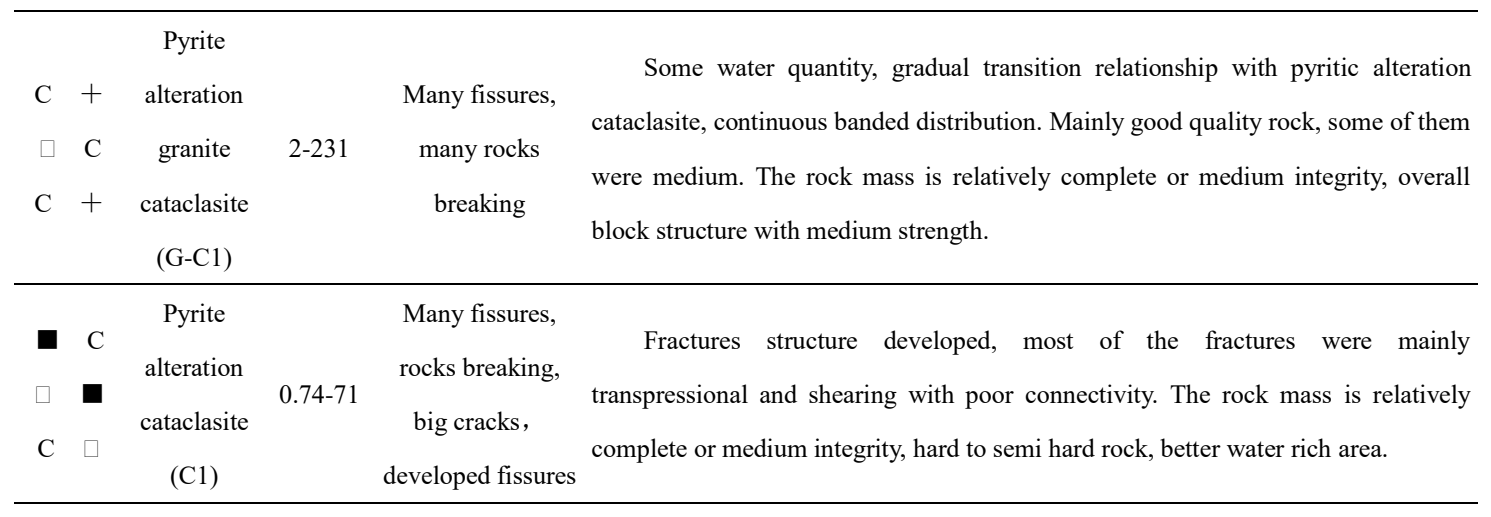

No water leaking,. Continuous distribution, the occurrence was consistent with the fault alteration zone. The boundary with the altered rock was clear with good $\triangle \Delta \triangle$ Fault gouge $\quad<0.1 \quad$ Undeveloped water resistance, which blocks the hydraulic connection between the hanging wall and foot wall. The fault is soft plastic-like gouge with very low strength, which were the main weak plane of the gold deposit, and close to the deposit, which has a great impact on the stability of the deposit and regional rock.

\begin{tabular}{|c|c|c|c|c|c|}
\hline$\square$ & $\mathrm{C}$ & $\begin{array}{c}\text { Pyrite } \\
\text { alteration } \\
\text { cataclasite } \\
\text { (C2) }\end{array}$ & $0.02-38$ & $\begin{array}{l}\text { Many fissures, } \\
\text { many rocks } \\
\text { breaking, many } \\
\text { big cracks }\end{array}$ & $\begin{array}{l}\text { Serious water leakage, universal gushing water, even gravitational flow, large } \\
\text { amount of water. The altered minerals were broken strongly because of the multiple } \\
\text { stress action. Water-abundance varies greatly, there were small tensile structural } \\
\text { planes with good hydraulic conductivity in some parts. The rock mass is relatively } \\
\text { complete or medium integrity with high strength. }\end{array}$ \\
\hline $\begin{array}{l}\mathrm{C} \\
\square\end{array}$ & $\begin{array}{l}+ \\
\mathrm{C} \\
+ \\
\mathrm{C}\end{array}$ & $\begin{array}{l}\text { Pyrite } \\
\text { alteration } \\
\text { granite } \\
\text { cataclasite } \\
\text { (G-C2) }\end{array}$ & $1.6-106$ & $\begin{array}{l}\text { Many fissures, } \\
\text { many rocks } \\
\text { breaking, some } \\
\text { big cracks }\end{array}$ & $\begin{array}{l}\text { Serious water leakage, frequently gushing water, even gravitational flow, large } \\
\text { amount of water. gradual transition relationship with pyritic alteration } \\
\text { cataclasite.broken caused by dynamic metamorphism, mainly good quality rock, } \\
\text { some of them were medium. The rock mass is relatively complete or medium } \\
\text { integrity with high strength. }\end{array}$ \\
\hline $\begin{array}{l}\mathrm{C} \\
+ \\
\mathrm{C}\end{array}$ & $\begin{array}{l}\mathrm{C} \\
+\end{array}$ & $\begin{array}{l}\text { Alteration } \\
\text { granite } \\
\text { (A-G2) }\end{array}$ & $4-316$ & $\begin{array}{c}\text { Some small } \\
\text { fissures filled } \\
\text { mud, some rock } \\
\text { breaking }\end{array}$ & $\begin{array}{l}\text { Very little water quantity, occasional water leaking. Little variation of } \\
\text { thickness and continuous banded distribution. Water-abundance varies greatly, most } \\
\text { of the fractures were mainly transpressional and shearing with poor connectivity. } \\
\text { Mainly good quality rock, some of them were medium. The rock mass is relatively } \\
\text { complete or medium integrity, overall block structure with medium strength. }\end{array}$ \\
\hline $\begin{array}{l}+ \\
+\end{array}$ & + & $\begin{array}{l}\text { Monzonitic } \\
\text { granite (G) }\end{array}$ & $>1000$ & $\begin{array}{l}\text { Undeveloped } \\
\text { fissures }\end{array}$ & $\begin{array}{l}\text { Large thickness with very poor water-abundance, good quality rock, complete } \\
\text { rock mass, block structure with medium strength. }\end{array}$ \\
\hline
\end{tabular}




\section{Methodology}

\section{Constitutive model}

When the constitutive model is used to describe the mechanical behavior of materials, the three characteristics of materials, namely, physical instability, path-dependence of nonlinear materials and nonlinear stress-strain feedback, can be solved by the explicit and dynamic solution method provided by FLAC3D. This method allows the numerical analysis to evolve with the real behavior of the materials system without considering the numerical instability. The constitutive model used in this paper includes null model and mohr-coulomb plasticity model, which is more consistent with the fracture process of rock mining process.

\section{1. null model}

The null model is used to represent that the rock material is mined, and the stress in the null grid is automatically set to 0 , that is, $\sigma_{\mathrm{ij}}^{N}=0$. The rock material corresponding to the null model can be set into different constitutive models in the subsequent simulation research. In this way, the mining method of excavation and backfilling can be simulated.

2. Mohr-coulomb plasticity model

(1) The law of elastic increment

The law of elastic increment is used to describe the mechanical response of rock material in shear. The mohr-coulomb criteria has three principal stress, $\sigma_{1}, \sigma_{2}, \sigma_{3}$, and three strain vectors, $\varepsilon_{1}, \varepsilon_{2}$, $\varepsilon_{3}$. The relationship is as follows:

$$
\begin{gathered}
\Delta \sigma_{1}=\alpha_{1} \Delta \varepsilon_{1}^{\mathrm{e}}+\alpha_{2}\left(\Delta \varepsilon_{2}^{\mathrm{e}}+\Delta \varepsilon_{3}^{\mathrm{e}}\right) \\
\Delta \sigma_{2}=\alpha_{1} \Delta \varepsilon_{2}^{\mathrm{e}}+\alpha_{2}\left(\Delta \varepsilon_{1}^{\mathrm{e}}+\Delta \varepsilon_{3}^{\mathrm{e}}\right) \\
\Delta \sigma_{3}=\alpha_{1} \Delta \varepsilon_{3}^{\mathrm{e}}+\alpha_{2}\left(\Delta \varepsilon_{1}^{\mathrm{e}}+\Delta \varepsilon_{2}^{\mathrm{e}}\right) \\
\alpha_{1}=K+\frac{4}{3} G \\
\alpha_{2}=K-\frac{2}{3} G
\end{gathered}
$$

while, $\sigma_{1}<\sigma_{2}<\sigma_{3}, \alpha_{1}, \alpha_{2}$ are the parameters of two materials, $\mathrm{G}$ is shear modulus, $\mathrm{K}$ is bulk modulus.

(2) Criteria of instability and flow

The mohr-coulomb strength criteria can be expressed in $\left(\sigma_{1}, \sigma_{3}\right)$ plane, as shown in Fig.4. The definition of instability envelopes is as follows:

From point A to point $\mathrm{B}$, based on the definition of instability strength $f^{\mathrm{s}}=0$, obtained:

$$
f^{\mathrm{s}}=\sigma_{1}-\sigma_{3} N_{\phi}+2 c \sqrt{N_{\phi}}
$$

From point $\mathrm{B}$ to point $\mathrm{C}$, based on the definition of tensile instability criteria $f^{\mathrm{s}}=0$, obtained:

$$
f^{t}=\sigma_{3}-\sigma^{t}
$$


While, $\phi$ is friction angle, $c$ is cohesion, $\sigma^{t}$ is tensile strength, and, $N_{\phi}=\frac{1+\sin (\phi)}{1-\sin (\phi)}$.

Because the tensile strength of the material cannot exceed $\sigma_{3}$ corresponding to the intersection point of the straight line $f^{\mathrm{s}}=0$ in $\left(\sigma_{1}, \sigma_{3}\right)$ plane and $\sigma_{1}=\sigma_{3}$, the expression for the maximum value is:

$$
\sigma_{\max }^{\mathrm{t}}=\frac{c}{\tan \phi}
$$

The expression of flow criteria can be obtained by the following methods. Function $h\left(\sigma_{1}, \sigma_{2}\right)=0$ is defined as the oblique line between $f^{\mathrm{s}}=0$ and $f^{t}=0$ in plane $\left(\sigma_{1}, \sigma_{3}\right)$.

Choose the function based on its positive and negative domains (Fig.5). The expression is as follows:

$$
h=\sigma_{3}-\sigma^{t}+\alpha^{P}\left(\sigma_{1}-\sigma^{P}\right)
$$

While, $\alpha^{P}, \quad \sigma^{P}$ are constants, $\alpha^{P}=\sqrt{1+N_{\phi}^{2}}+N_{\phi}, \sigma^{P}=\sigma^{t} N_{\phi}-2 c \sqrt{N_{\phi}}$.

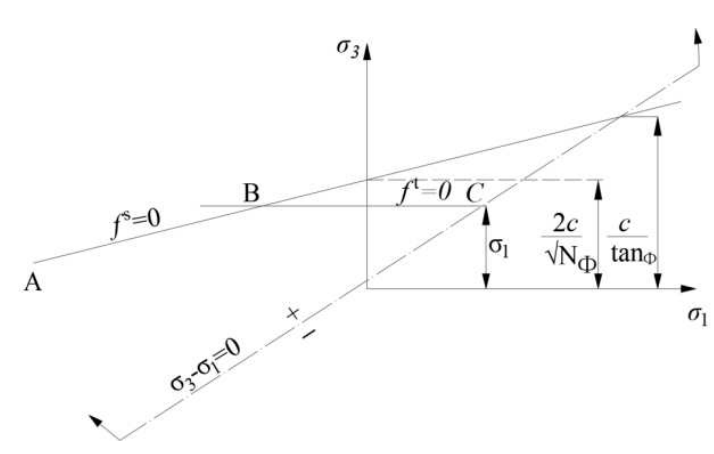

Fig. 4 FLAC3D mohr-coulomb strength criteria

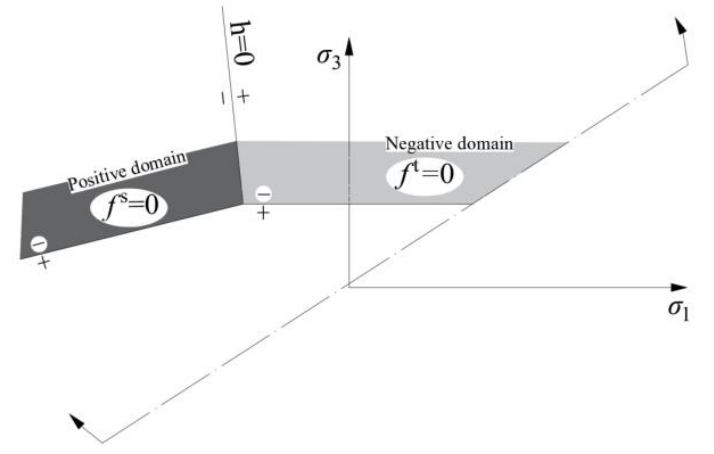

Fig.5 Mohr-coulomb model-domain used to define flow criteria

Suppose an elastic point breaks through the yield function, it means that point lies in the positive or negative domain of $h=0$. If the stress point is in the positive domain, it means that the point is in the shear yield state, and the stress point is on the $f^{\mathrm{s}}=0$ curve. If the stress point is in the negative domain, it means that the point is in the tensile yield state, and the stress point is on the $f^{t}=0$ curve.

\section{Model Establishment}

FLAC3D uses the way of inputting data and command-line file to establish model, it is laborious and time-consuming to establish a complicated three-dimensional geological model. In this paper, we use the third-party software, that is, Sufer17, Rhino 6 and Griddle plug-in to realize the automation of modeling, it can further improve the accuracy and reliability of three-dimensional numerical simulation. It is convenient to establish a complicated three-dimensional geological model and debug, check and modify the grid in rhino 6 software. f3grid model file can be generated and imported into FLAC3D for subsequent simulation.

Based on the statistical analysis of borehole data and profile map, a three-dimensional geological model with the length of $1800 \mathrm{~m}$ (from -1000 to 800) in X direction, $1500 \mathrm{~m}$ (from -500 to 1000) in $\mathrm{Y}$ 
direction, surface elevation in top and $-1500 \mathrm{~m}$ in bottom was established with the scale of 1:1. Kriging interpolation was used to generate contour map of each strata based on Sufer17 (Fig. 6-13). It can be seen from the figure that the terrain is high in the northeast and low in the southwest, the elevation changes little, and there is no big undulation in general. From east to west, the metagabbro strata first increases and then decreases, the thickness of the middle part is the largest, and the thickness of the east-west edge is small. A-G1, G-C1, C1, C2, G-C2 are higher in the east, lower in the west, and maintain a roughly consistent trend. A-G2 higher in the east and lower in the west, slightly lower in the middle of the west.

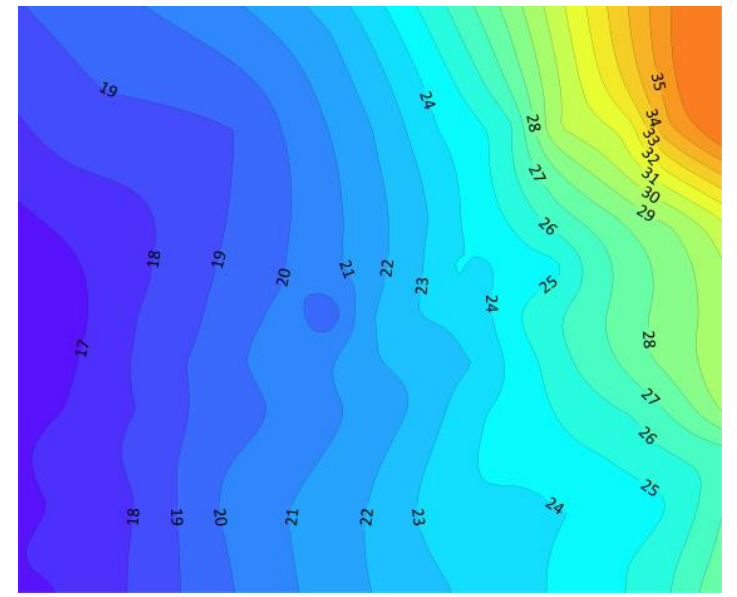

Fig.6 Contour map of surface

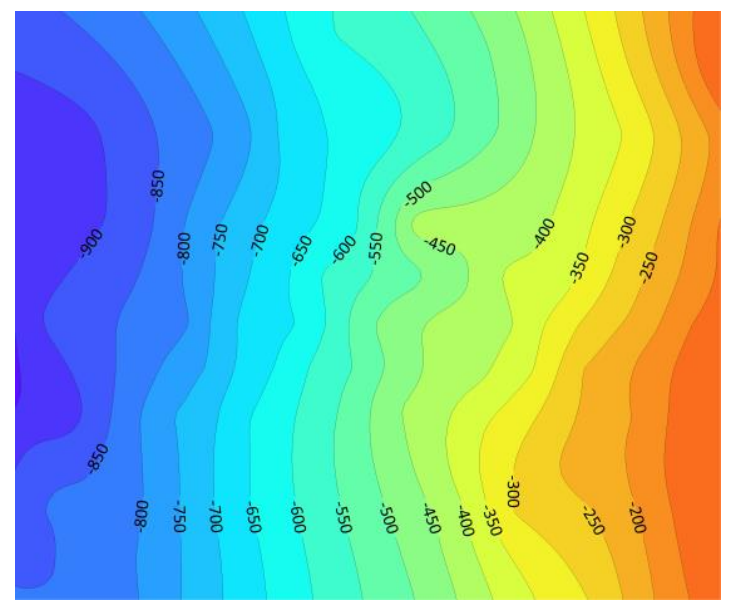

Fig.8 Contour map of A-G bottom

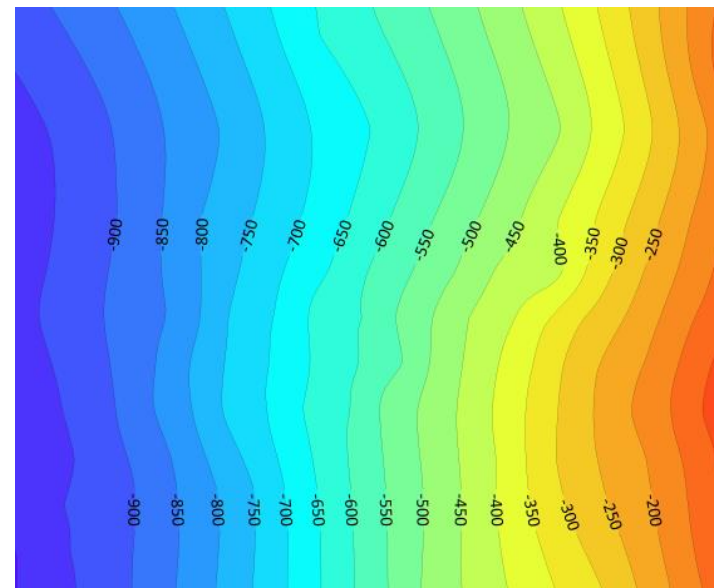

Fig.10 Contour map of $\mathrm{C} 1$ bottom

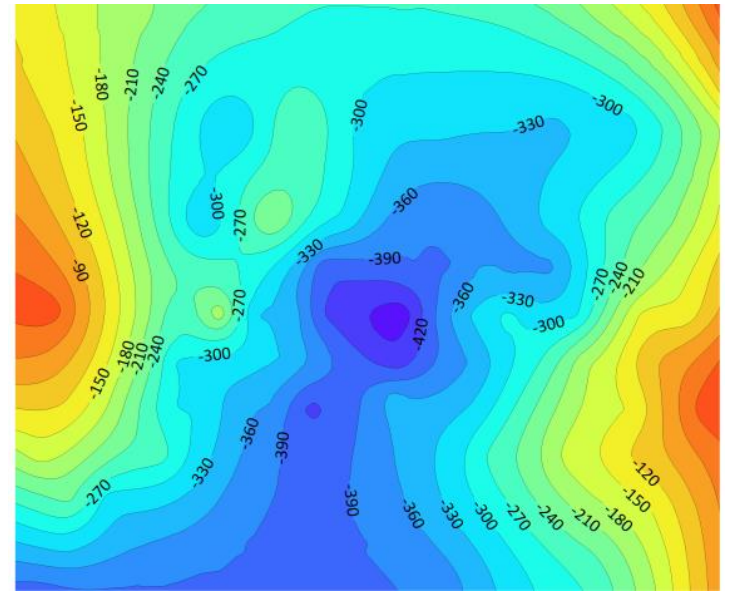

Fig.7 Contour map of M bottom

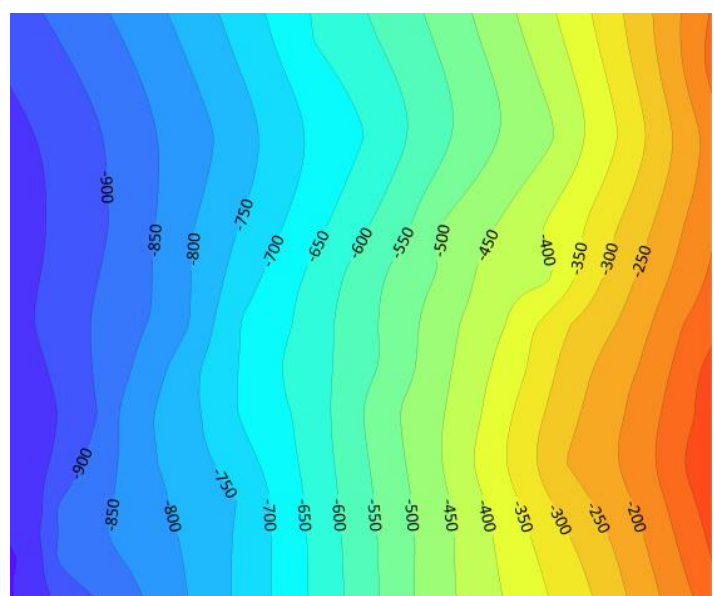

Fig.9 Contour map of G-C1 bottom

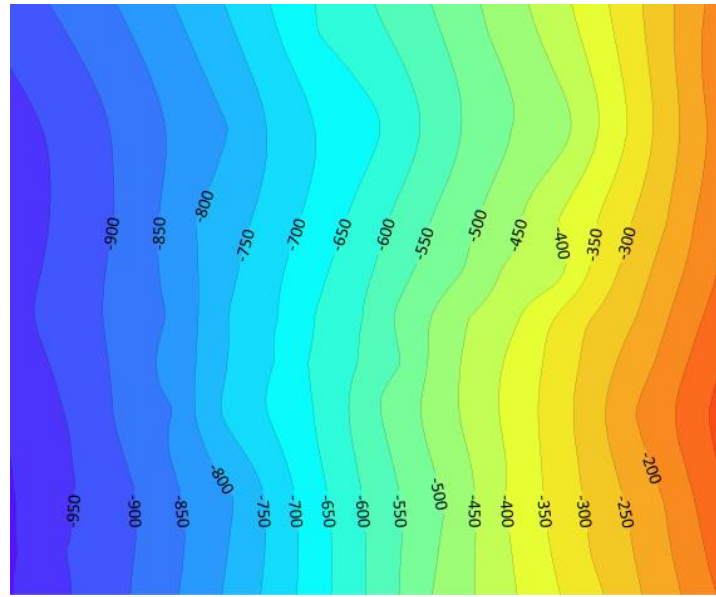

Fig.11 Contour map of $\mathrm{C} 2$ bottom 


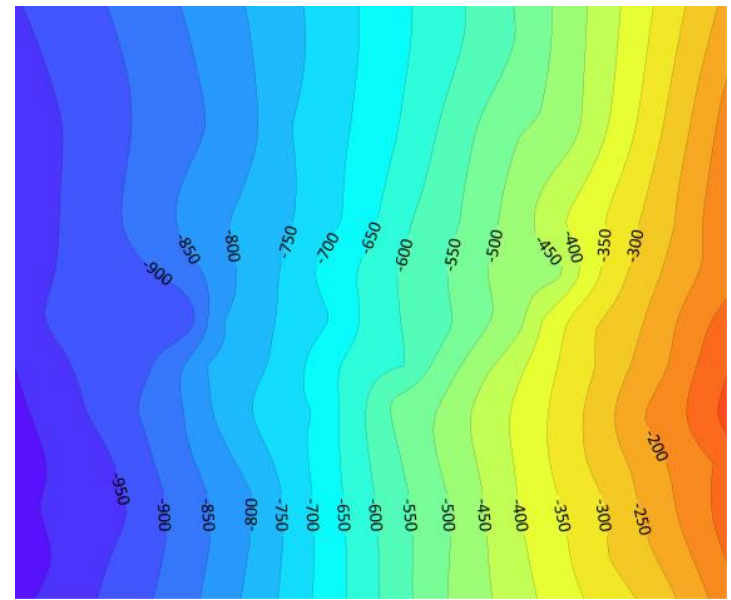

Fig.12 Contour map of G-C2 bottom

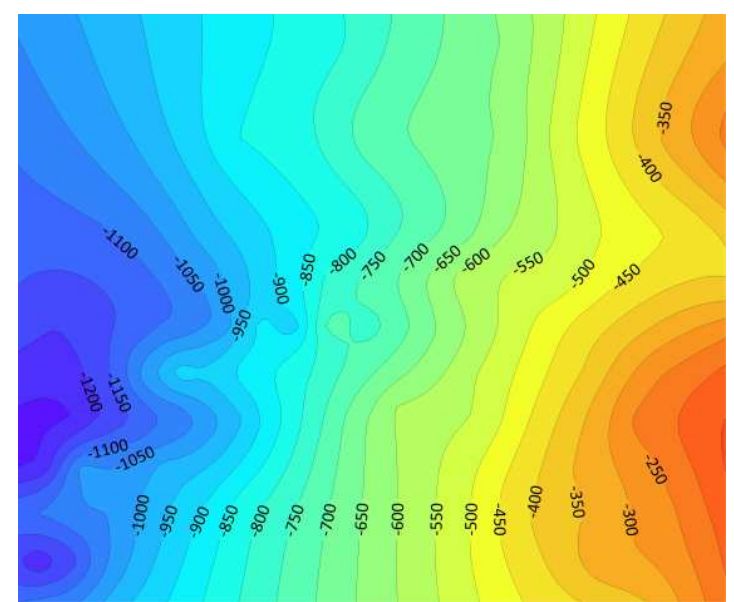

Fig.13 Contour map of A-G2 bottom

Import in Rhino 6 for three-dimensional modeling. The schemas with hexahedron based and tetrahedron assisted mesh were generated which can well deal with the break angles and transition area between strata (Fig.14). Where $p$ is the gridpoint and tetrahedron and tetrahedron is zone. The three-dimensional geological model is divided into 1617318 zones and 956775 gridpoint (Fig.15). Considering the height of the stope slice is $3 \mathrm{~m}$, the zone of the $\mathrm{C} 2$ and G-C2 strata was densified to the side length of $3 \mathrm{~m}$, so as to facilitate the research of the key areas near the Jiaojia faults surface. The interface in FLAC3D is used to simulate fault, and established (Fig.16) between C1 and C2.
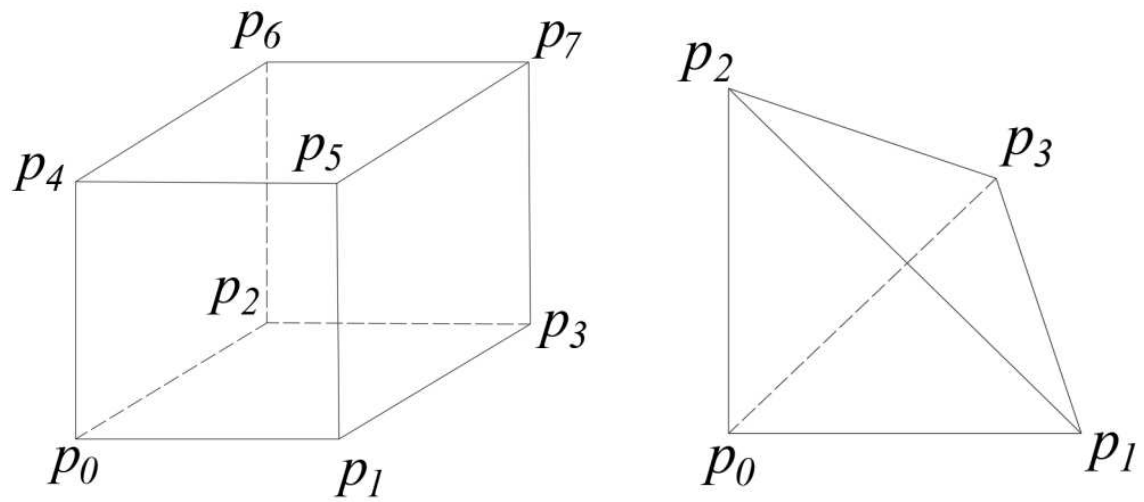

Fig. 14 Hexahedron and tetrahedron zone that make up the mesh

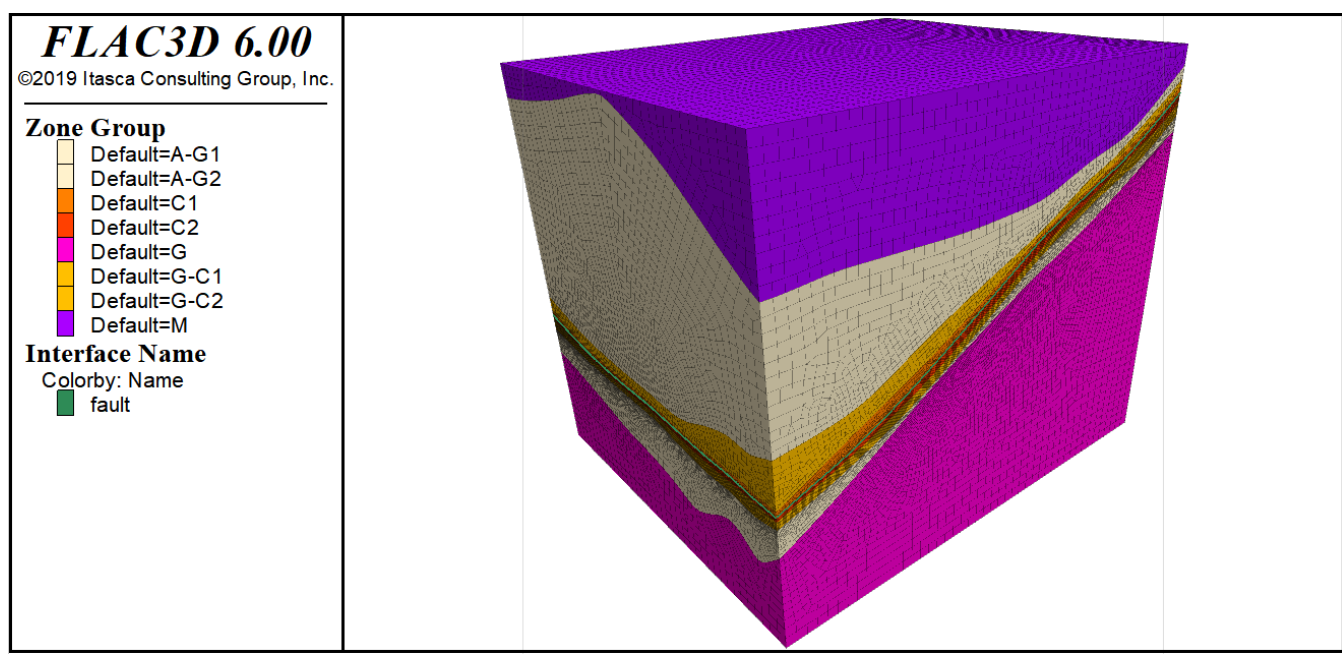

Fig.15 Three-dimensional geological model of study area 


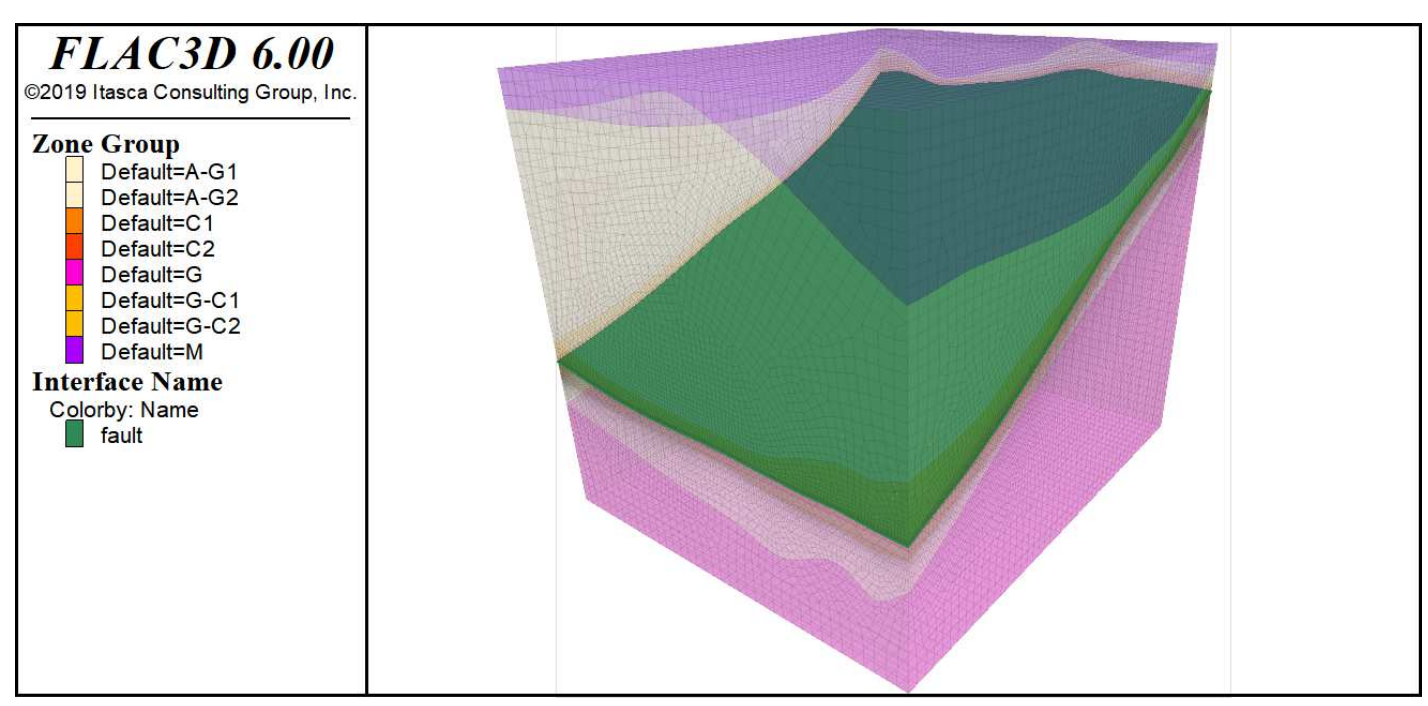

Fig.16 Jiaojia main fault surface of study area

\section{Generate initial stress field}

The horizontal displacement of $\mathrm{x}$-direction and $\mathrm{y}$-direction boundary of the model were fixed, the vertical displacement of bottom boundary of the model were fixed. Set the gridpoint velocity and displacement of the initial stress field to 0 , use the self-weight stress field as the initial stress field of numerical simulation, and the gravity is 9.8 (Fig.17). With the increase of depth, the compressive stress increases gradually. The mechanical parameters of each rock materials, filling material and mian fault surface are as follows (Table 2). History chart of mechanical unbalanced-maximum is close to 0 indicated the model has good convergence effect and can be used for subsequent excavation simulation (Fig.18).

Table 2 Mechanical parameters of rock materials

\begin{tabular}{|c|c|c|c|c|c|c|c|c|}
\hline $\begin{array}{l}\text { Name of } \\
\text { materials }\end{array}$ & $\begin{array}{c}\text { bulk } \\
\text { Modulus (Pa) }\end{array}$ & $\begin{array}{c}\text { shear } \\
\text { modulus }(\mathrm{Pa})\end{array}$ & $\begin{array}{c}\text { tensile strength } \\
\text { (Pa) }\end{array}$ & $\begin{array}{l}\text { cohesion } \\
\qquad(\mathrm{Pa})\end{array}$ & $\begin{array}{l}\text { internal } \\
\text { friction angle } \\
\qquad(\mathrm{Pa})\end{array}$ & $\begin{array}{l}\text { Density } \\
\left(\mathrm{kg} / \mathrm{m}^{3}\right)\end{array}$ & $\begin{array}{l}\text { stiffness-nor } \\
\qquad \operatorname{mal}(\mathrm{Pa})\end{array}$ & $\begin{array}{l}\text { tiffness-shear } \\
\qquad(\mathrm{Pa})\end{array}$ \\
\hline M & $5.48 \mathrm{E}+10$ & $1.63 \mathrm{E}+10$ & $5.90 \mathrm{E}+06$ & $1.20 \mathrm{E}+07$ & 38 & $2.80 \mathrm{E}+03$ & / & / \\
\hline A-G1 & $1.20 \mathrm{E}+10$ & $1.00 \mathrm{E}+10$ & $1.70 \mathrm{E}+06$ & $1.00 \mathrm{E}+07$ & 39 & $2.80 \mathrm{E}+03$ & / & l \\
\hline G-C1 & $3.70 \mathrm{E}+10$ & $2.40 \mathrm{E}+10$ & $4.10 \mathrm{E}+06$ & $9.70 \mathrm{E}+06$ & 38 & $2.80 \mathrm{E}+03$ & / & l \\
\hline $\mathrm{C} 1$ & $4.60 \mathrm{E}+10$ & $1.30 \mathrm{E}+10$ & $3.70 \mathrm{E}+06$ & $6.80 \mathrm{E}+06$ & 38 & $2.80 \mathrm{E}+03$ & & \\
\hline $\begin{array}{l}\text { Main fault } \\
\text { surface }\end{array}$ & l & / & $1.50 \mathrm{E}+06$ & $4.00 \mathrm{E}+06$ & 38 & & $3.00 \mathrm{E}+10$ & $3.00 \mathrm{E}+10$ \\
\hline $\mathrm{C} 2$ & $5.10 \mathrm{E}+10$ & $1.34 \mathrm{E}+10$ & $4.00 \mathrm{E}+06$ & $6.90 \mathrm{E}+06$ & 38 & $2.80 \mathrm{E}+03$ & / & l \\
\hline $\mathrm{G}-\mathrm{C} 2$ & $5.30 \mathrm{E}+10$ & $2.40 \mathrm{E}+10$ & $4.20 \mathrm{E}+06$ & $1.10 \mathrm{E}+07$ & 38 & $2.80 \mathrm{E}+03$ & l & l \\
\hline A-G2 & $2.60 \mathrm{E}+10$ & $1.10 \mathrm{E}+10$ & $5.00 \mathrm{E}+06$ & $1.70 \mathrm{E}+07$ & 40 & $2.80 \mathrm{E}+03$ & / & / \\
\hline $\mathrm{G}$ & $2.70 \mathrm{E}+10$ & $2.10 \mathrm{E}+10$ & $8.30 \mathrm{E}+06$ & $1.60 \mathrm{E}+07$ & 40 & $2.80 \mathrm{E}+03$ & / & l \\
\hline Filling material & $4.18 \mathrm{E}+09$ & $3.00 \mathrm{E}+09$ & $6.00 \mathrm{E}+05$ & $7.60 \mathrm{E}+05$ & 37 & $2.50 \mathrm{E}+03$ & / & / \\
\hline
\end{tabular}




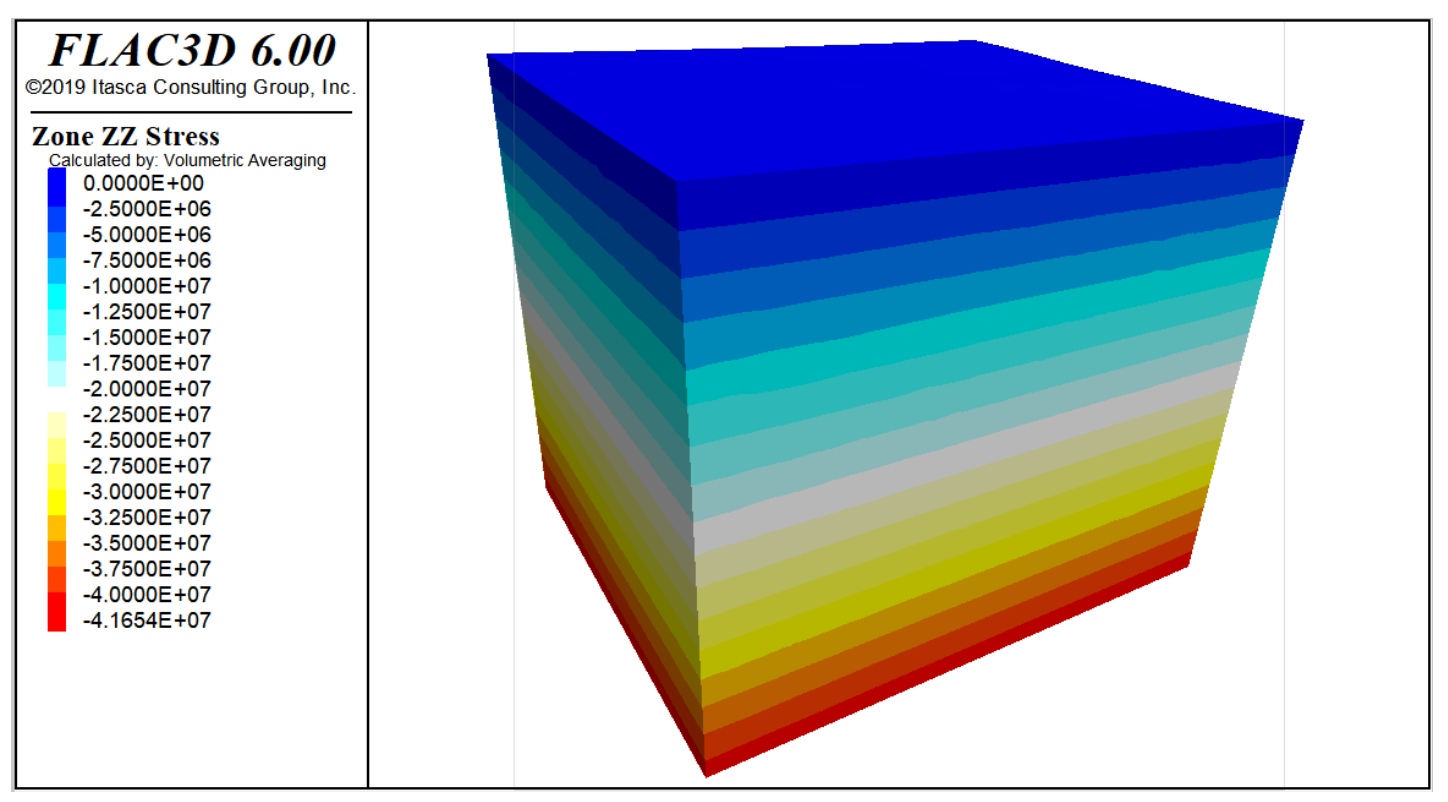

Fig.17 Initial stress field of principal stress in $\mathrm{Z}$ direction

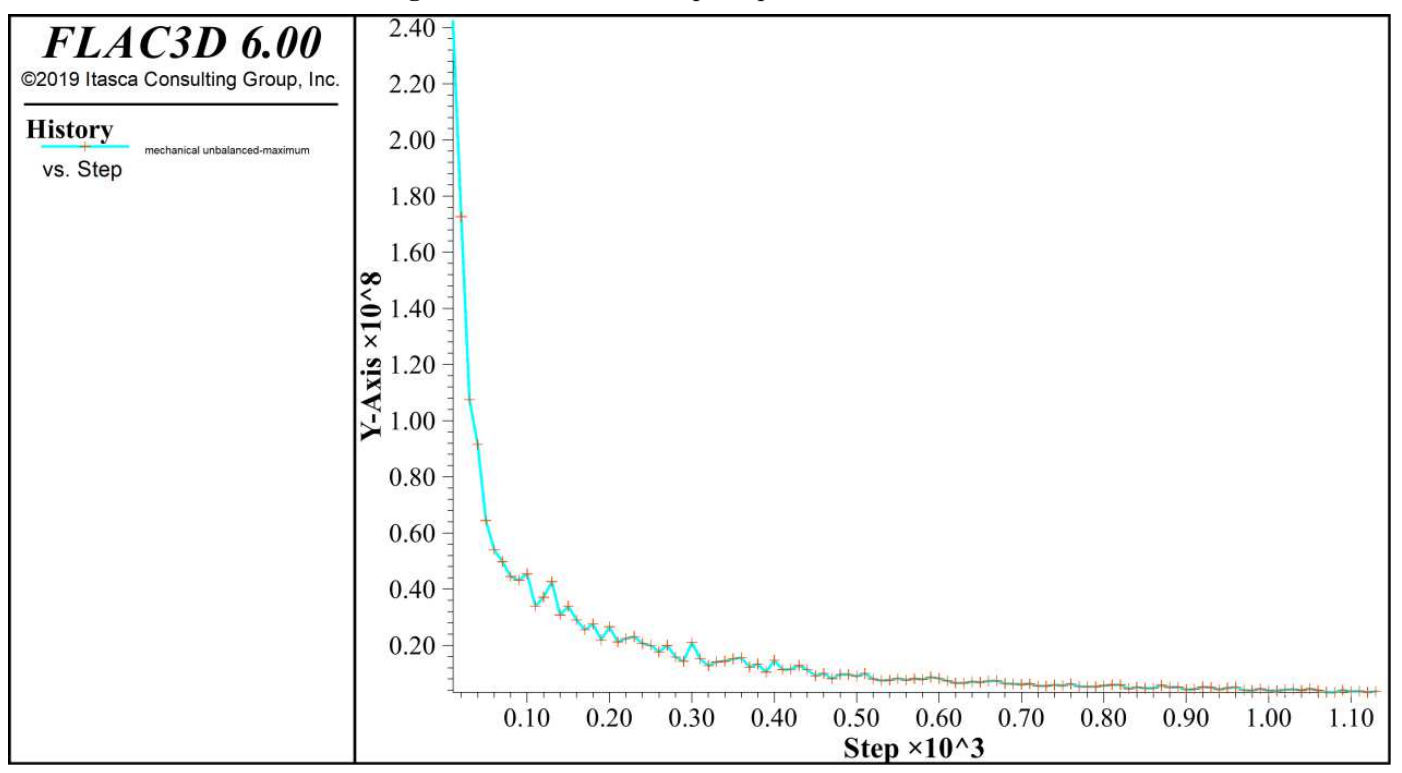

Fig.18 History chart of mechanical unbalanced-maximum

\section{Analysis and discussion of results}

\section{Simulate of mining process}

The ore body distribution of Jiaojia gold mine is mainly controlled by the fault alteration zone and mainly occurred in the $\mathrm{C} 2$ and G-C2 in the footwall of the main fault surface. We adopt downward horizontal slice stoping-filling mining method at $-700 \mathrm{~m}$ level, the length of the slice stope is $90 \mathrm{~m}$, which is consistent with the $\mathrm{x}$-axis direction. The height of the slice stope is $3 \mathrm{~m}$, there are four slices in all, that is, from $-703 \mathrm{~m}$ to -700 , from $-706 \mathrm{~m}$ to $-703 \mathrm{~m}$, from $-709 \mathrm{~m}$ to $-706 \mathrm{~m}$, and from $-712 \mathrm{~m}$ to $-709 \mathrm{~m}$, mining from top to bottom. The mining sequence of the "one stope panels" (Fig.19) is applied for the slice stope, that is, 15 pieces of 1,3,5..29 are mined at first, then filled with these 15 pieces, 15 pieces of 2,4,6...30 are mined at second and filled with these 15 pieces. The height range of model mining is from $-712 \mathrm{~m}$ to $-700 \mathrm{~m}$ in $\mathrm{Z}$ direction, the length of $\mathrm{X}$ direction along the footwall of main fault surface is consistent with the length of slice stope, and the wide of $Y$ direction is $30 \mathrm{~m}$ on both sides with 112 exploration line as the center. 
$90 \mathrm{~m}$

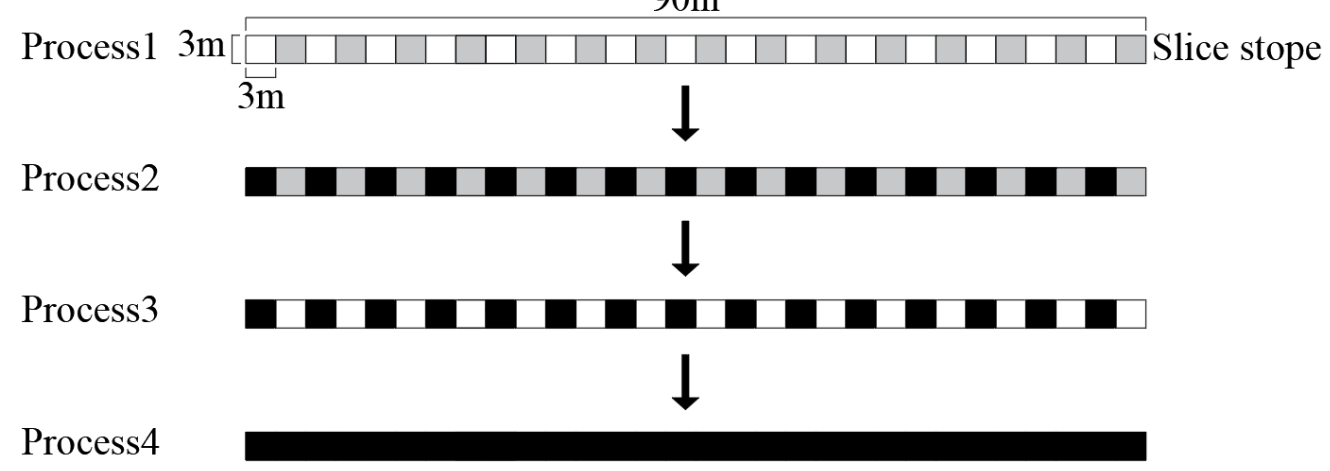

$\square$ Mined area $\square$ Virgin area $\quad \square$ Filled area

Fig.19 Schematic diagram of mining steps

Analysis of the plasticity area

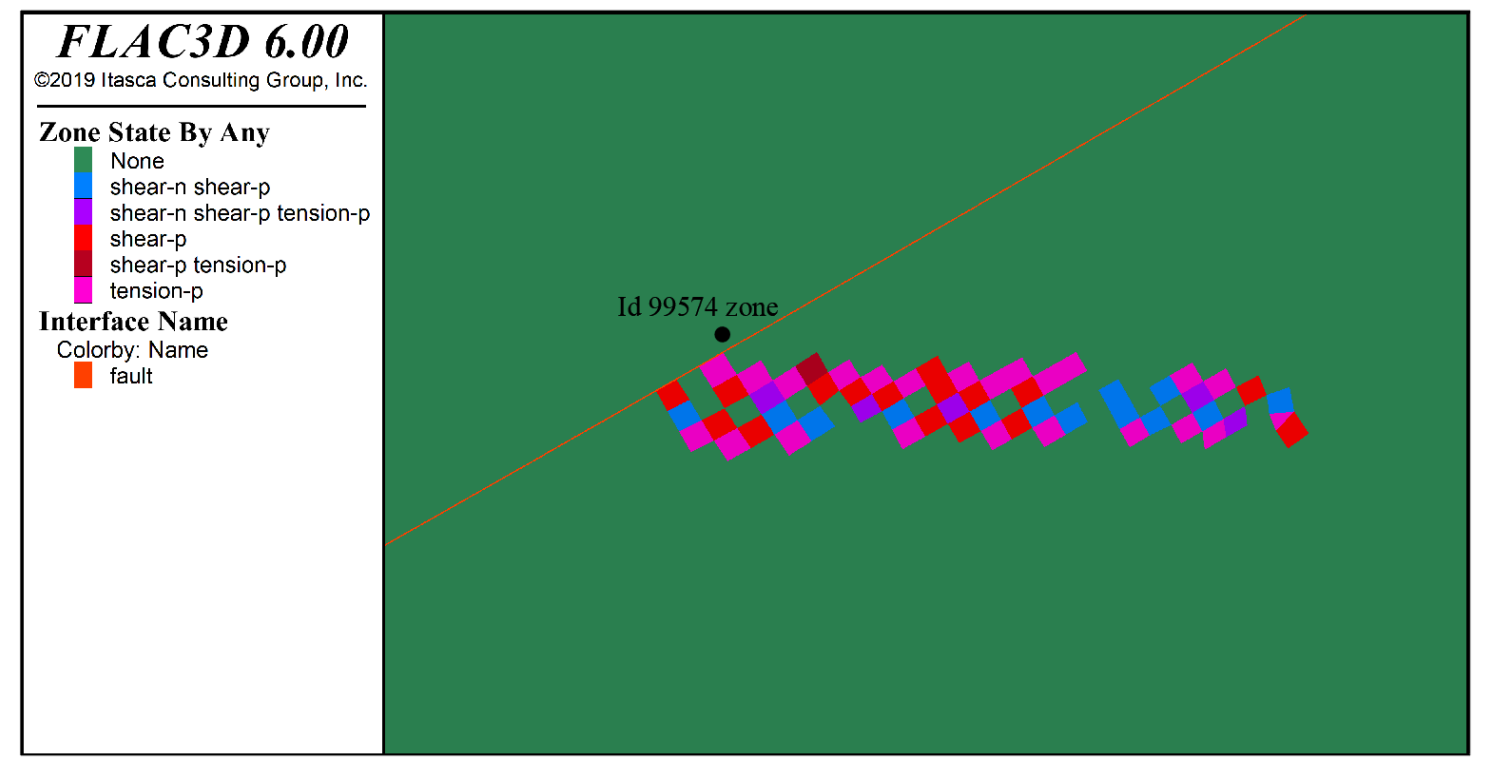

Fig.20 Overburden plastic zone when mining from $-700 \mathrm{~m}$ to $-703 \mathrm{~m}$ slice stope

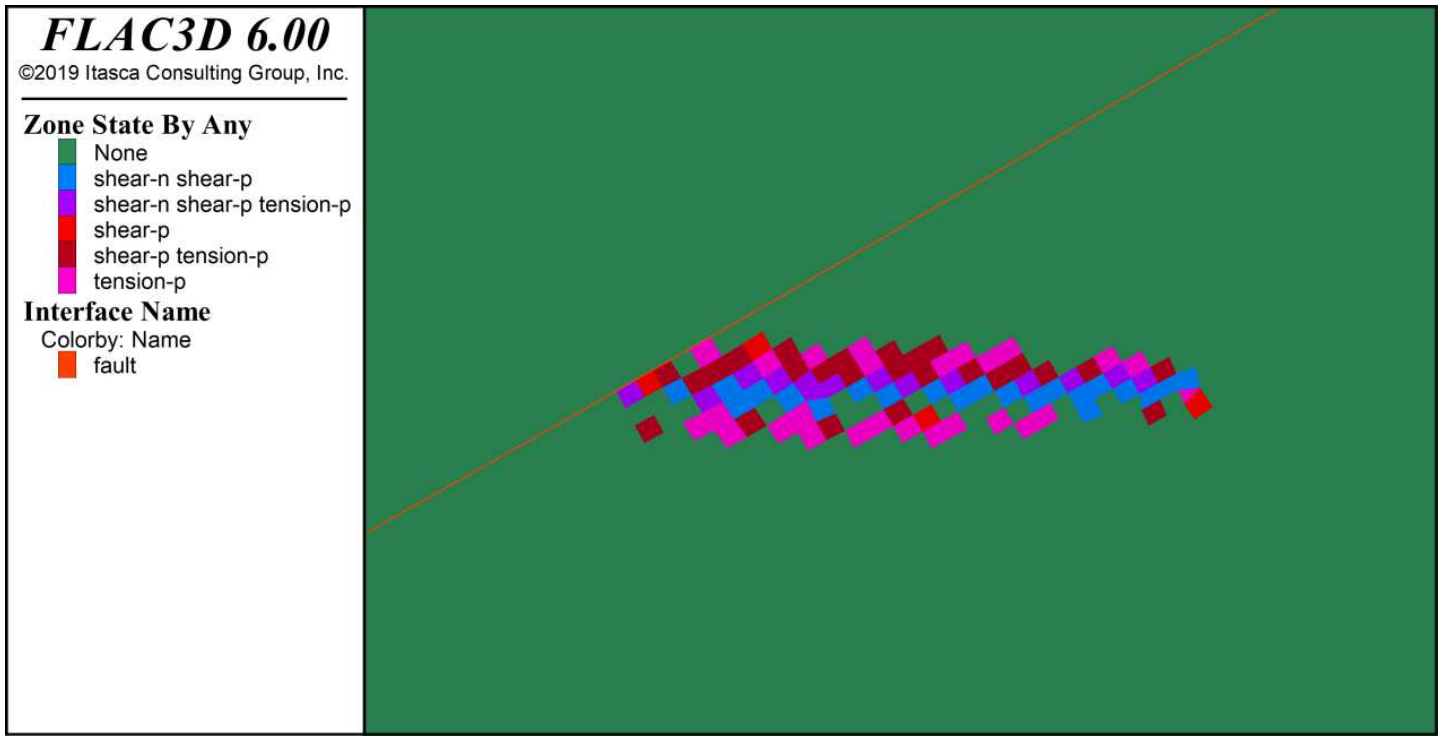

Fig.21 Overburden plastic zone when mining from $-703 \mathrm{~m}$ to $-706 \mathrm{~m}$ slice stope 


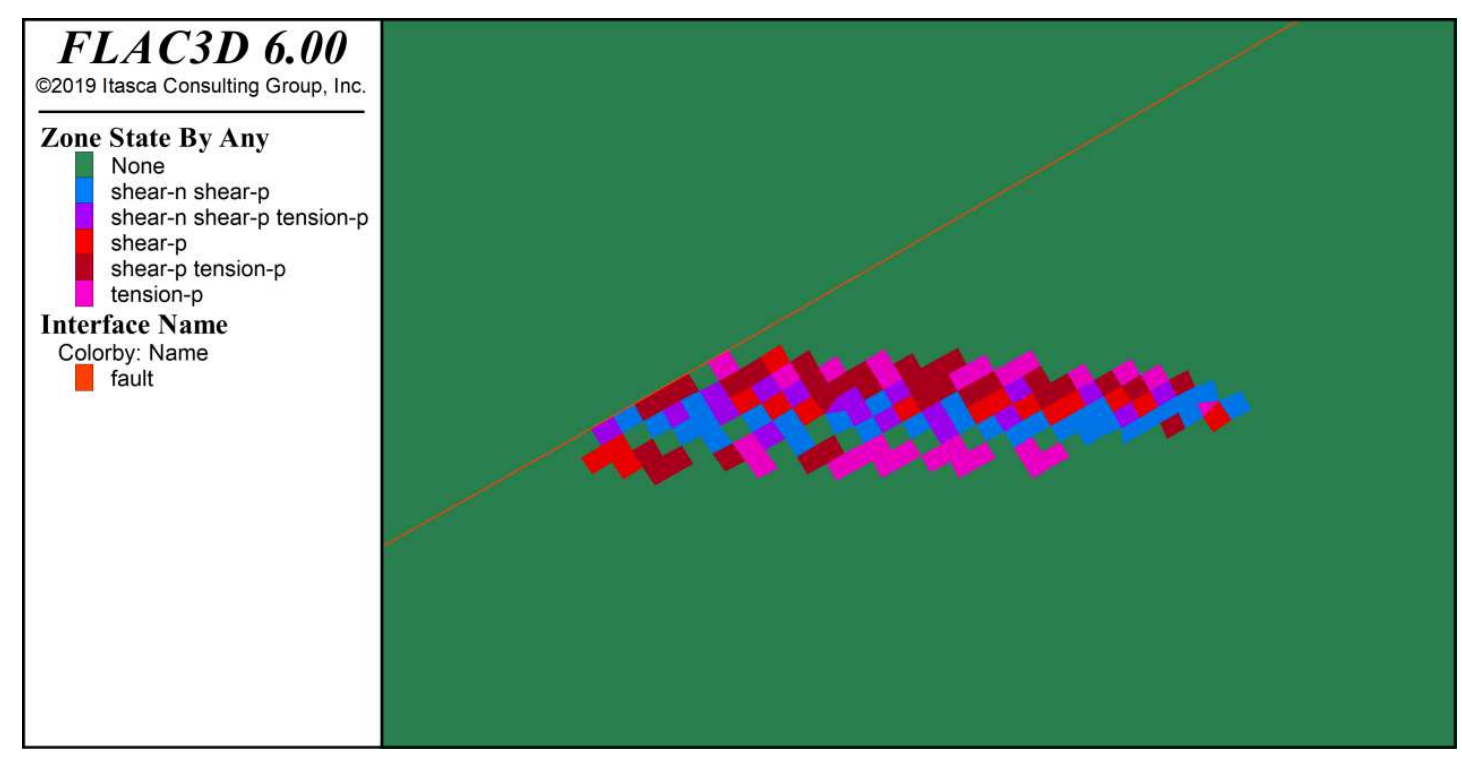

Fig.22 Overburden plastic zone when mining from -706 $\mathrm{m}$ to $-709 \mathrm{~m}$ slice stope

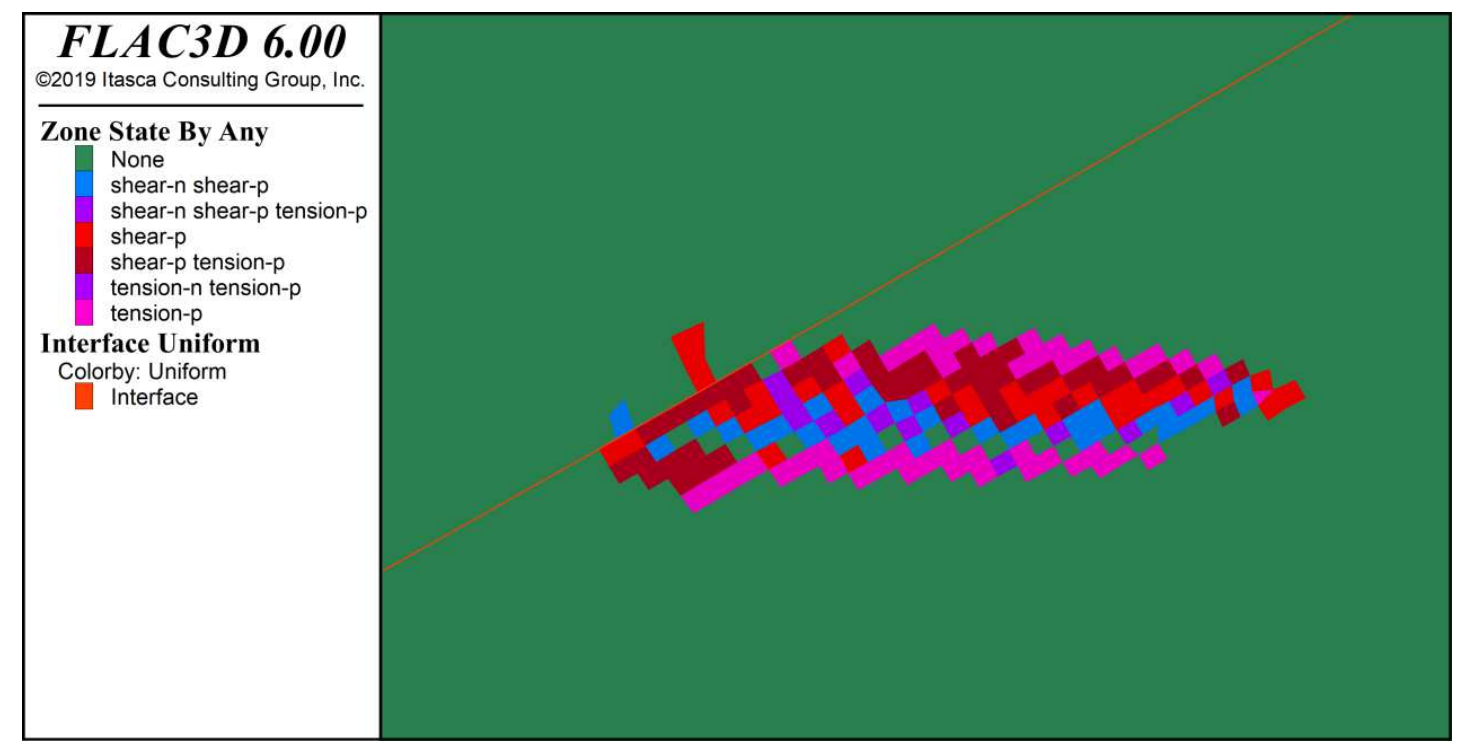

Fig.23 Overburden plastic zone when mining from -709 $\mathrm{m}$ to $-712 \mathrm{~m}$ slice stope

As seen in Fig.20-23, when mining from $-700 \mathrm{~m}$ to - $703 \mathrm{~m}$ slice, the development height of the water-conducting fractured zone is $7.1 \mathrm{~m}$ with the shape of nearly horizontal. When mining from -703 $\mathrm{m}$ to $-706 \mathrm{~m}$ slice, the development height of the water-conducting fractured zone is $10.2 \mathrm{~m}$ with the shape of nearly horizontal, the failure height of the plastic zone of the roof develops little at this time. When mining from $-706 \mathrm{~m}$ to $-709 \mathrm{~m}$ slice, the development height of the water-conducting fractured zone is $15.1 \mathrm{~m}$ with the shape of micro arch. When mining from $-709 \mathrm{~m}$ to $-712 \mathrm{~m}$ slice, the development height of the water-conducting fractured zone is $21.2 \mathrm{~m}$ with the shape of roughly micro arch, the failure height of the plastic zone of the roof develops more at this time, shear failure occurred in the hanging wall between $-701 \mathrm{~m}$ and $-709 \mathrm{~m}$. It can be seen that with the progress of mining, the failure range of the plastic area near the fault is larger than that far away from the fault, we inferred that because of the fault gouge was soft plastic-like gouge with very low strength, which caused slight sliding of the fault and had a great impact on the stability of the deposit and surrounding rock. The failure range of the middle plastic area is slightly larger than right area, we speculate the reason is that 
the gold roof cannot support the surrounding rock stress over time and the increase of backfill space in middle stope.

\section{Analysis of ZZ-Stress distribution}

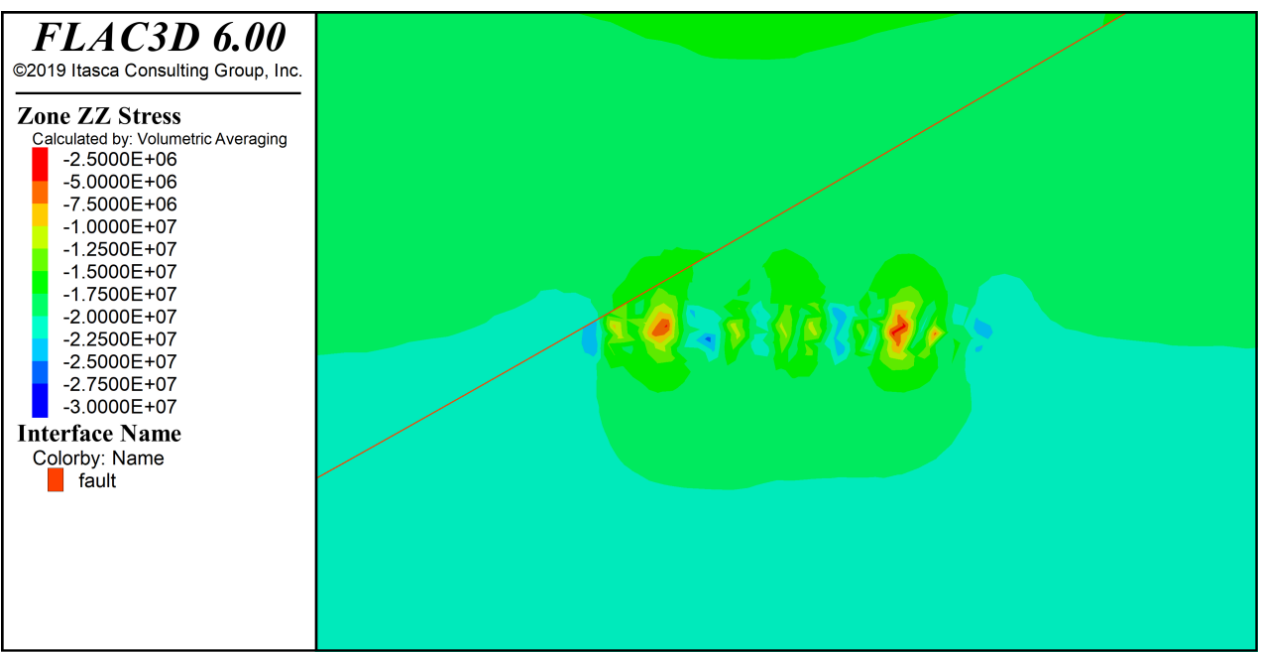

Fig.24 ZZ-Stress distribution when mining from $-700 \mathrm{~m}$ to $-703 \mathrm{~m}$ slice stope

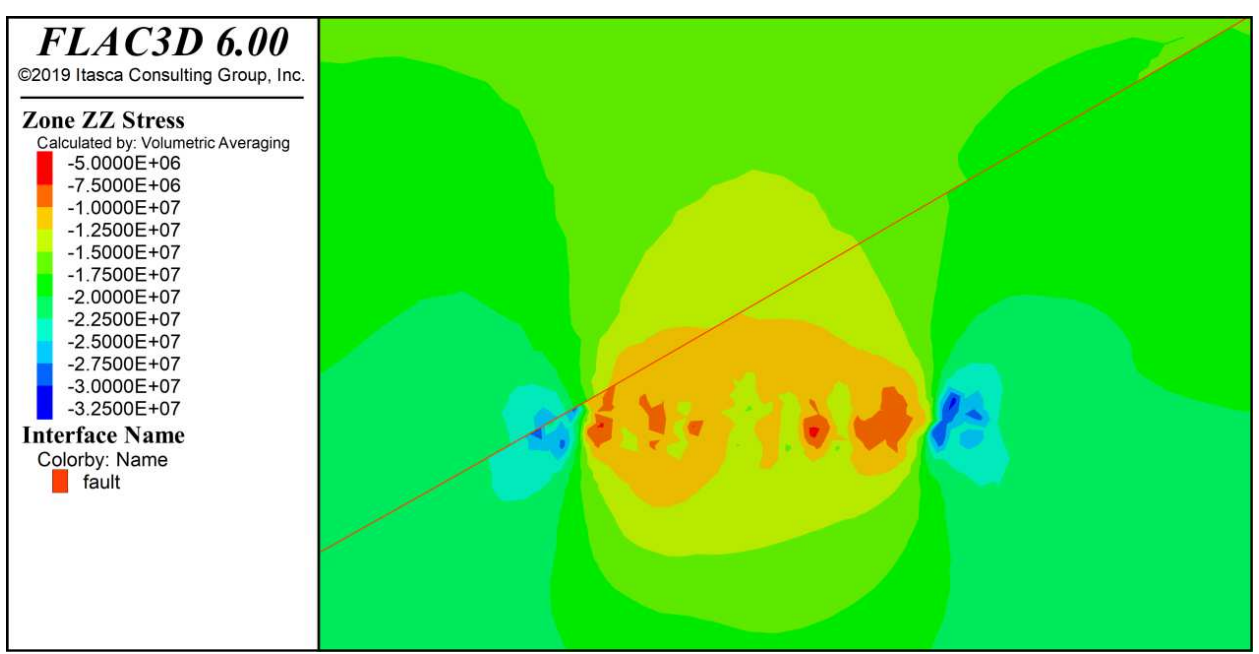

Fig.25 ZZ-Stress distribution when mining from $-703 \mathrm{~m}$ to $-706 \mathrm{~m}$ slice stope

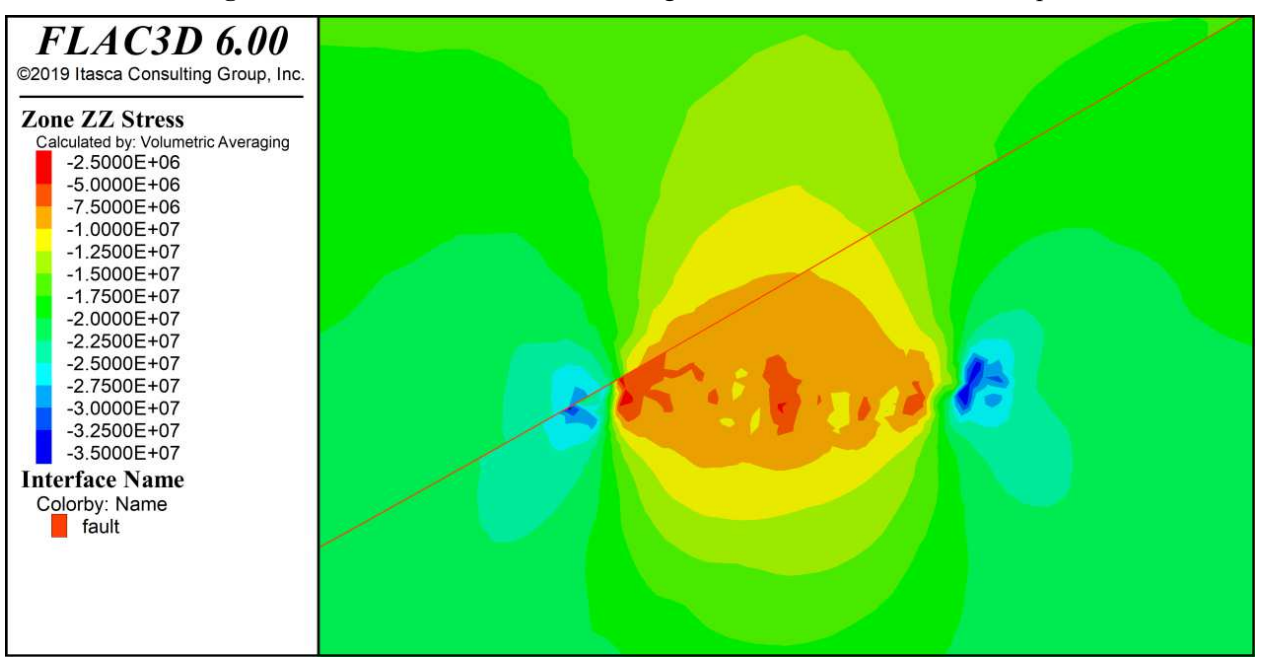

Fig.26 ZZ-Stress distribution when mining from $-706 \mathrm{~m}$ to $-709 \mathrm{~m}$ slice stope 


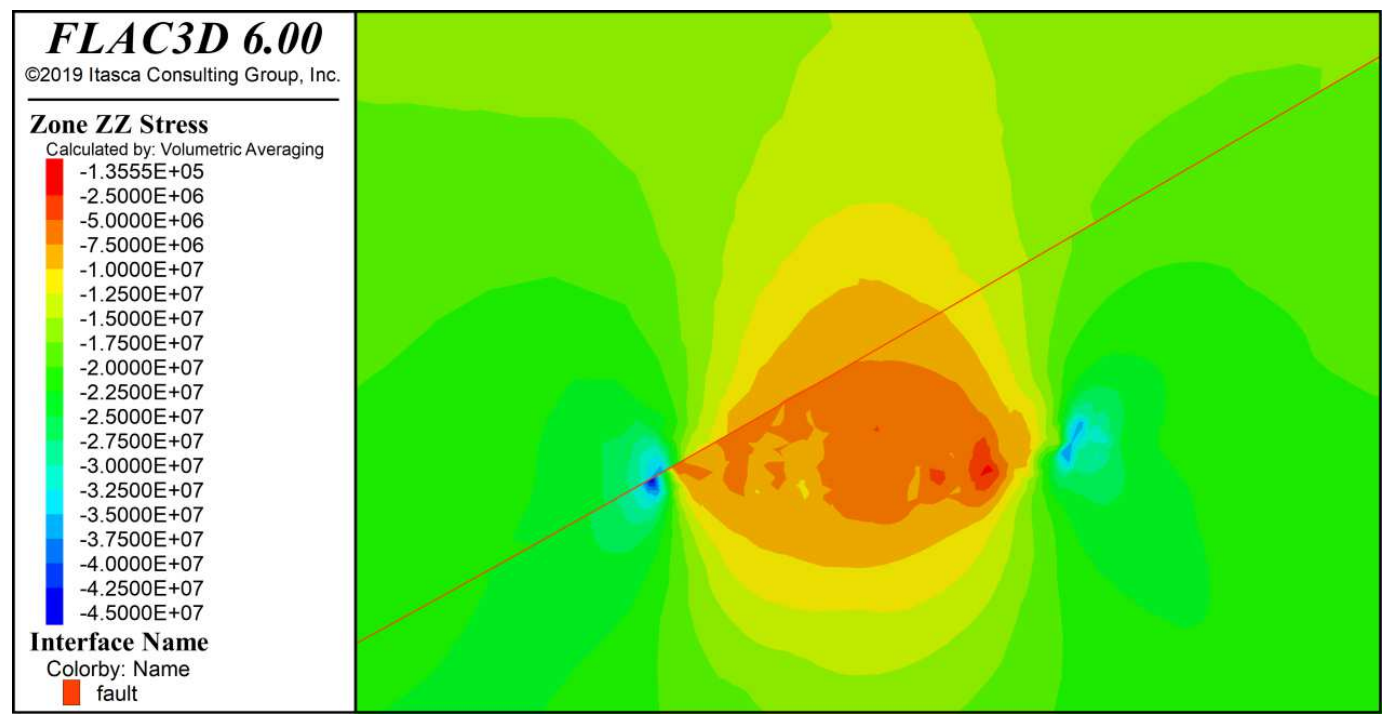

Fig.27 ZZ-Stress distribution when mining from $-709 \mathrm{~m}$ to $-712 \mathrm{~m}$ slice stope

With the process of gold mining, the original rock stress is redistributed, the stress concentration zone is formed in the front and back of the stope after mining (Fig.24-27). The stress distribution on both sides of the fault is not continuous, and it is larger in the hanging wall than that in the footwall. When mining from $-700 \mathrm{~m}$ to $-703 \mathrm{~m}$ slice, the concentrated stress in front of the stope reaches 27.5 $\mathrm{MPa}$, When mining from $-703 \mathrm{~m}$ to $-706 \mathrm{~m}$ slice, the concentrated stress in front of the stope reaches 32.5 $\mathrm{MPa}$, When mining from $-706 \mathrm{~m}$ to $-709 \mathrm{~m}$ slice, the concentrated stress in front of the stope reaches $35 \mathrm{MPa}$, When mining from $-709 \mathrm{~m}$ to $-712 \mathrm{~m}$ slice, the concentrated stress in front of the stope reaches $45 \mathrm{MPa}$. The total compressive stress gradually increases from the mining slice to its up and down.

\section{Analysis of ZZ-stress history chart at id 99574 zone}

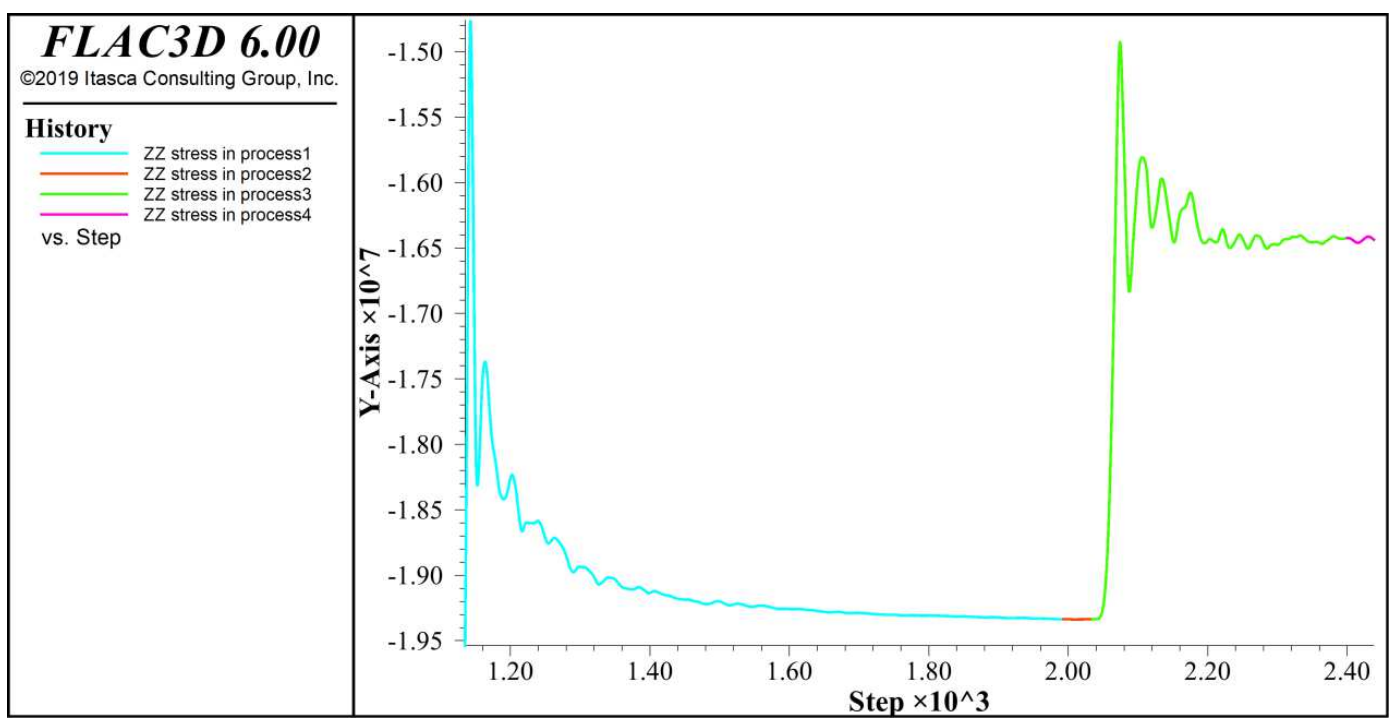

Fig.28 ZZ-stress history chart at id 99574 zone when mining from -700 $\mathrm{m}$ to $-703 \mathrm{~m}$ slice stope 


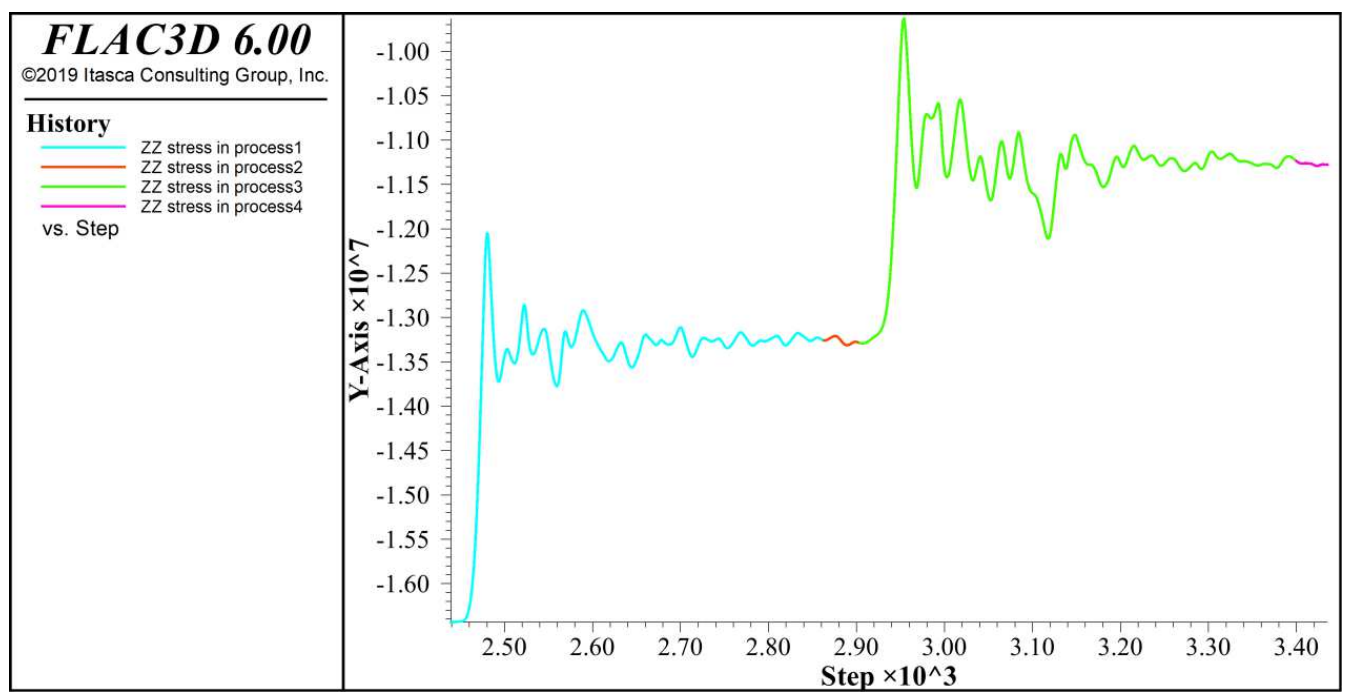

Fig.29 ZZ-stress history chart at id 99574 zone when mining from $-703 \mathrm{~m}$ to $-706 \mathrm{~m}$ slice stope

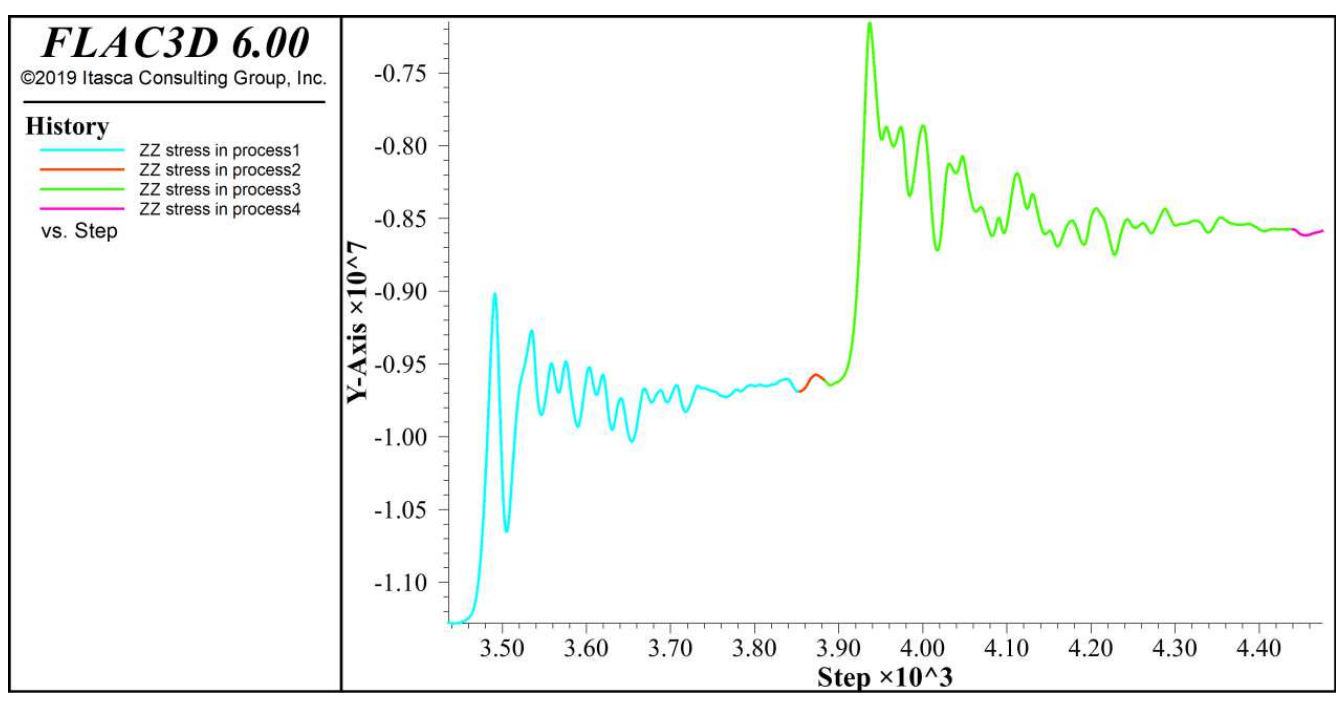

Fig.30 ZZ-stress history chart at id 99574 zone when mining from -706 $\mathrm{m}$ to $-709 \mathrm{~m}$ slice stope

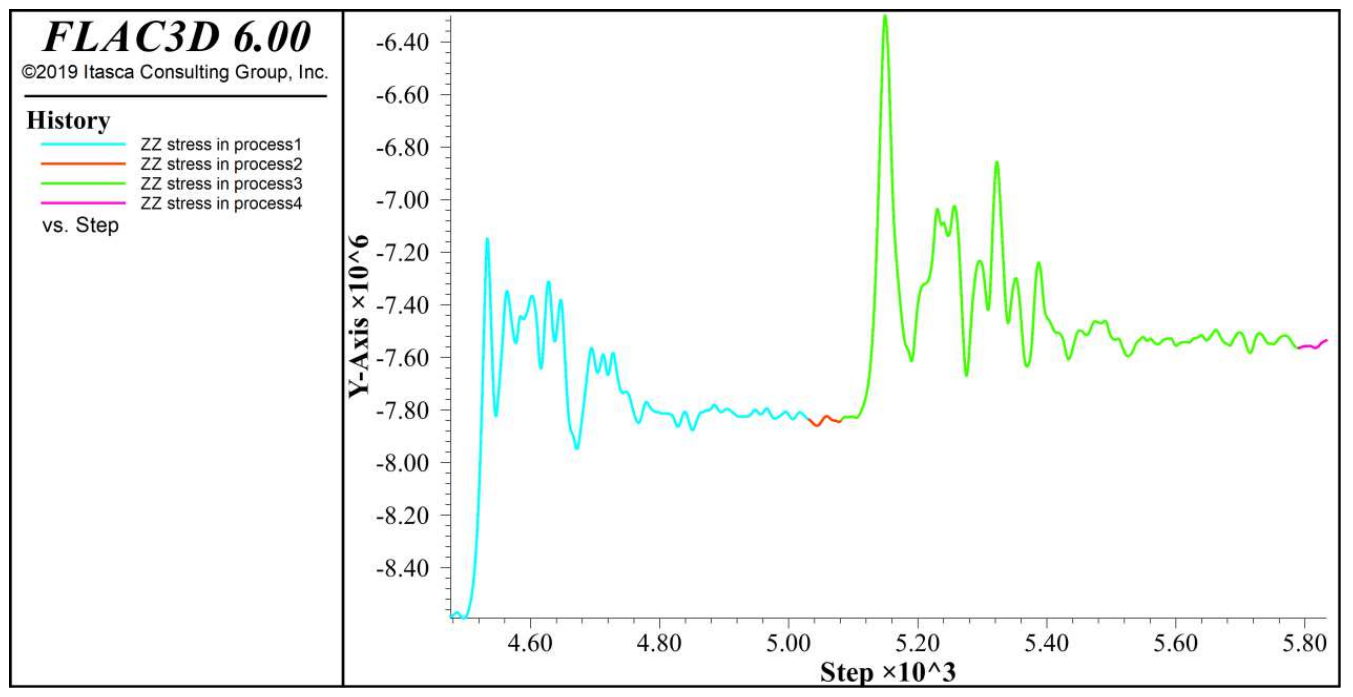

Fig.31 ZZ-stress history chart at id 99574 zone when mining from $-709 \mathrm{~m}$ to $-712 \mathrm{~m}$ slice stope

It can be seen from Fig.28-31 that the zz-stress of id 99574 zone in each slice scope experiences two peak values and reach a state of equilibrium. The second peak value is larger than the first time 
except when mining from $-700 \mathrm{~m}$ to $-703 \mathrm{~m}$ slice, it shows that the stress state of surrounding rock is most unstable in process 3 , which is easy to occur tension plastic failure. When mining from $-700 \mathrm{~m}$ to $-703 \mathrm{~m}$ slice, the pressure stress value at the peak 1 is $14.8 \mathrm{MPa}$, and the pressure stress value at the equilibrium state 1 is $19.3 \mathrm{MPa}$, which is the maximum value in the whole mining process, the reason may be that the original rock stress was damaged by the initial mining, which resulted in the redistribution of stress. The pressure stress value at the peak 2 is $14.9 \mathrm{MPa}$, and the pressure stress value at the equilibrium state 1 is $16.4 \mathrm{MPa}$. When mining from $-703 \mathrm{~m}$ to $-706 \mathrm{~m}$ slice, the pressure stress value at the peak 1 is $12.4 \mathrm{MPa}$, and the pressure stress value at the equilibrium state 1 is 13.3 $\mathrm{MPa}$, the pressure stress value at the peak 2 is $9.6 \mathrm{MPa}$, and the pressure stress value at the equilibrium state 2 is $11.3 \mathrm{MPa}$. When mining from $-706 \mathrm{~m}$ to $-709 \mathrm{~m}$ slice, the pressure stress value at the peak 1 is $9 \mathrm{MPa}$, and the pressure stress value at the equilibrium state 1 is $9.6 \mathrm{MPa}$, the pressure stress value at the peak 2 is $7.1 \mathrm{MPa}$, and the pressure stress value at the equilibrium state 2 is $8.6 \mathrm{MPa}$. When mining from $-709 \mathrm{~m}$ to $-712 \mathrm{~m}$ slice, the pressure stress value at the peak 1 is $7.1 \mathrm{MPa}$, and the pressure stress value at the equilibrium state 1 is $7.8 \mathrm{MPa}$, the pressure stress value at the peak 2 is $6.3 \mathrm{MPa}$, and the pressure stress value at the equilibrium state 2 is $7.5 \mathrm{MPa}$. It can be seen that with the development of mining, the pressure stress gradually decreases, and the difference between the peak value and the equilibrium state value gradually decreases, indicating that the stress state of the surrounding rock gradually tends to be stable, and the filling mining method reduces the instability of the surrounding rock stress, which is conducive to safe mining.

\section{Conclusion}

In this paper, three-dimensional geological modeling was established based on borehole data to simulate the development height characteristics of the overburden water-conducting fractured zone and spatial and temporal distribution of mining stress field in deep mining of Jiaojia gold mine. The main conclusions are as follows:

(1) The maximum height of the water-conducting fractured zone is $21.2 \mathrm{~m}$ during the whole mining at $-700 \mathrm{~m}$ level, shape from near horizontal to micro arch, the failure range of the plastic area near the fault is larger than that far away from the fault, the failure range of the middle plastic area is slightly larger than that of right area, shear failure occurred in the hanging wall between $-701 \mathrm{~m}$ and $709 \mathrm{~m}$ when mining from $-709 \mathrm{~m}$ to $-712 \mathrm{~m}$ slice.

(2) The stress concentration zone is formed in the front and back of the stope during mining process. The stress distribution on both sides of the fault is not continuous, and it is in the hanging wall larger than that in the footwall. The stress in the concentrated area increases with the increase of mining depth, and the maximum value is $45 \mathrm{MPa}$. The total compressive stress gradually increases from the mining slice to its up and down.

(3) The zz-stress of id 99574 zone in each slice scope experiences two peak values and reach a state of equilibrium. The second peak value is larger than the first time except when mining from -700 $\mathrm{m}$ to $-703 \mathrm{~m}$ slice, it shows that the stress state of surrounding rock is most unstable in process 3 , which is easy to occur tension plastic failure. the pressure stress value at the equilibrium state 1 is $19.3 \mathrm{MPa}$. The pressure stress value at the equilibrium state 2 is $19.3 \mathrm{MPa}$, which is the maximum compressive stress during mining.

(4) Because the Jiaojia fault is soft plastic-like gouge with very low strength, which causes slight sliding and has a great impact on the stability of the deposit and surrounding rock, so the safety of gold mining near the fault should be noted. 
Acknowledgments We gratefully acknowledge the financial support of the National Natural Science Foundation of China (No.42002282, No.51804184, No.41807283), and the Key projects of Shandong Natural Science Foundation (No.ZR2020KE023).

\section{Reference}

Almadani S, Ibrahim E, Al-Amri A (2019) Delineation of a fractured granite aquifer in the Alwadeen area, Southwest Saudi Arabia using a geoelectrical resistivity survey. Arabian Journal of Geosciences, 12: 1-13. https://doi:10.1007/s12517-019-4646-Z

Chu FJ (2012) Study on Low-dilution-loss and Safety Mining Technology of Deep Mining Transition in Daye Iron Mine. Wuhan University of Technology, China. (In Chinese)

Dar I A, Sankar K, Dar M A (2010) Remote sensing technology and geographic information system modeling: An integrated approach towards the mapping of groundwater potential zones in Hardrock terrain, Mamundiyar basin. Journal of Hydrology, 2010, 394: 285-295. https://doi.org/:10.1016/j.jhydrol.2010.08.022

Fan H, Wang LG, Lu YL, et al. (2020) Height of water-conducting fractured zone in a coal seam overlain by thin bedrock and thick clay layer: a case study from the Sanyuan coal mine in North China. Environmental Earth Science, 79 : 125. https://doi.org/10.1007/s12665-020-8873-0

Gao WF, Shi LQ, Han J, et al (2020) Study on control water of Ordovician aquifer: a coal mine of Feicheng mining area, China. Carbonates Evaporites 35: $\quad$ https://doi.org/10.1007/s13146-020-00588-3

Guo C, Yang Z, Li S, et al (2020) Predicting the Water-Conducting Fracture Zone (WCFZ) Height Using an MPGA-SVR Approach. Sustainability, 12: 1809. https://doi.org/:10.3390/su12051809

Helmut K(1983) Mining Subsidence Engineering. Springer Verlag press, Berlin.

Maria K, Brixel B, Jalali M (2019) Transient hydraulic tomography approach to characterize main flowpaths and their connectivity in fractured media. Advances in Water Resources, 136: 103500. https://doi.org/:10.1016/j.advwatres.2019.103500

Nikić, Z., Pušić, M., Papić, P., \& Marić, N (2019) Hydrodynamic model of hydrogeologic fracture system in Gruda ultramafic rocks, western Serbia. Journal of Hydrology: 124268. https://doi.org/:10.1016/j.jhydrol.2019.124268

N.S, Magesh, Chandrasekar, et al (2012) Delineation of groundwater potential zones in Theni district, Tamil Nadu, using remote sensing, GIS and MIF techniques. Geoscience Frontiers, 3:189-196. https://doi.org/:10.1016/j.gsf.2011.10.007

Qiu M, Han J, Zhou Y, et al. (2017) Prediction reliability of water inrush through the coal mine floor. Mine Water and the Environment, 36(2), 217-225. https://doi.org/10.1007/s10230-017-0431-y

Ross S (2018) Interpretations of Mine Water Pump-Out Data and Revisions to Caving and Fracturing Models for Longwalls. Mine Water \& the Environment,3: 676-685. https://doi.org/:10.1007/s10230-019-00627-z

Sener E, Davraz A, Ozcelik M (2005) An integration of GIS and remote sensing in groundwater investigations: A case study in Burdur, Turkey. Hydrogeology Journal, 13: 826-834. https://doi.org/:10.1007/s10040-004-0378-5

Shi LQ, Gao WF, Han J, et al. (2017). A nonlinear risk evaluation method for water inrush through the seam floor. Mine Water and the Environment, 36: 597-605. https://doi.org/10.1007/s10230-017-0449-1

Shi LQ, Qiu M, Wang Y, et al (2019) Evaluation of water inrush from underlying aquifers by using a modified water-inrush coefficient model and water-inrush index model: a case study in Feicheng coalfield, China. Hydrogeology Journal, 6: 2105-2119. https://doi.org/10.1007/s10040-019-01985-2

Shi LQ, Xu DJ, Wang Y, et al (2019) A novel conceptual model of fracture evolution patterns in the overlying strata during horizontal coal seam mining. Arabian Journal of Geosciences, 12: 326. https://doi.org/10.1007/s12517-019-4486-X Syd SP (1978) Coal Mine Ground Control. A wiley-interscicncc press, New York. 
Terhemba SB, Huajian Y, Song L, et al (2020) High-resolution 3-D crustal shear-wave velocity model reveals structural and seismicity segmentation of the central-souther Tanlu Fault zone, eastern China. Tectonophysics, 20: 228372. https://doi.org/10.1016/j.tecto.2020.228372 


\section{Figures}

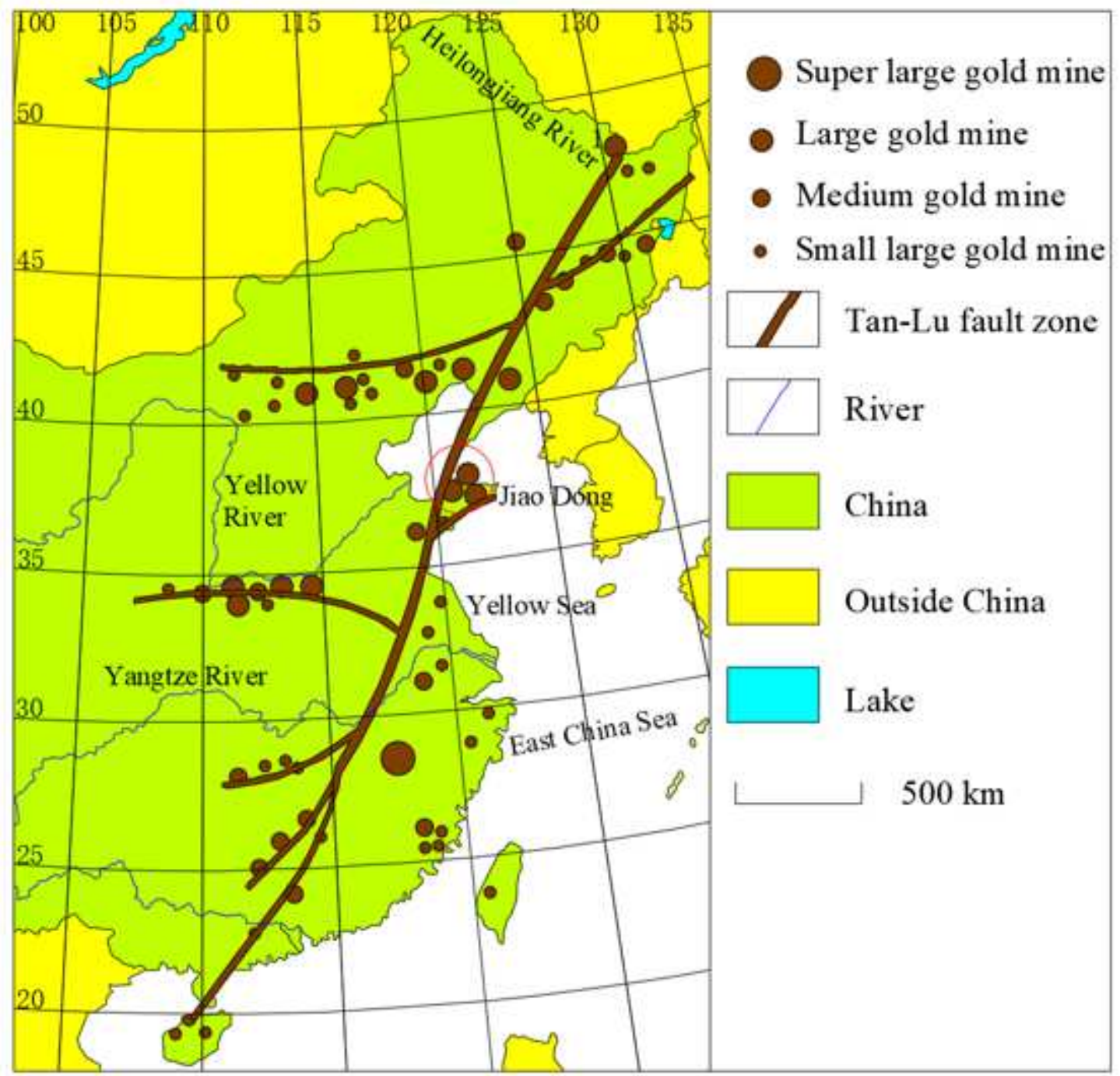

Figure 1

Please see the Manuscript PDF file for the complete figure caption Note: The designations employed and the presentation of the material on this map do not imply the expression of any opinion whatsoever on the part of Research Square concerning the legal status of any country, territory, city or area or of its authorities, or concerning the delimitation of its frontiers or boundaries. This map has been provided by the authors. 


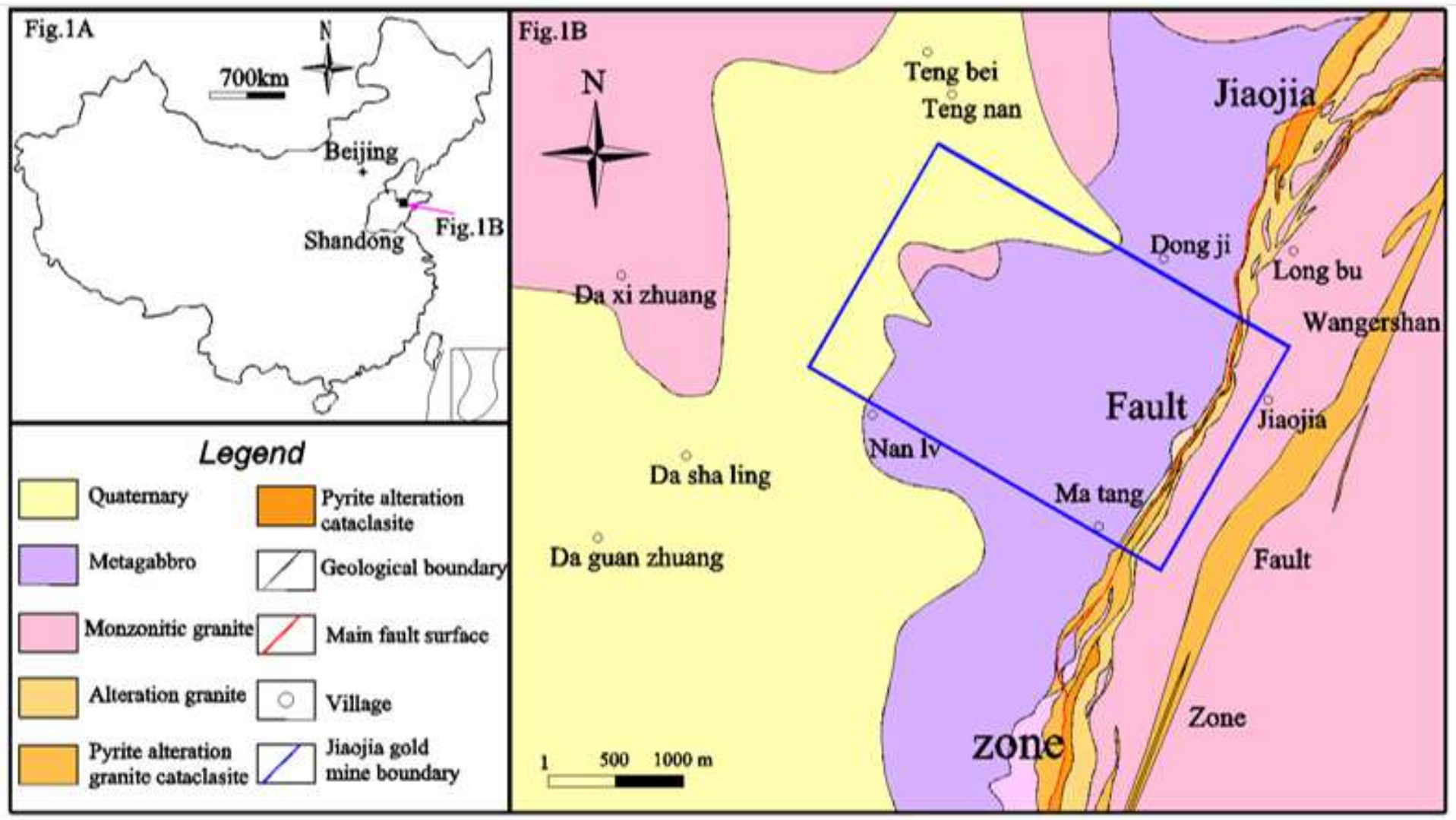

Figure 2

Please see the Manuscript PDF file for the complete figure caption Note: The designations employed and the presentation of the material on this map do not imply the expression of any opinion whatsoever on the part of Research Square concerning the legal status of any country, territory, city or area or of its authorities, or concerning the delimitation of its frontiers or boundaries. This map has been provided by the authors. 

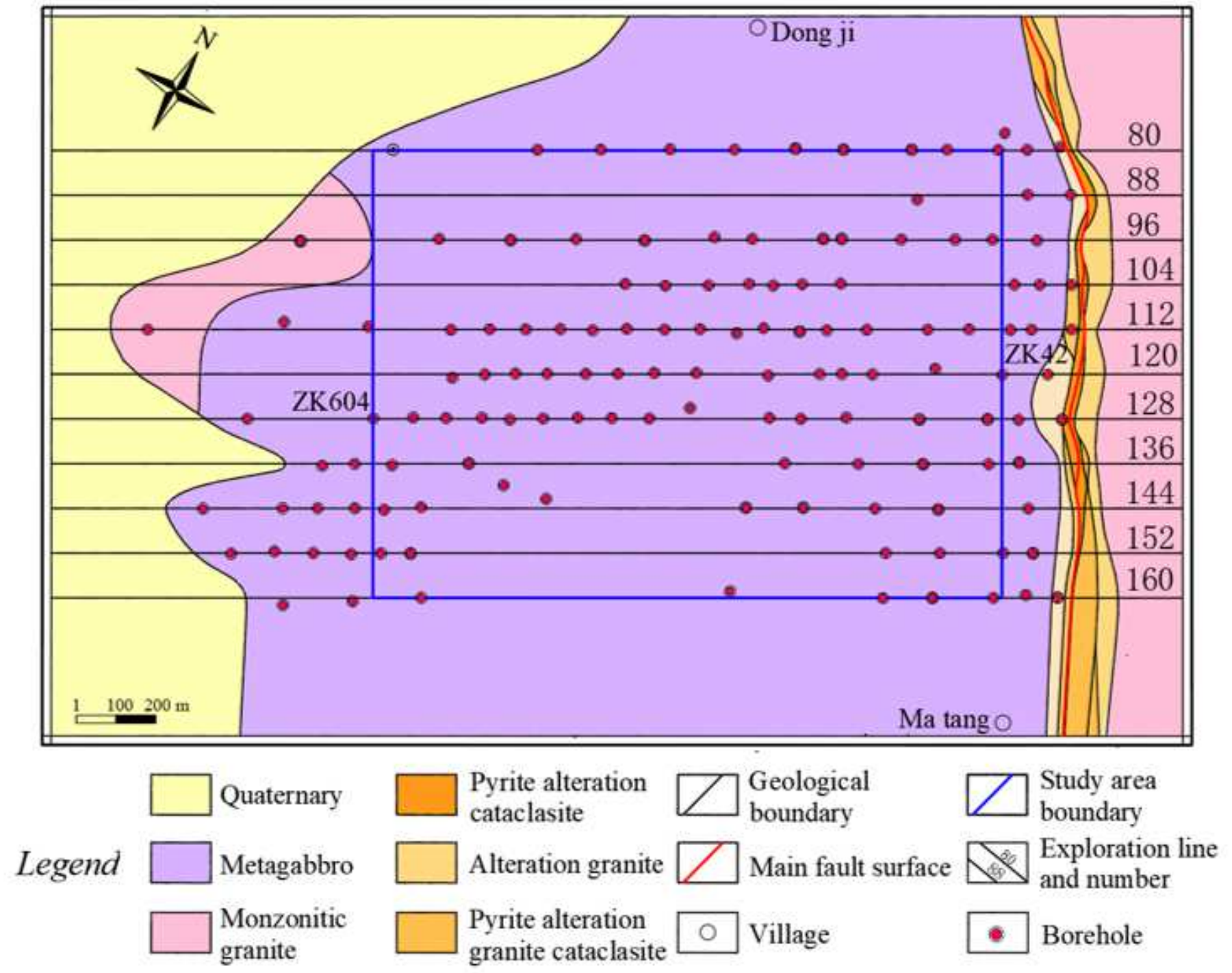

\section{Figure 3}

Please see the Manuscript PDF file for the complete figure caption Note: The designations employed and the presentation of the material on this map do not imply the expression of any opinion whatsoever on the part of Research Square concerning the legal status of any country, territory, city or area or of its authorities, or concerning the delimitation of its frontiers or boundaries. This map has been provided by the authors. 


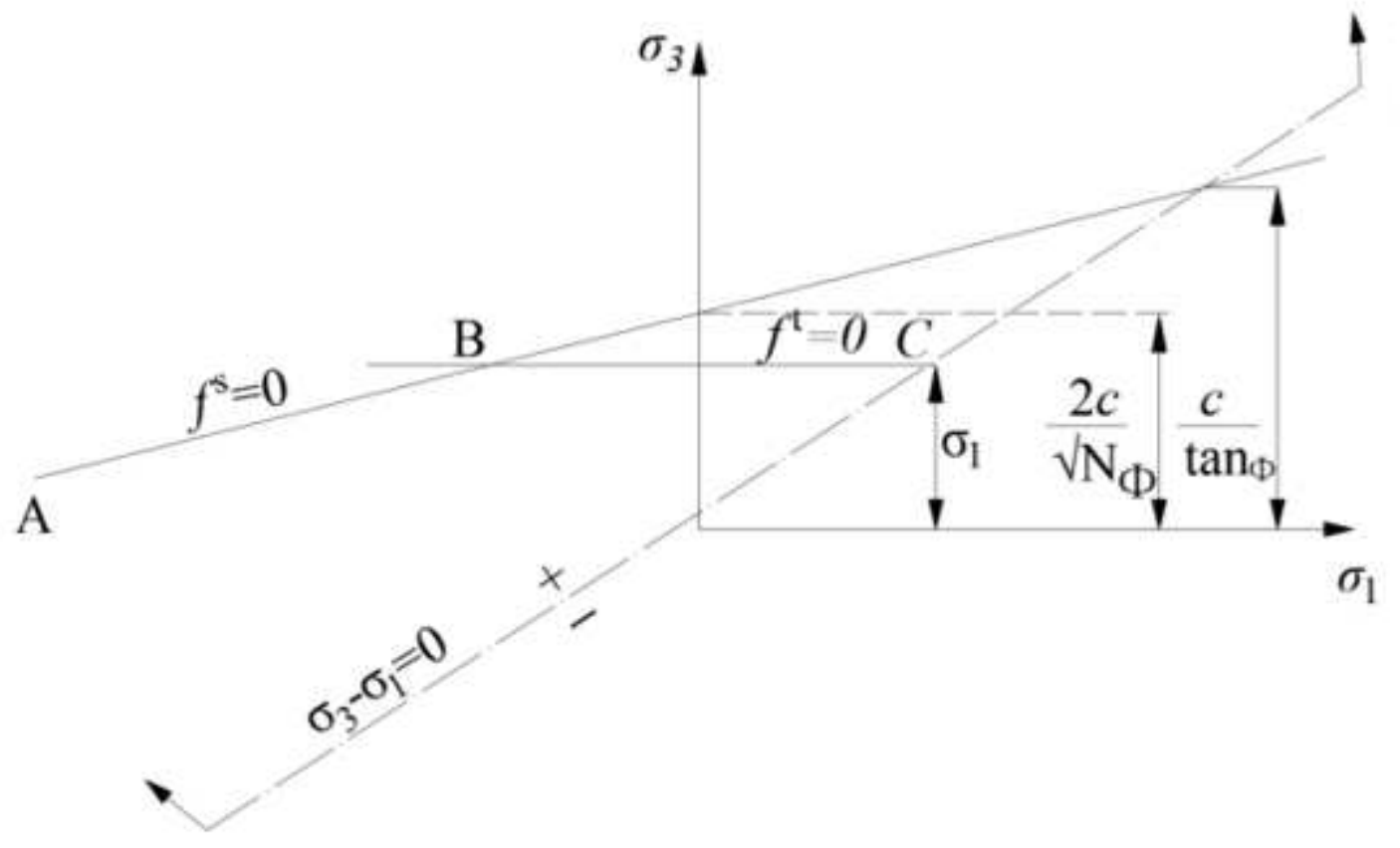

Figure 4

Please see the Manuscript PDF file for the complete figure caption

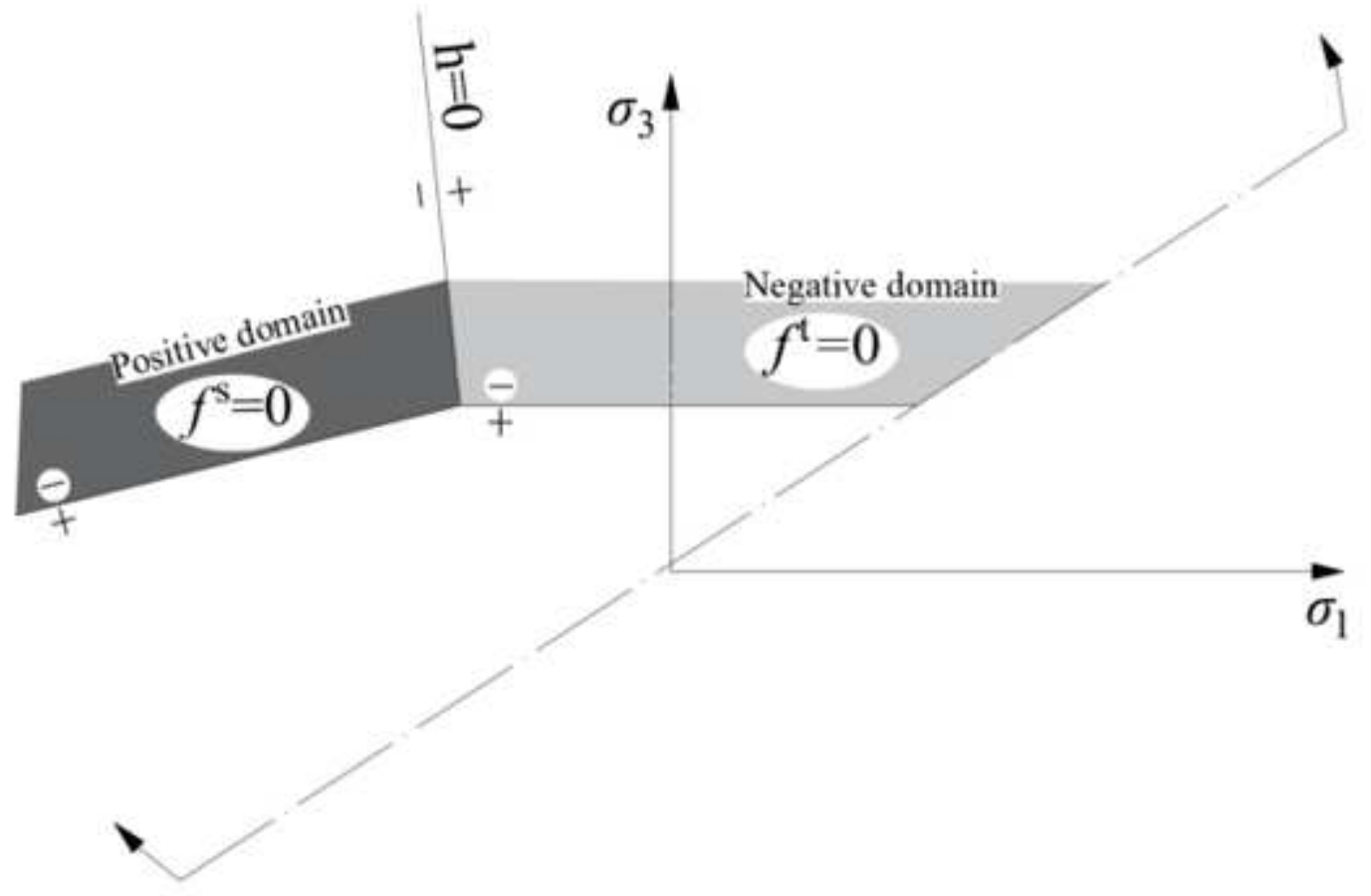

Figure 5

Please see the Manuscript PDF file for the complete figure caption 


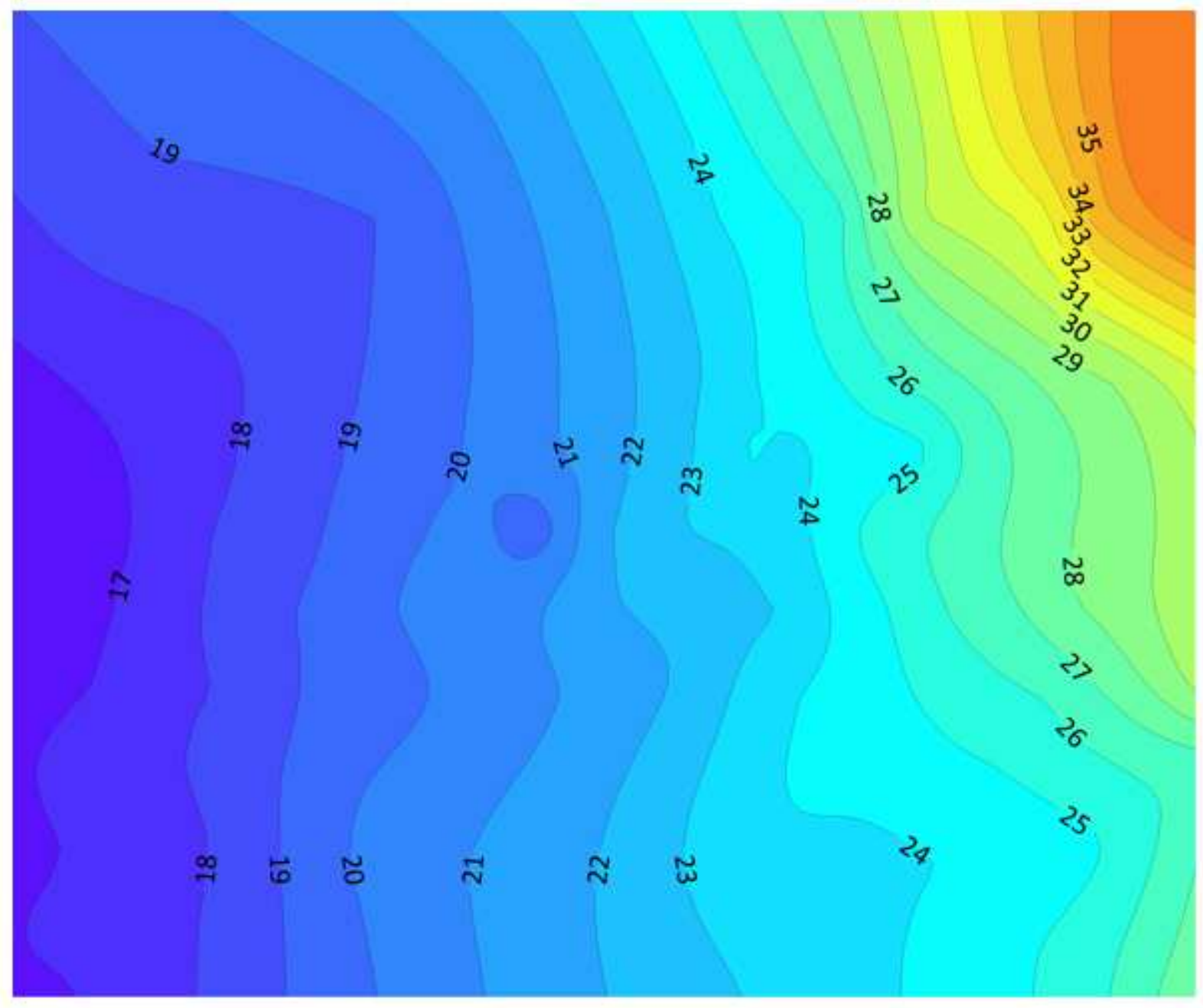

Figure 6

Please see the Manuscript PDF file for the complete figure caption 


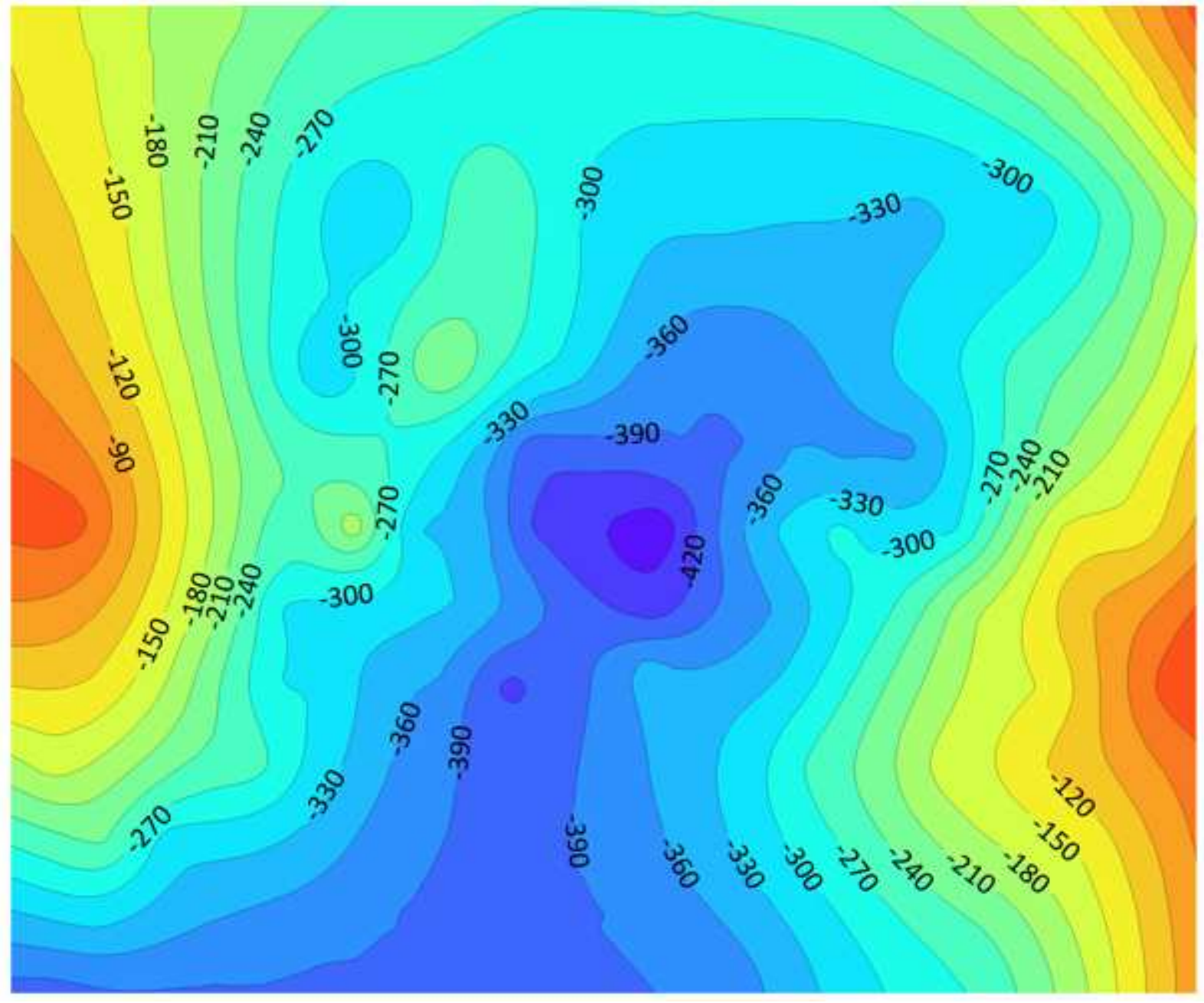

Figure 7

Please see the Manuscript PDF file for the complete figure caption 


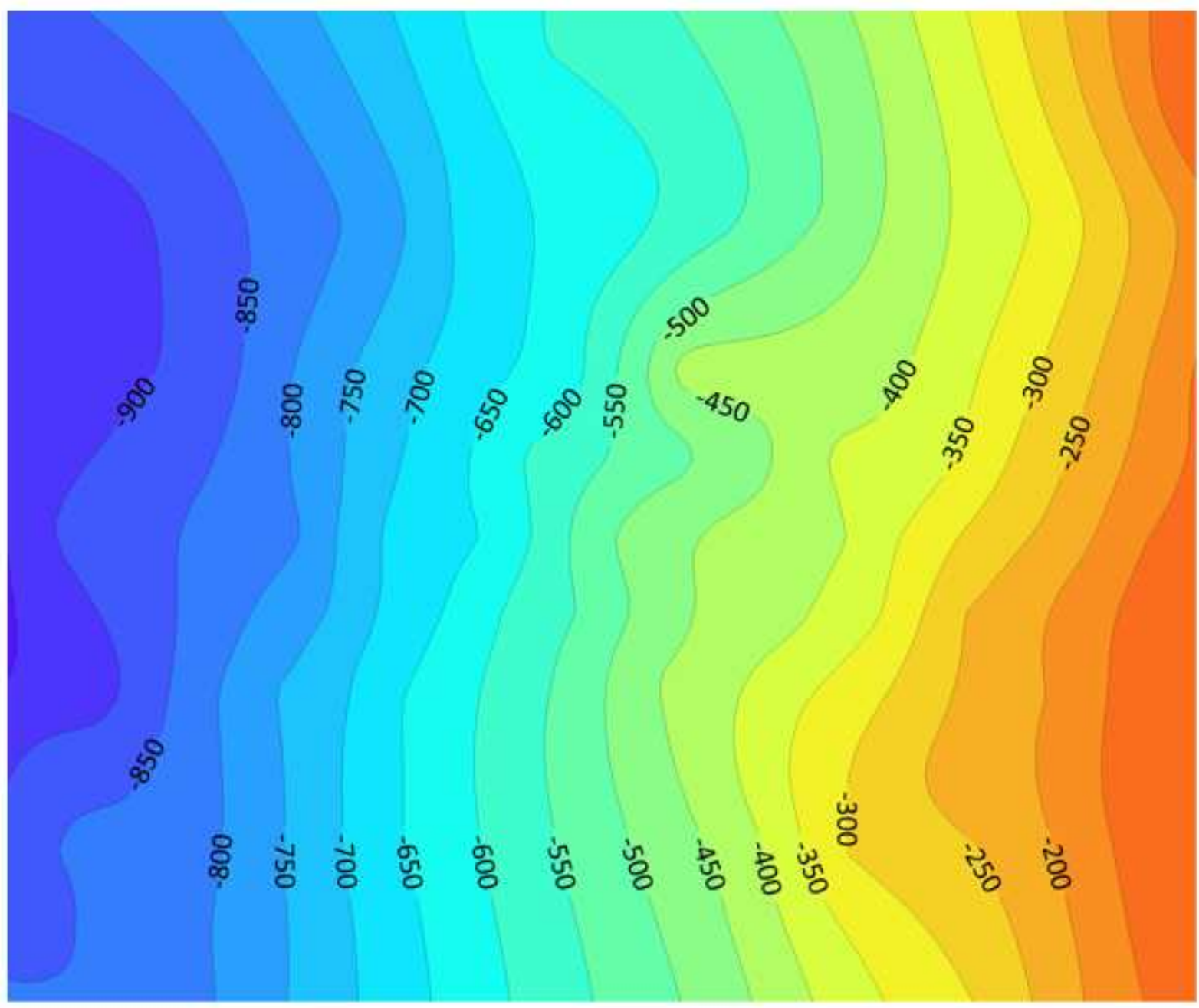

Figure 8

Please see the Manuscript PDF file for the complete figure caption 


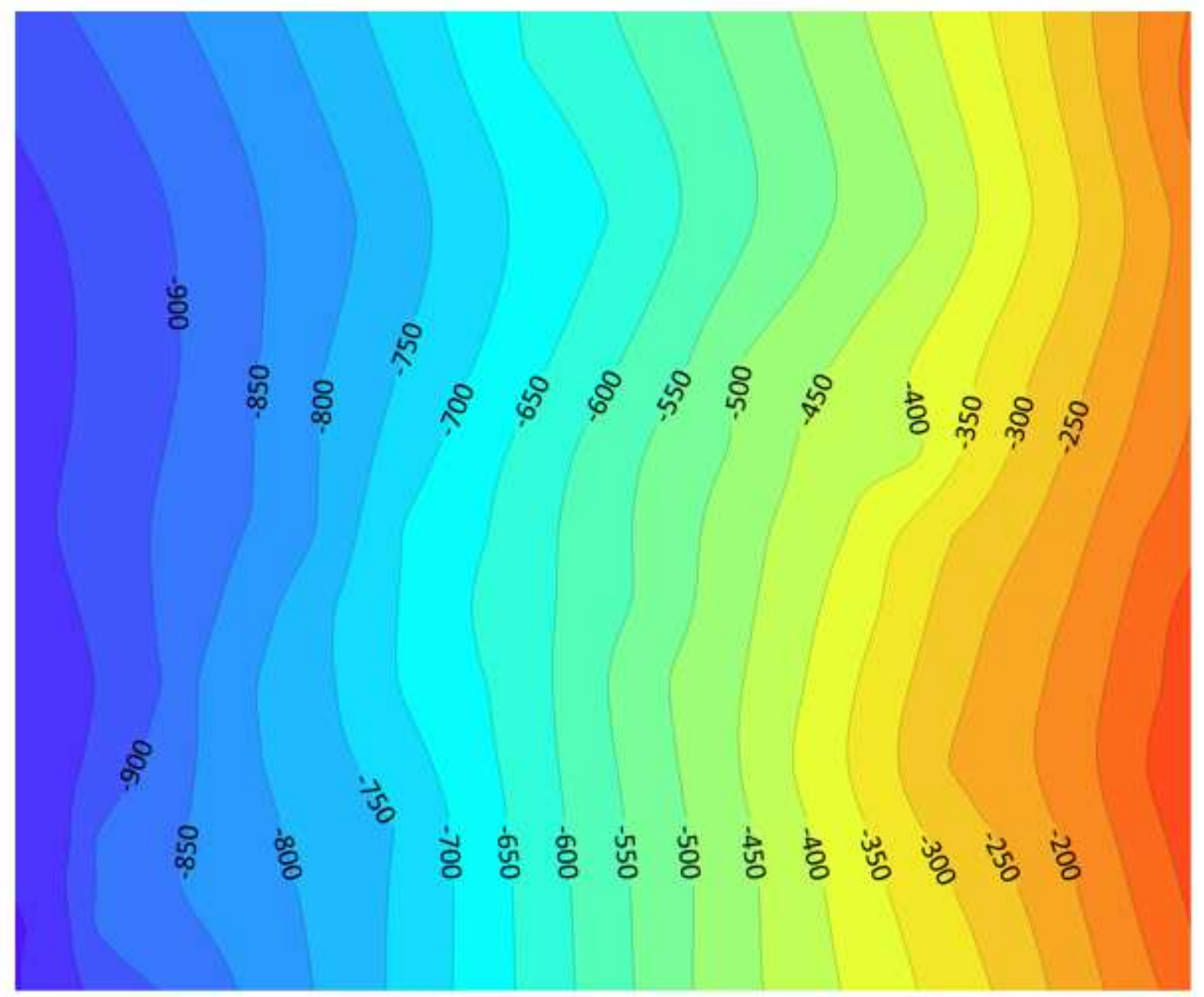

Figure 9

Please see the Manuscript PDF file for the complete figure caption 


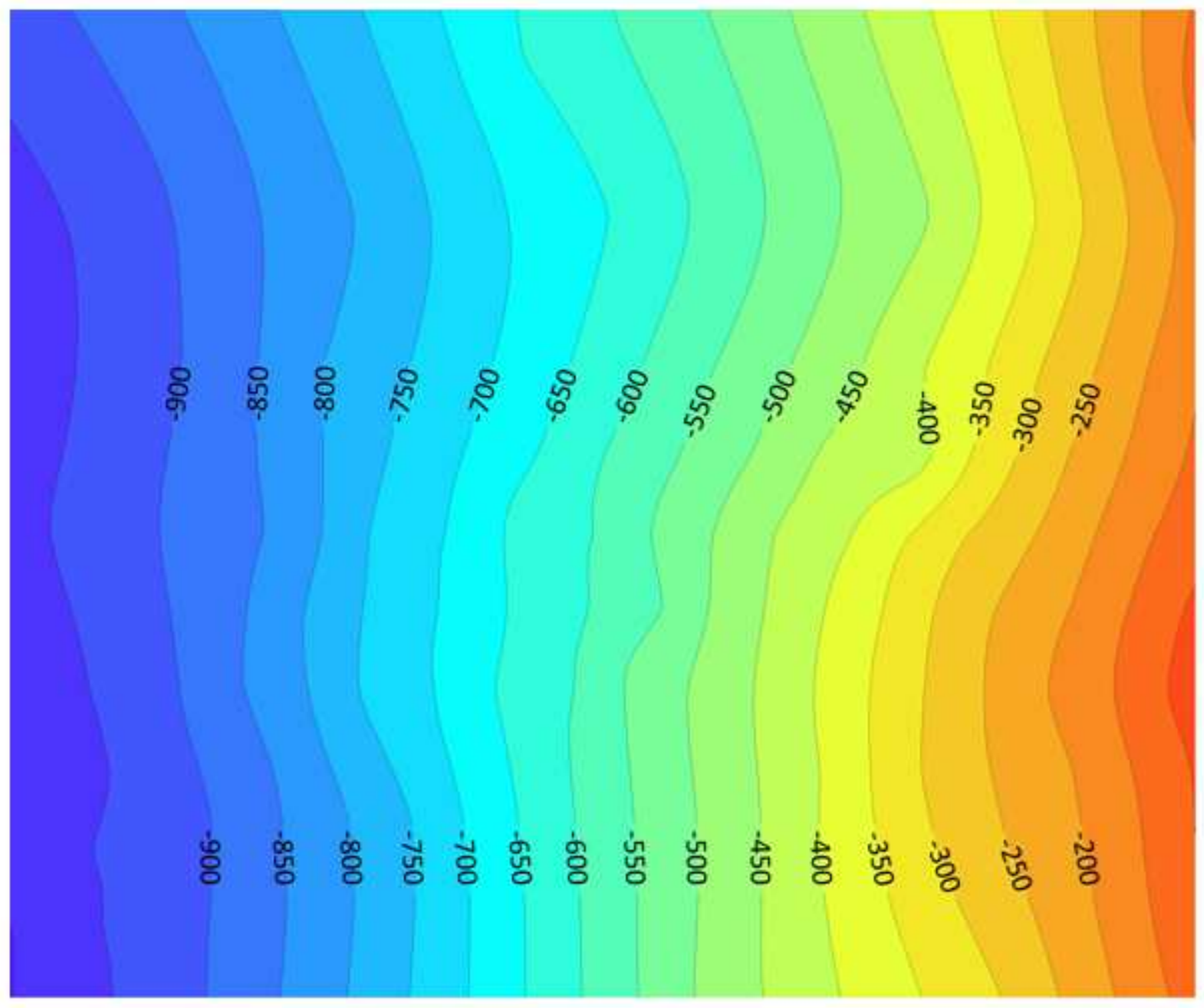

Figure 10

Please see the Manuscript PDF file for the complete figure caption 


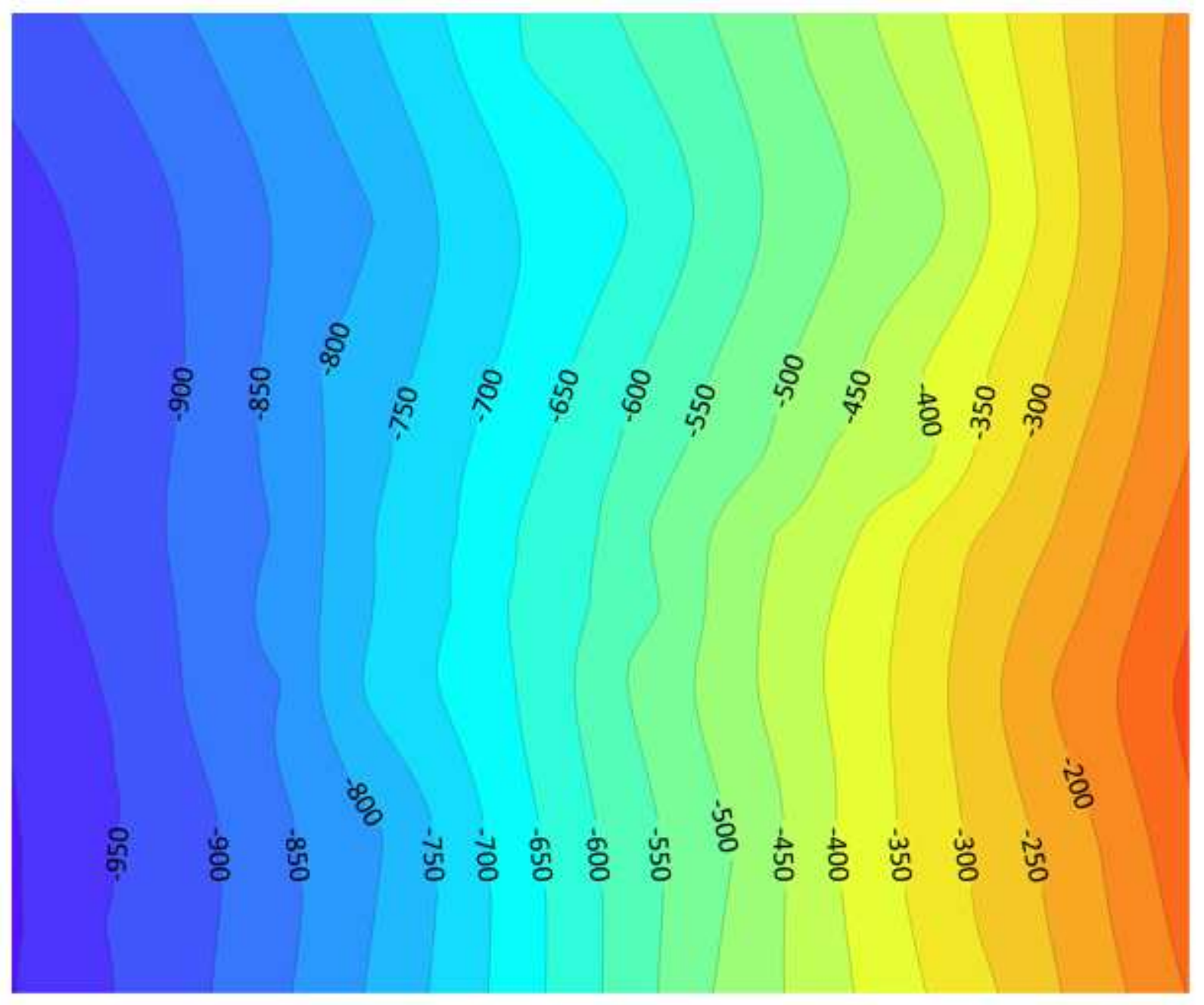

Figure 11

Please see the Manuscript PDF file for the complete figure caption 


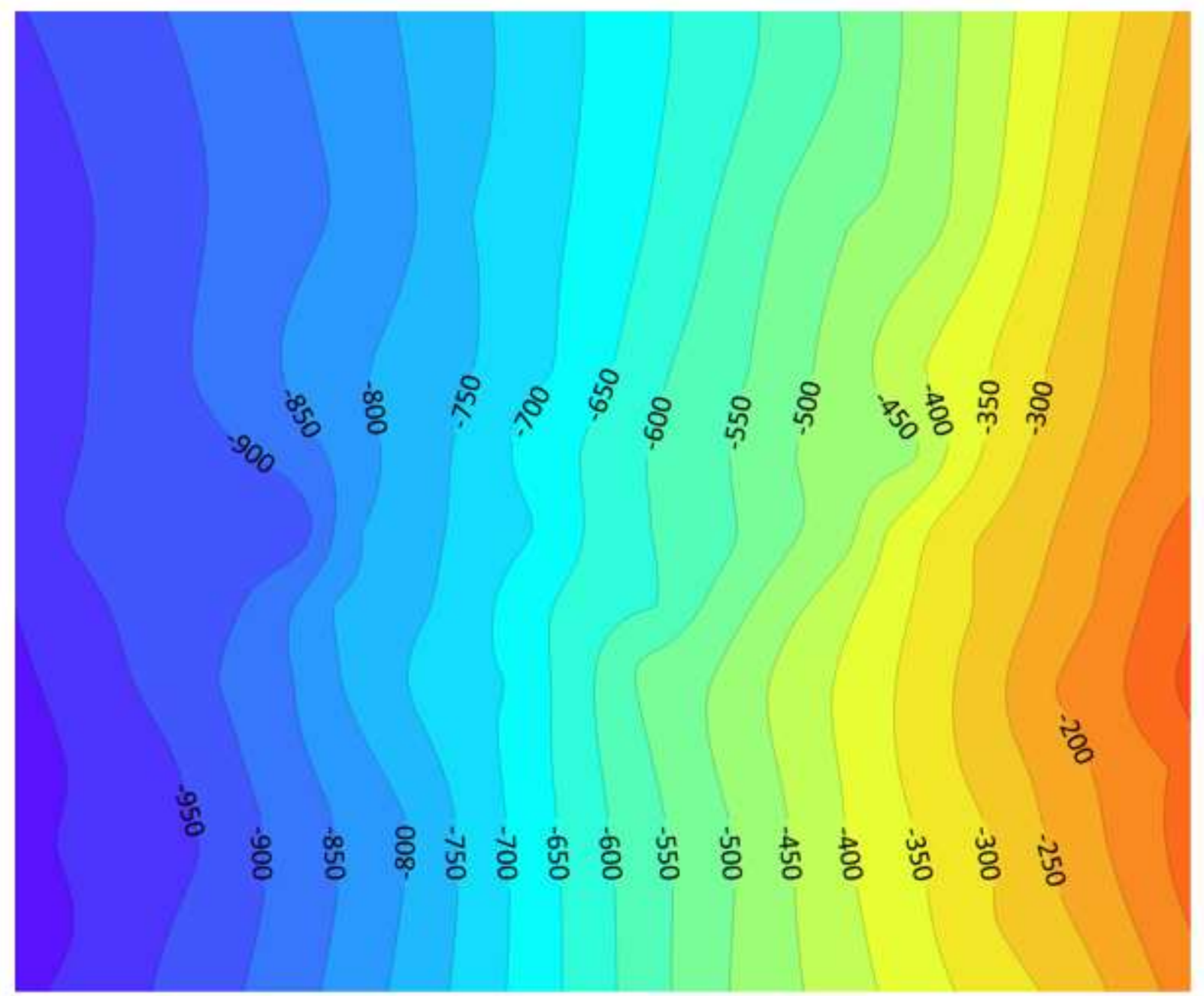

Figure 12

Please see the Manuscript PDF file for the complete figure caption 


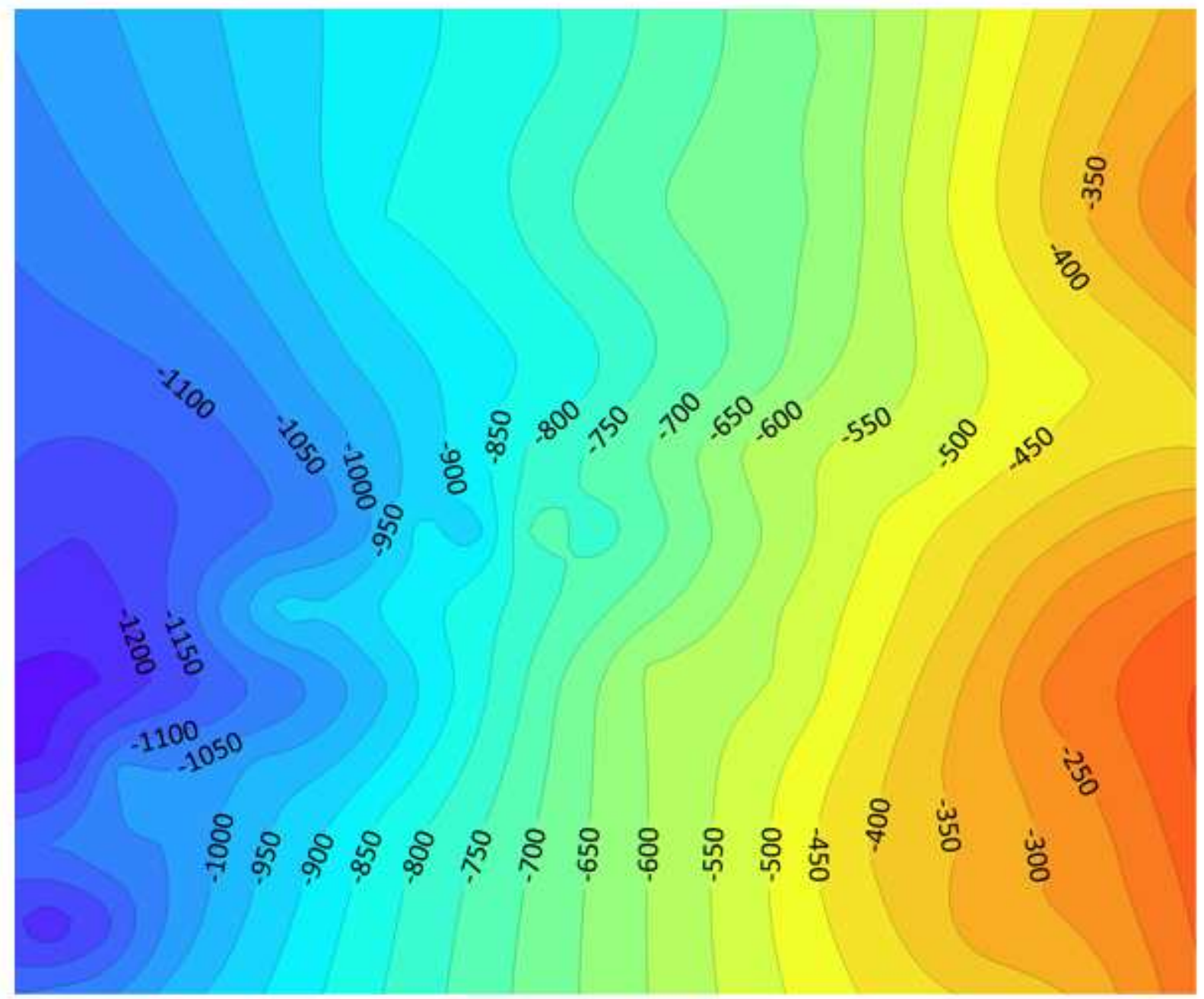

Figure 13

Please see the Manuscript PDF file for the complete figure caption
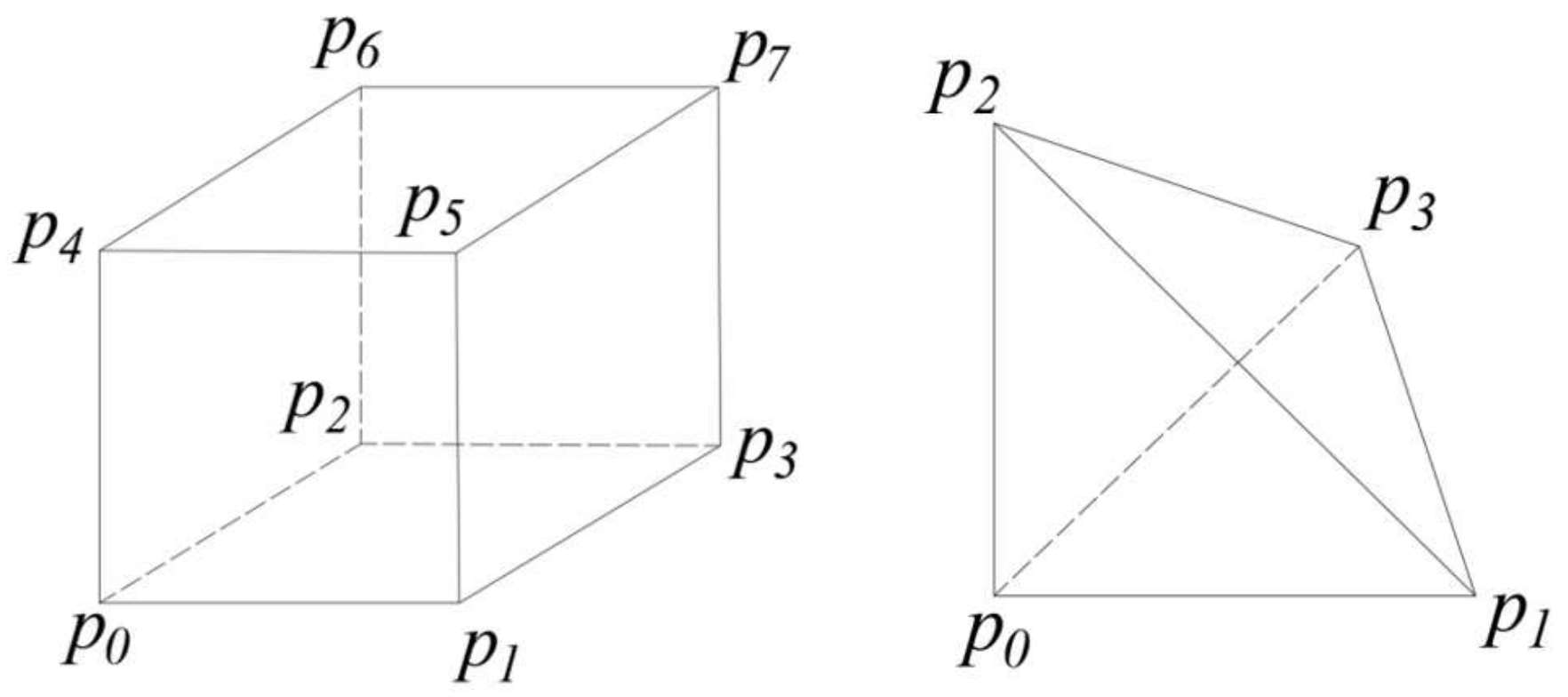
Figure 14

Please see the Manuscript PDF file for the complete figure caption

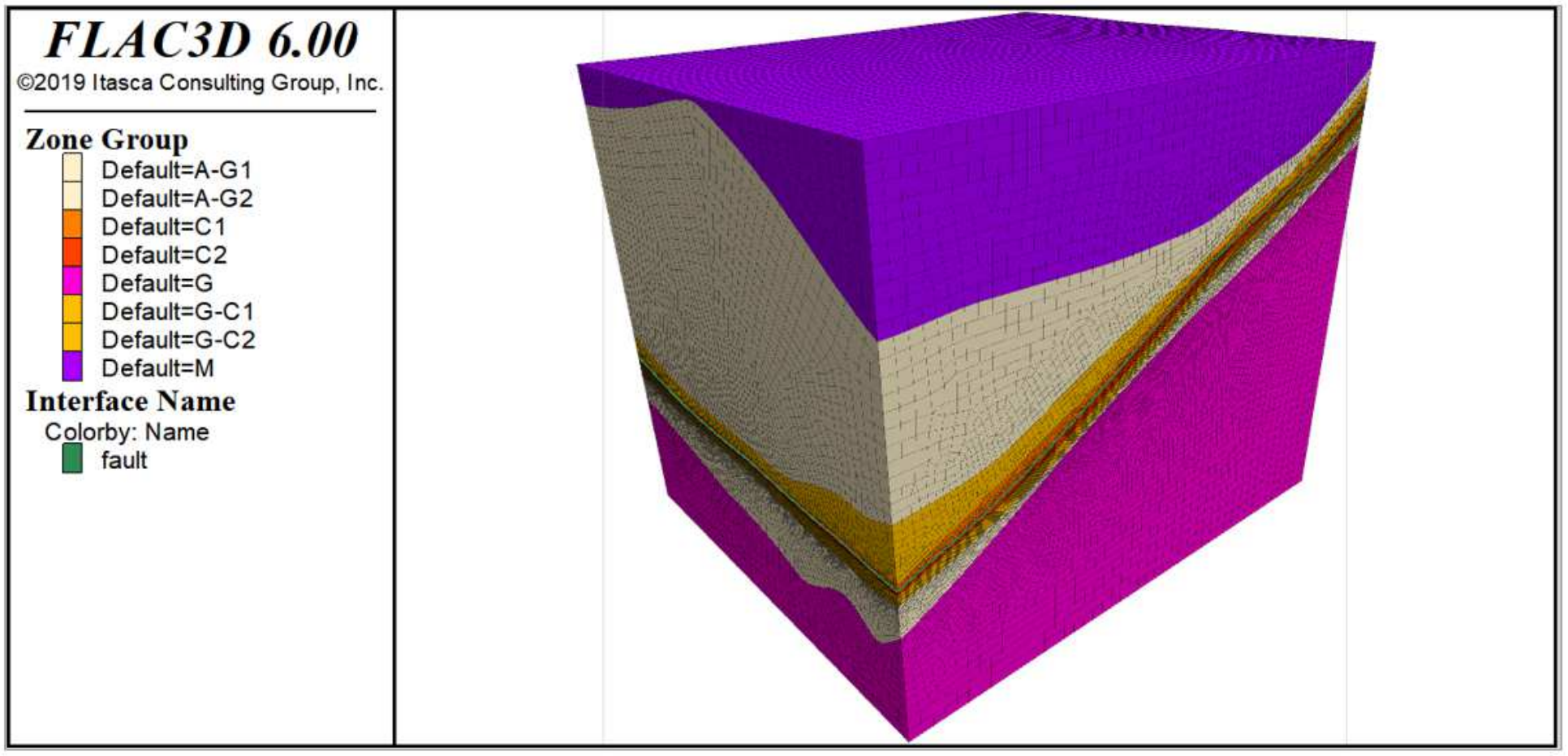

Figure 15

Please see the Manuscript PDF file for the complete figure caption

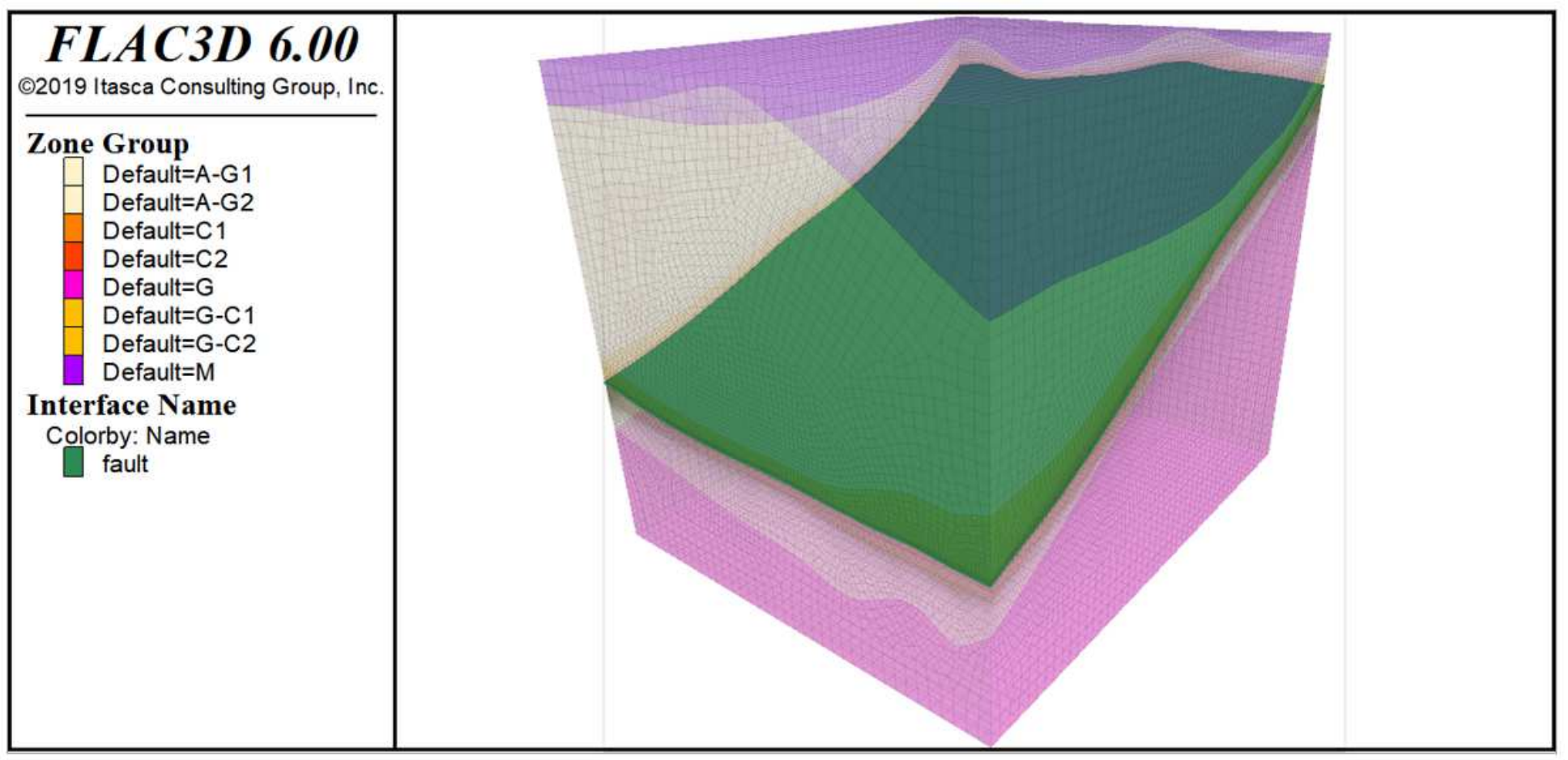

Figure 16 
Please see the Manuscript PDF file for the complete figure caption

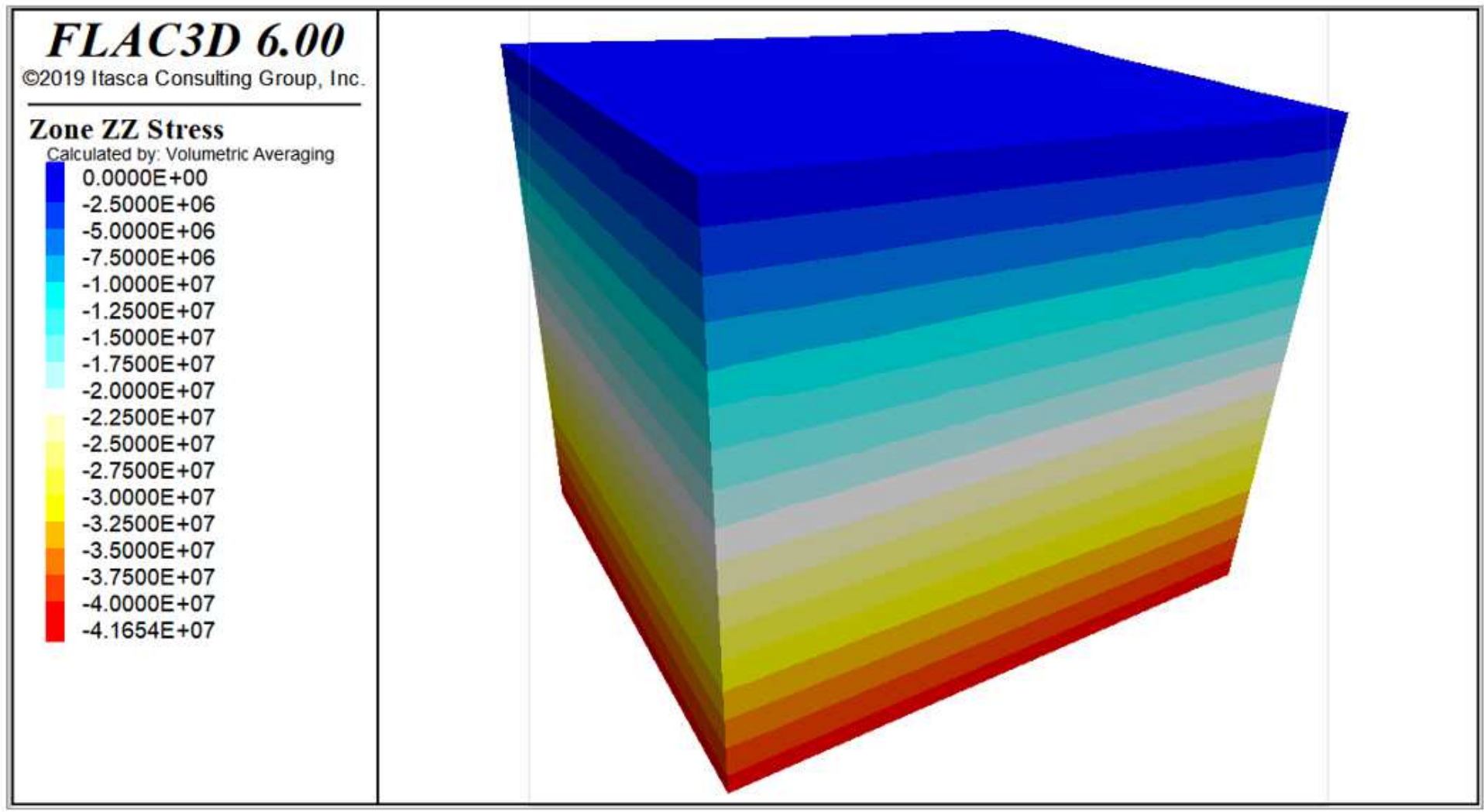

Figure 17

Please see the Manuscript PDF file for the complete figure caption

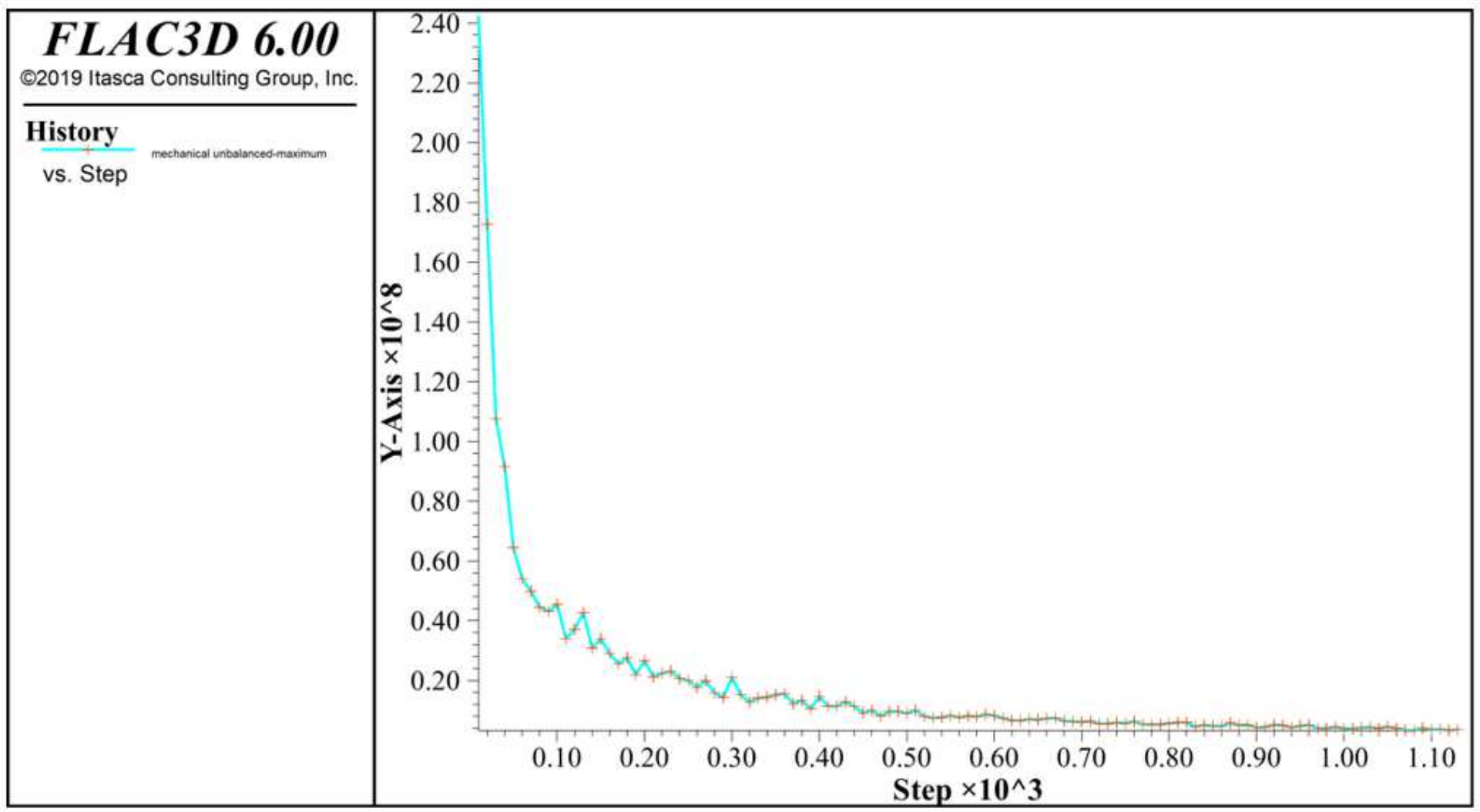


Figure 18

Please see the Manuscript PDF file for the complete figure caption

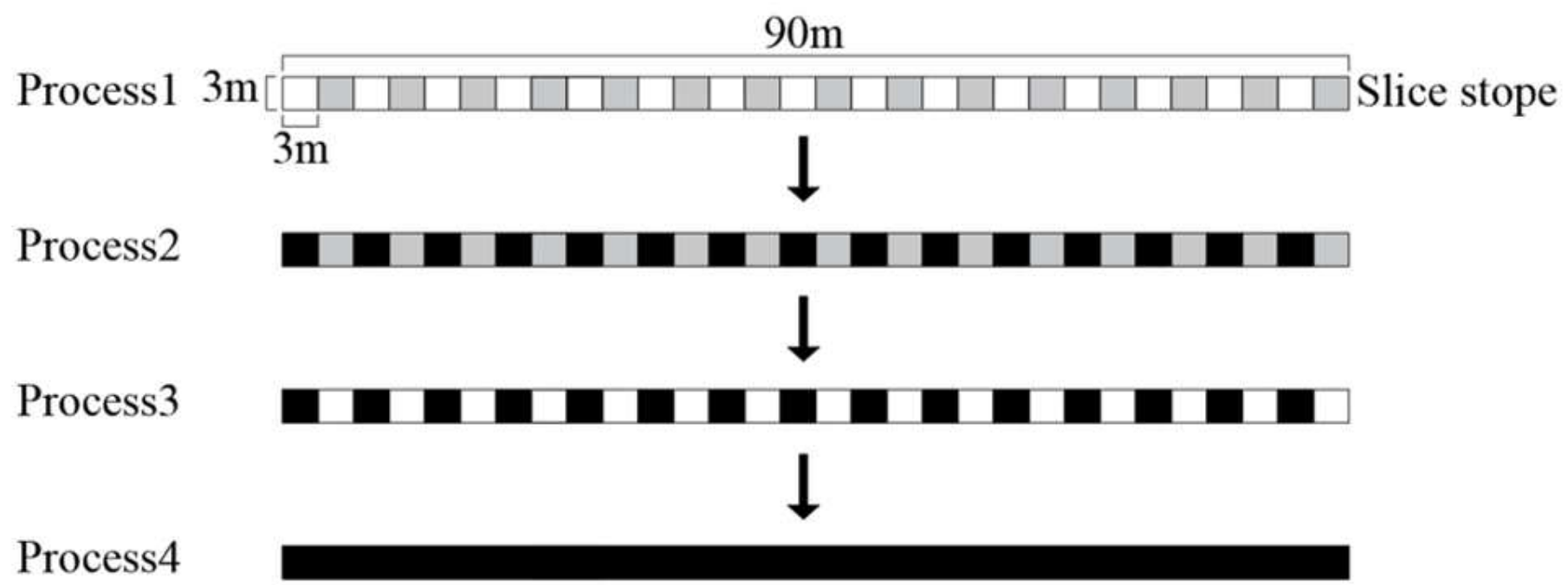

Figure 19

Please see the Manuscript PDF file for the complete figure caption

FLAC3D 6.00

(C)2019 Itasca Consulting Group, Inc.

Zone State By Any None

shear-n shear-p

shear-n shear-p tension-p

shear-p

shear-p tension- $p$

tension-p

Interface Name

Colorby: Name

Id 99574 zone

fault

$\square$ Mined area $\square$ Virgin area $\quad$ Filled area 
Please see the Manuscript PDF file for the complete figure caption

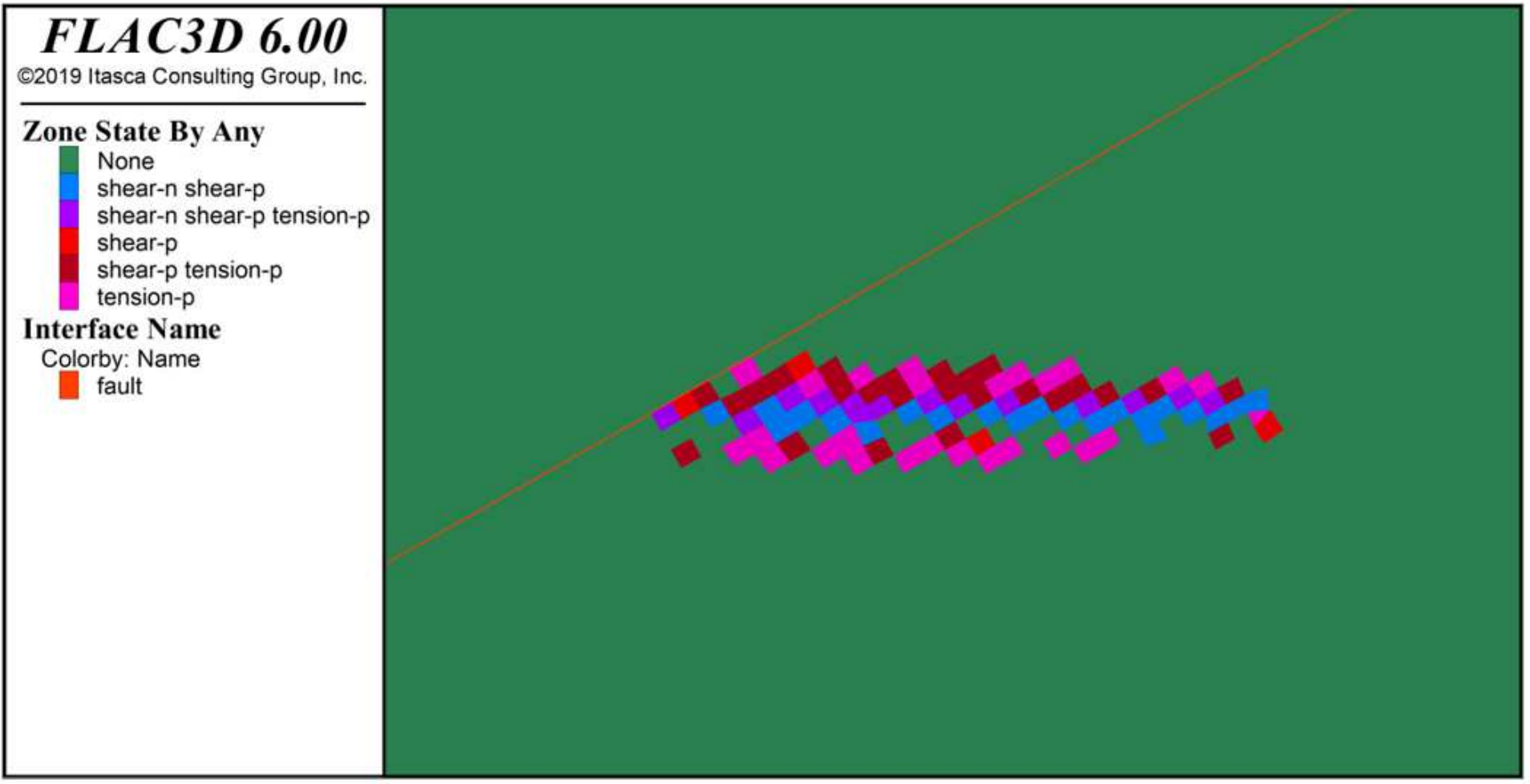

\section{Figure 21}

Please see the Manuscript PDF file for the complete figure caption

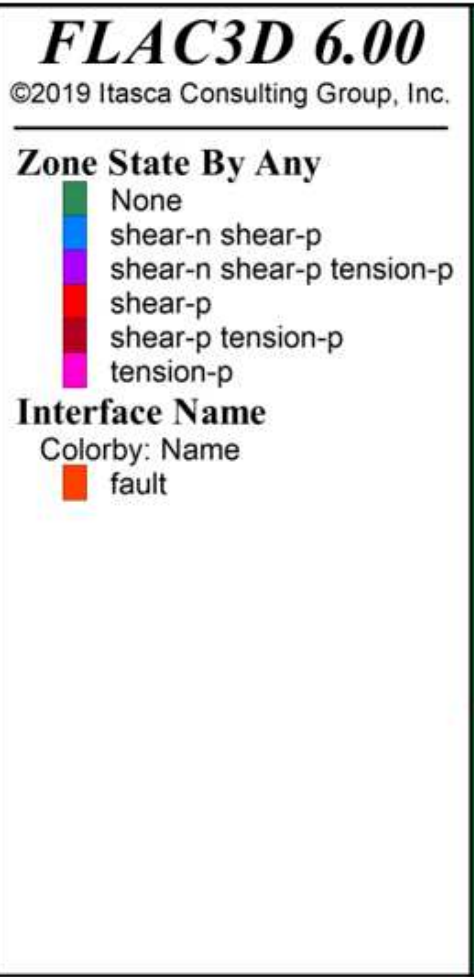

Figure 22 


\section{FLAC3D 6.00}

(C2019 Itasca Consulting Group, Inc.

\section{Zone State By Any \\ None \\ shear-n shear- $p$ \\ shear-n shear-p tension-p \\ shear-p \\ shear- $p$ tension- $p$ \\ tension- $n$ tension- $p$ \\ tension-p \\ Interface Uniform \\ Colorby: Uniform \\ Interface}

\section{Figure 23}

Please see the Manuscript PDF file for the complete figure caption

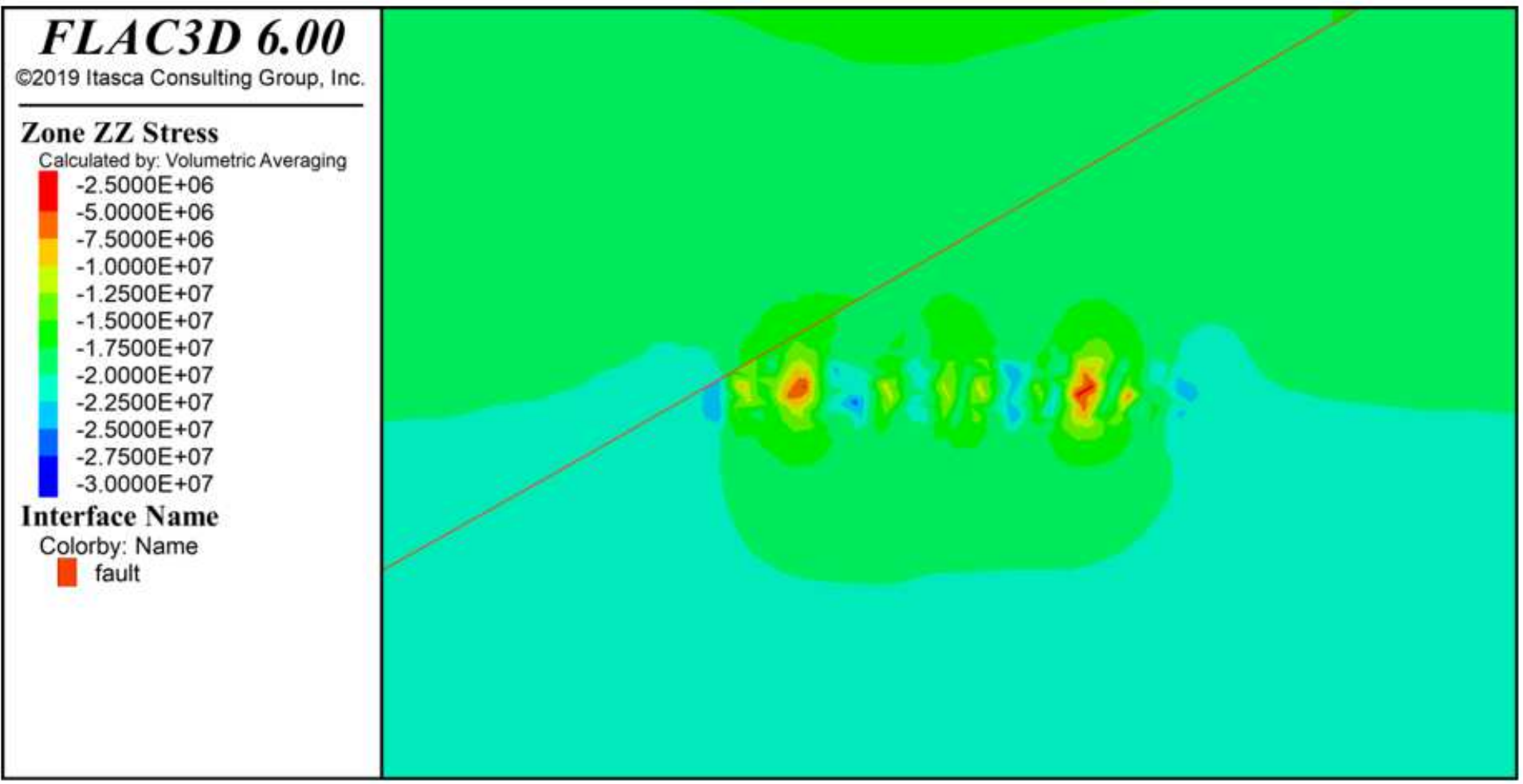

Figure 24 
Please see the Manuscript PDF file for the complete figure caption

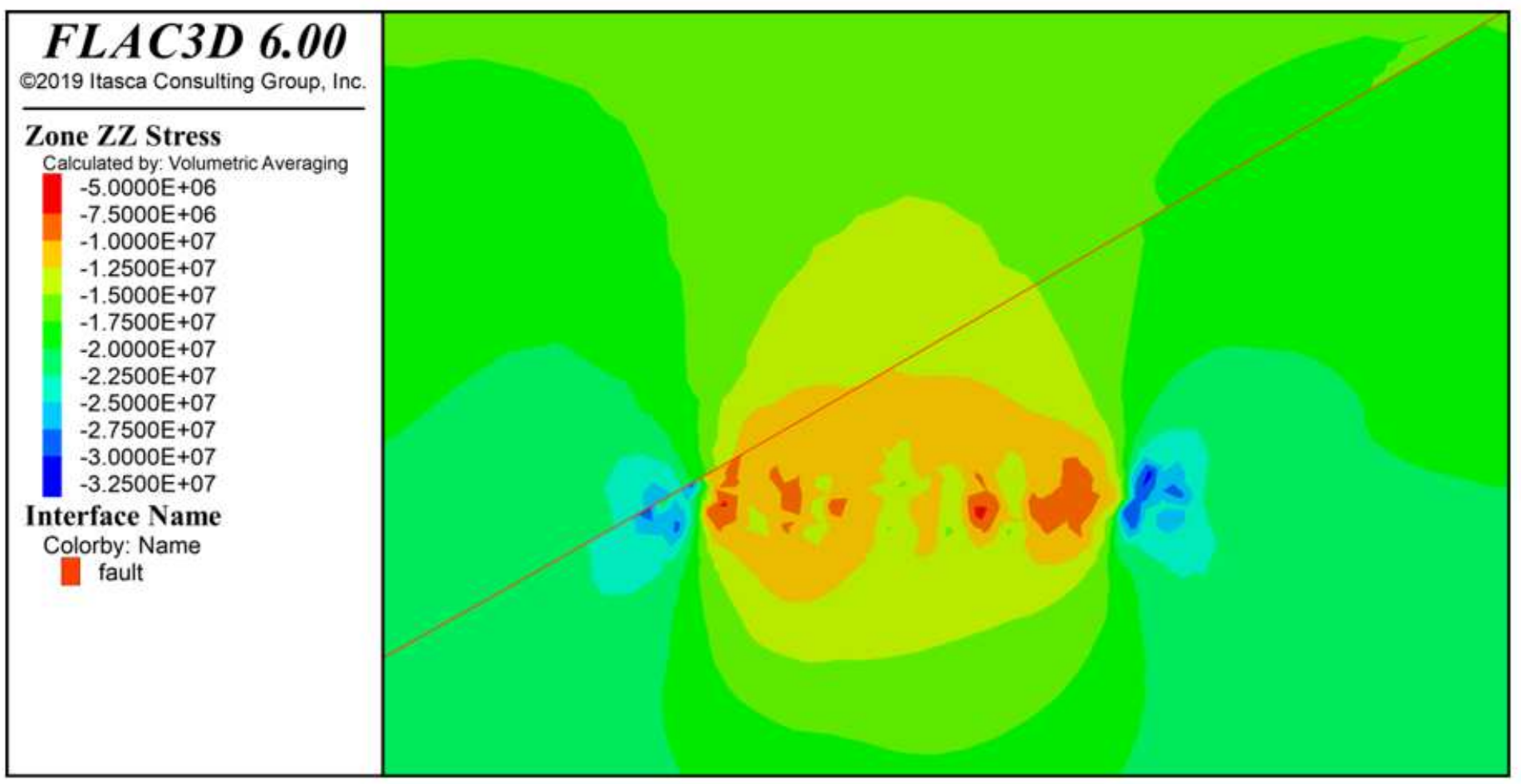

Figure 25

Please see the Manuscript PDF file for the complete figure caption

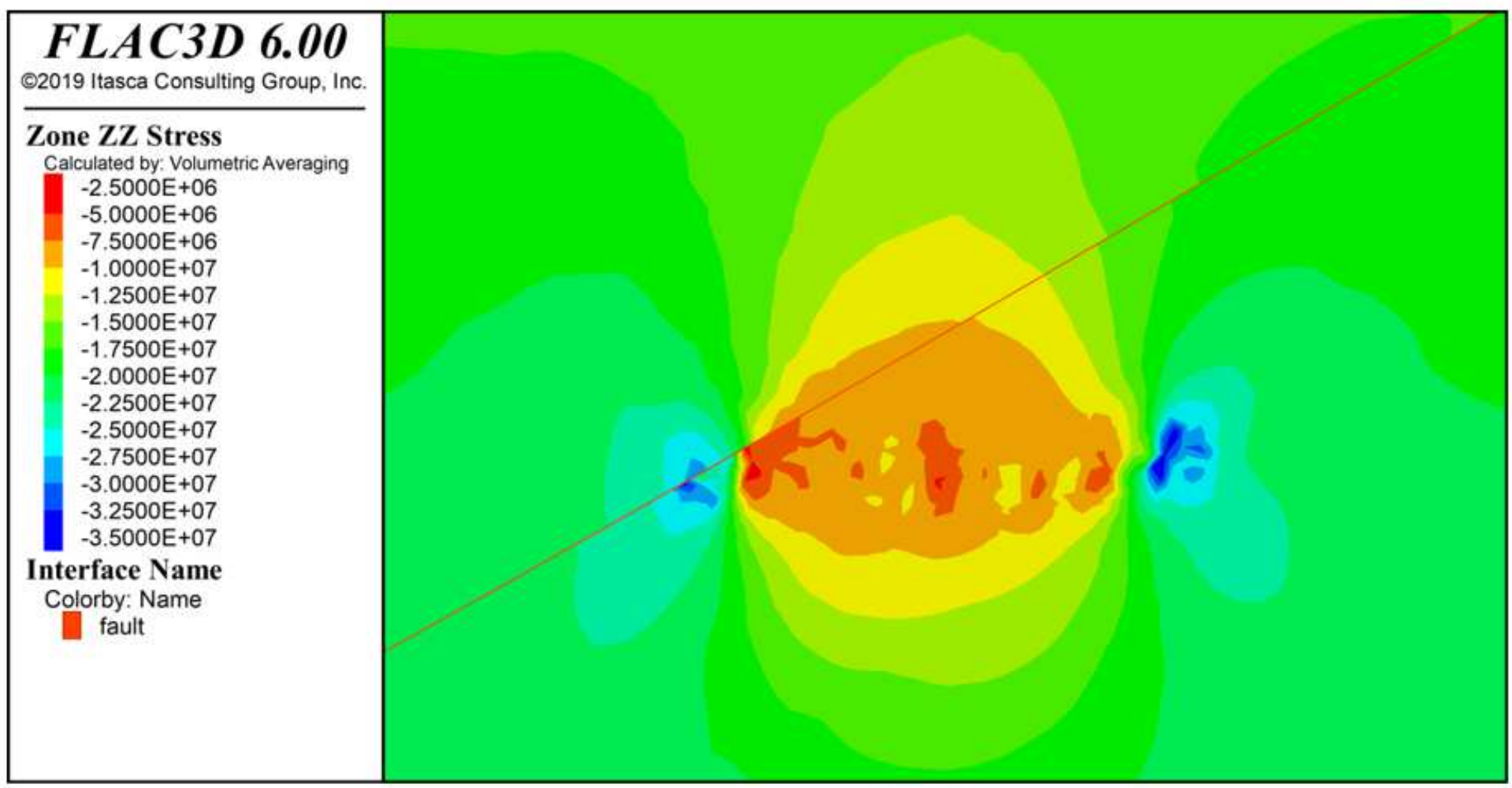

Figure 26 
Please see the Manuscript PDF file for the complete figure caption

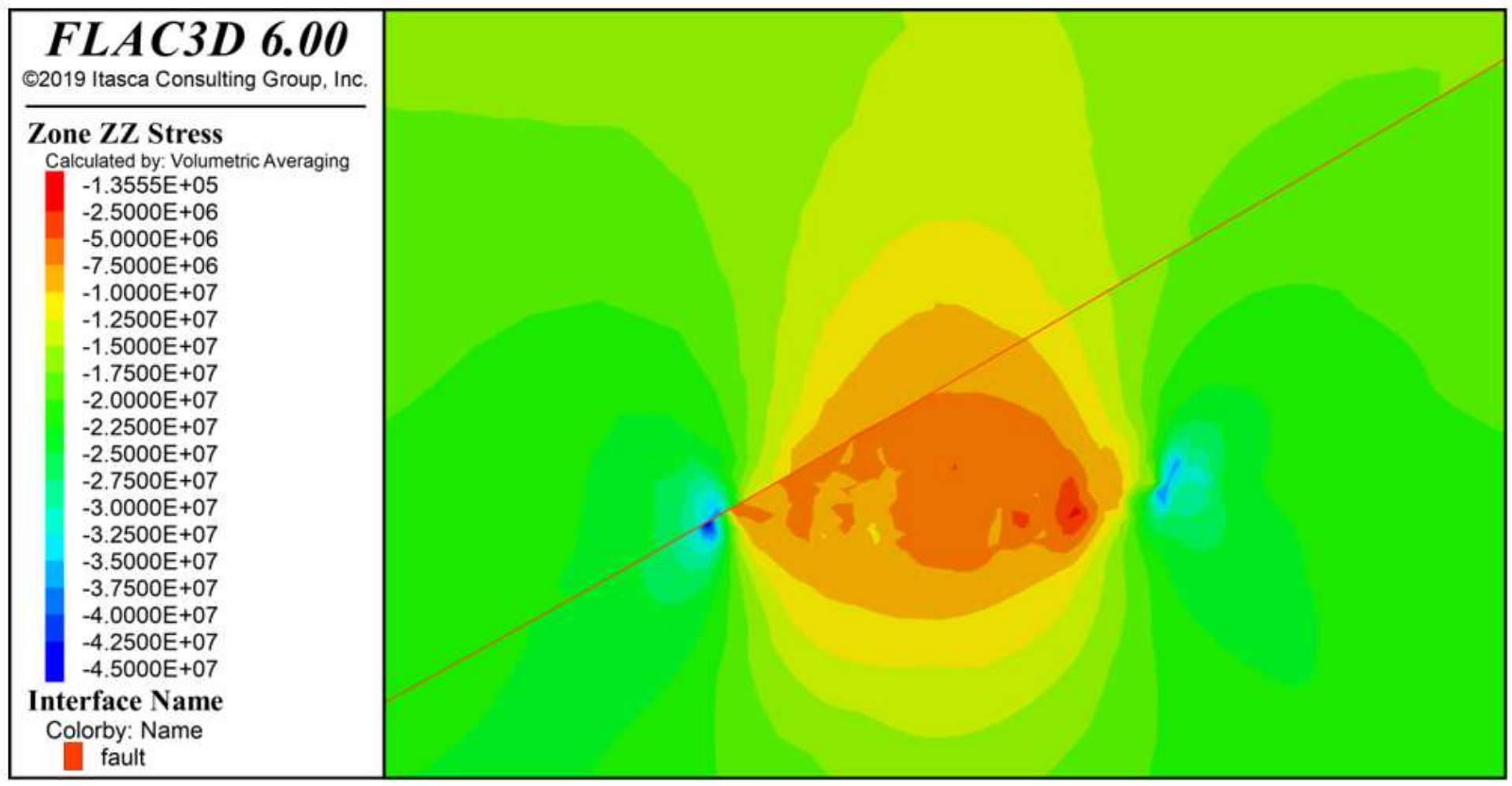

Figure 27

Please see the Manuscript PDF file for the complete figure caption

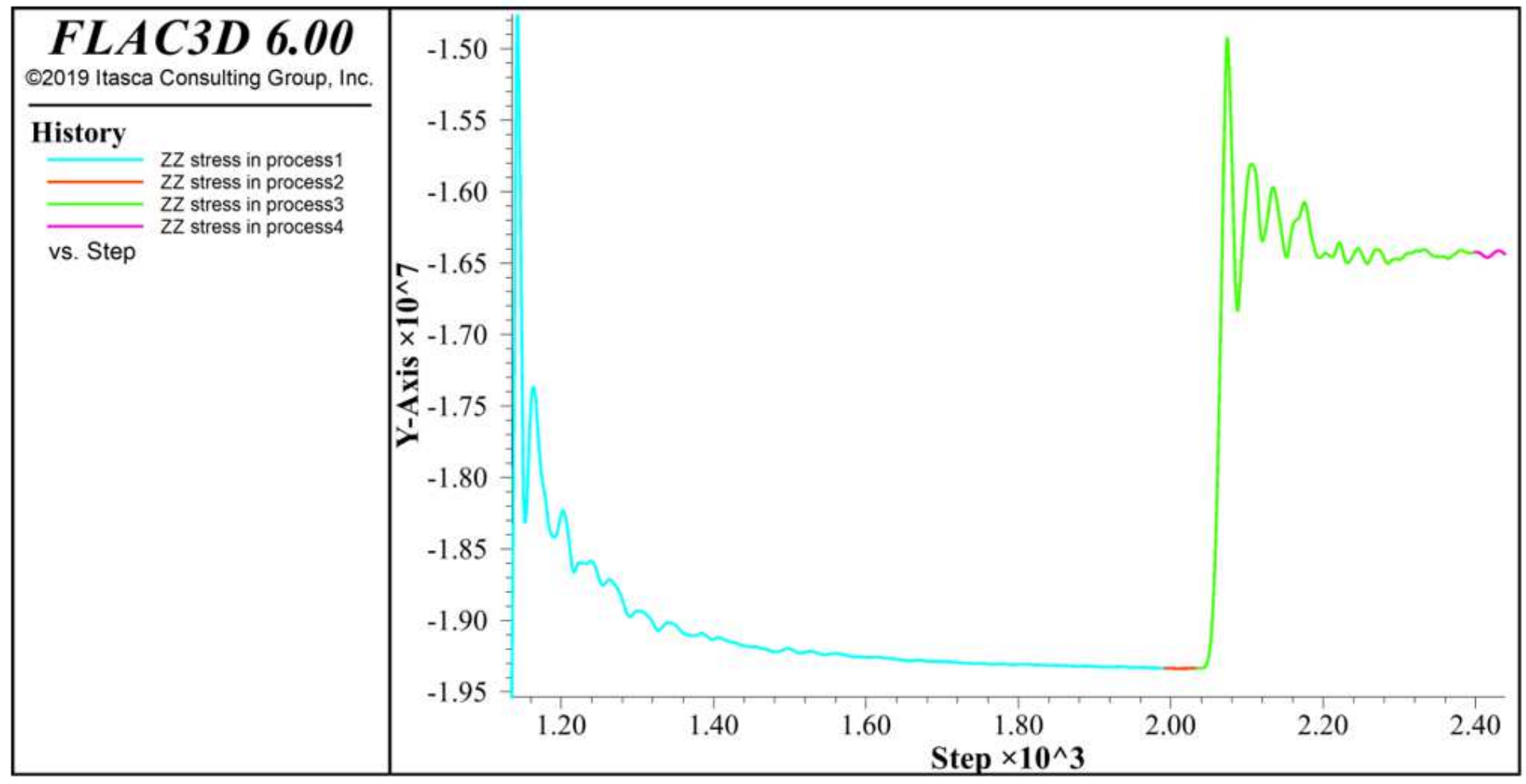

Figure 28 
Please see the Manuscript PDF file for the complete figure caption

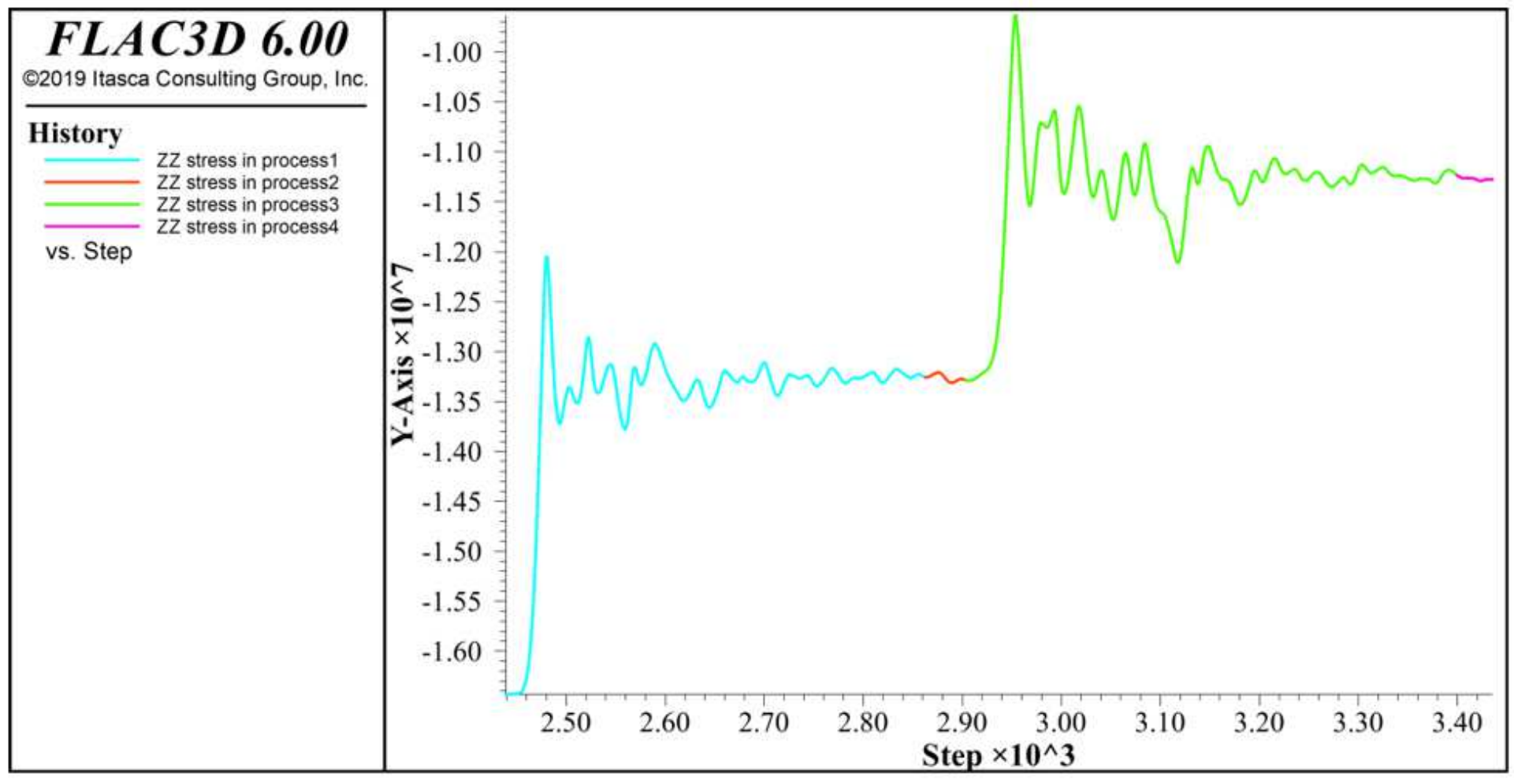

Figure 29

Please see the Manuscript PDF file for the complete figure caption

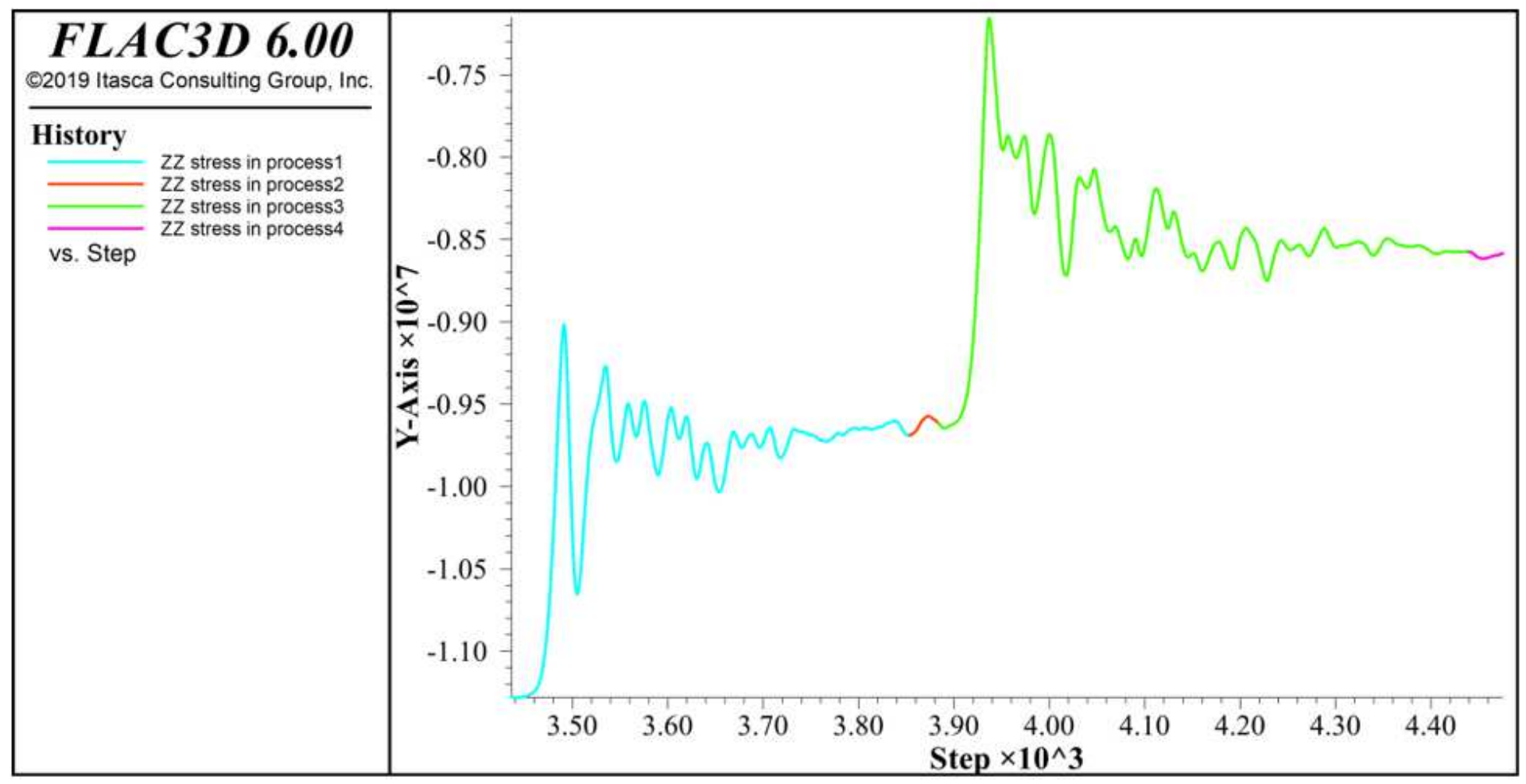

Figure 30 
Please see the Manuscript PDF file for the complete figure caption

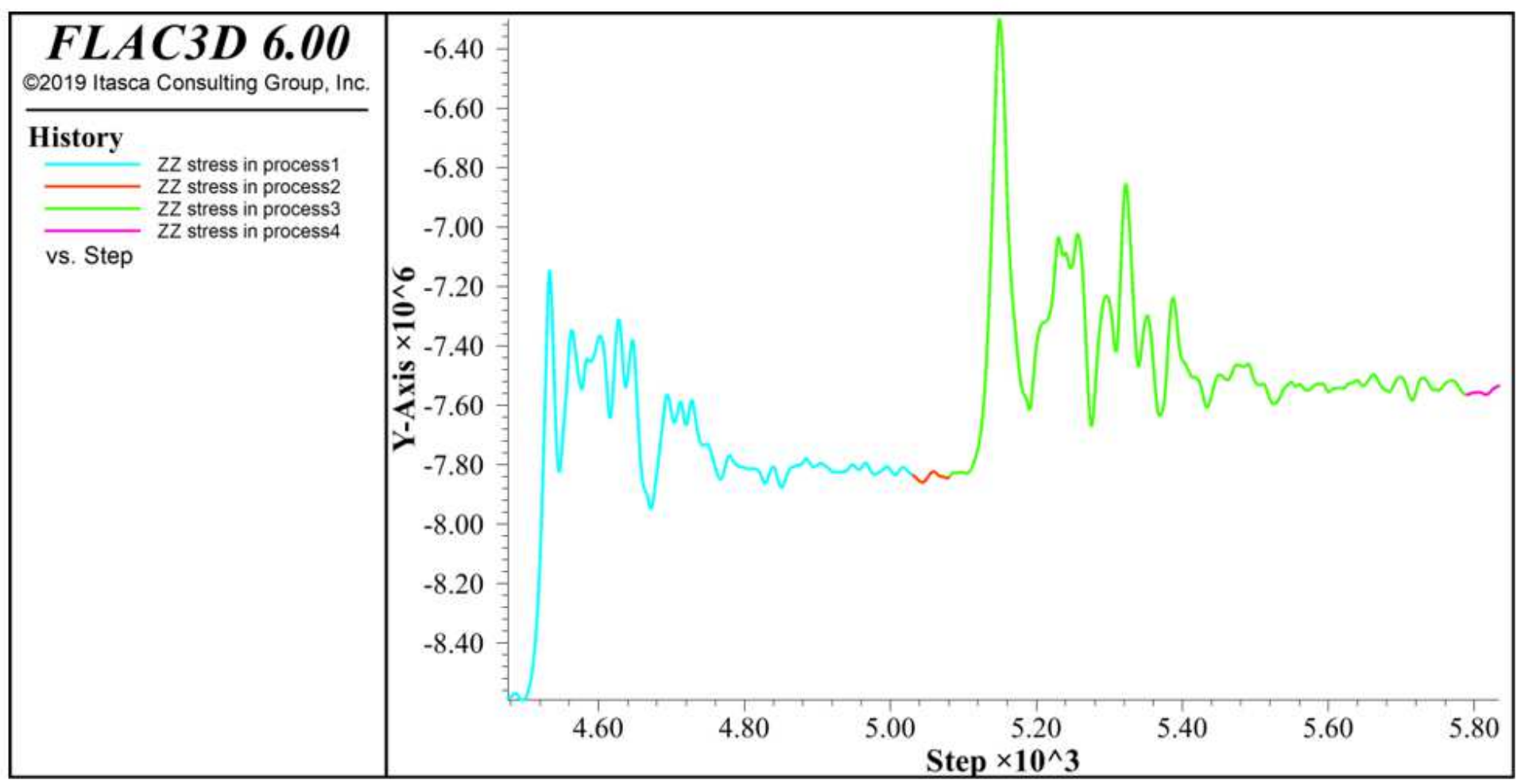

\section{Figure 31}

Please see the Manuscript PDF file for the complete figure caption 